\title{
Leilões para publicidade na Internet
}

\author{
Atol Fortin de Oliveira \\ DISSERTAÇÃO APRESENTADA \\ $\mathrm{AO}$ \\ Instituto DE MATEMÁticA E EstatísticA \\ DA \\ UNIVERSIDADE DE SÃO PAULO \\ PARA \\ OBTENÇÃO DO TÍTULO \\ DE \\ Mestre EM CiÊnCIAS \\ Programa: Ciência da Computação \\ Orientadora: Profa. Dra. Cristina Gomes Fernandes
}

Durante o desenvolvimento deste trabalho o autor recebeu auxílio financeiro da FAPESP.

São Paulo, setembro de 2012 


\section{Leilões para publicidade na Internet}

Esta versão da dissertação contém as correções e alterações sugeridas pela Comissão Julgadora durante a defesa da versão original do trabalho, realizada em 27/09/2012. Uma cópia da versão original está disponível no

Instituto de Matemática e Estatística da Universidade de São Paulo.

Comissão Julgadora:

- Prof ${ }^{\mathrm{a}}$. Dra ${ }^{\mathrm{a}}$. Cristina Gomes Fernandes (orientadora) - IME-USP

- Prof. Dr. Arnaldo Mandel - IME-USP

- Prof. Dr. Flávio Keidi Miyazawa - UNICAMP 


\section{Resumo}

\section{Leilões para publicidade na Internet}

Neste projeto apresentamos três modelos para publicidade na Internet, e mecanismos associados a cada modelo, analisando suas propriedades como estabilidade, otimalidade, prova de estratégia, e consumo de tempo. Primeiramente apresentamos um dos primeiros artigos publicados sobre o problema de leilões para publicidade na Internet, que descreve essencialmente o funcionamento dos atuais leilões para publidade na Internet. Em seguida, apresentamos outros dois modelos. O primeiro deles permite publicidade com exclusividade. O segundo modelo permite mais opções ao leiloiro e aos anunciantes, ao permitir preços mínimos de venda e preços máximos de compra.

Palavras-chave: teoria dos jogos, leilões, mecanismos, publicidade, Internet. 


\section{Abstract}

\section{Auctions for Internet advertising}

In this project we present three Internet sponsored search advertising models, and mechanisms related to each model, analyzing properties such as stability, optimality, strategy-proof, and time consumption. We start presenting one of the first articles on the problem of sponsored search advertising. Next, we present other two models. The first one allows exclusivity advertising. The second model allows a wider variety of options for both the auctioneer and the bidders, including minimum selling prices and maximum buying prices.

Keywords: game theory, auctions, mechanisms, advertisement, Internet. 


\section{Sumário}

$\begin{array}{ll}\text { Introdução } & 1\end{array}$

1 Preliminares sobre mecanismos e leilões $\quad 3$

1.1 Notação . . . . . . . . . . . . . . . . . . . . . . . . . 3

1.1 .1 Taxa de cliques . . . . . . . . . . . . . . . . . . . . . . . . . . 3

1.2 Informações e mecanismo de um leilão . . . . . . . . . . . . . . . . 4

1.3 Objetivos de um leilão . . . . . . . . . . . . . . . . . . . . . . . . . . . .

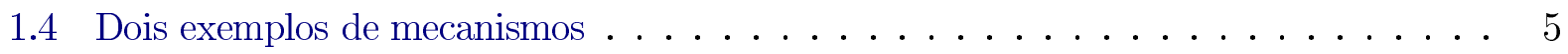

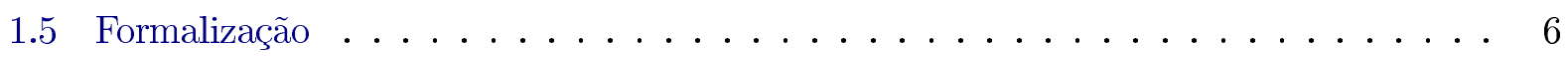

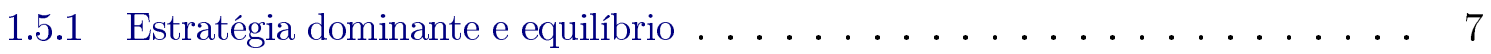

1.5.2 Mecanismo Vickrey-Clarke-Groves . . . . . . . . . . . . . . 8

2 Leilões simplificados para publicidade na Internet $\quad 11$

2.1 Introdução . . . . . . . . . . . . . . . . . . . . . . 11

2.2 Formalização do problema . . . . . . . . . . . . . . . . . 11

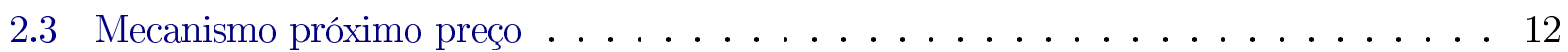

2.4 Mecanismo leilão gradual . . . . . . . . . . . . . . . . . . 14

2.5 Exemplo utilizando o mecanismo leilão gradual . . . . . . . . . . . . . . . . . . . 14

2.6 Análise do mecanismo leilão gradual . . . . . . . . . . . . . . . . . . . . . . . . . . . . . . . . . . 15

2.6.1 Exemplo das estratégias de um anunciante . . . . . . . . . . . . . . . 15

2.6.2 Mecanismo leilão gradual é à prova de estratégia . . . . . . . . . . . . . . . . . . . 17

2.6.3 Leilão gradual é o único mecanismo à prova de estratégia . . . . . . . . . . . 18

2.7 Comparação entre o leilão gradual e o próximo preço . . . . . . . . . . . . . . . 20

2.7.1 As ofertas determinadas estão em equilíbrio . . . . . . . . . . . . . . . 21

2.7.2 Exemplos de ofertas em equilíbrio para o próximo preço . . . . . . . . . . . . . 22

2.8 Cenário dinâmico dos leilões simplificados . . . . . . . . . . . . . . . . 23

3 Leilões com exclusividade para publicidade na Internet 25

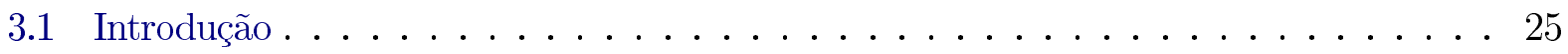

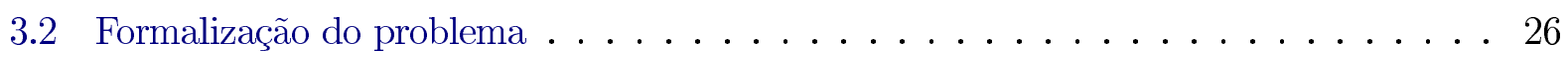

3.3 Notação . . . . . . . . . . . . . . . . . . . . . . . . . . . . . . . . . . . . . . . . . . . . . . . . . . .

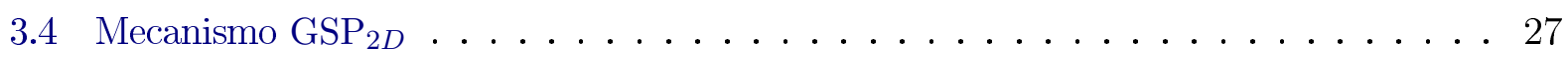

3.4 .1 Exemplos do $\mathrm{GSP}_{2 D} \ldots \ldots \ldots \ldots \ldots \ldots \ldots \ldots$

3.4 .2 Exemplos não intuitivos do $\mathrm{GSP}_{2 D} \ldots \ldots \ldots \ldots \ldots \ldots$

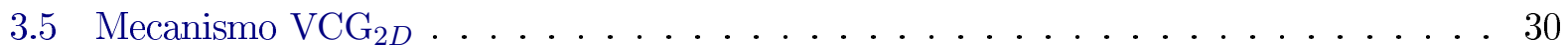


3.6 Comparação entre $\mathrm{GSP}_{2 D}$ e $\mathrm{VCG}_{2 D} \ldots \ldots \ldots \ldots \ldots \ldots \ldots \ldots \ldots \ldots \ldots$

3.6 .1 Eficiência do $\mathrm{GSP}_{2 D} \ldots \ldots \ldots \ldots \ldots \ldots \ldots$

3.6 .2 Lucro do $\mathrm{GSP}_{2 D} \ldots \ldots \ldots \ldots \ldots \ldots \ldots$

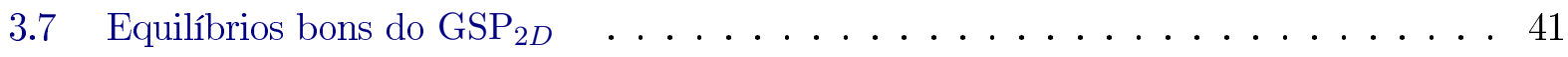

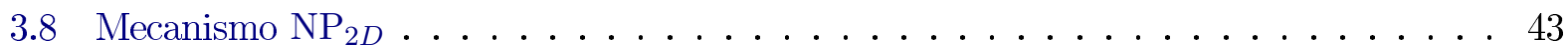

3.8 .1 Eficiência do $\mathrm{NP}_{2 D} \ldots \ldots \ldots \ldots \ldots \ldots \ldots \ldots$

3.8 .2 Lucro do $\mathrm{NP}_{2 D} \ldots \ldots \ldots \ldots \ldots \ldots \ldots \ldots$

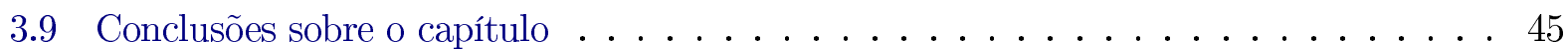

4 Leilões genéricos $\quad 47$

4.1 Introdução . . . . . . . . . . . . . . . . . . . . . . 47

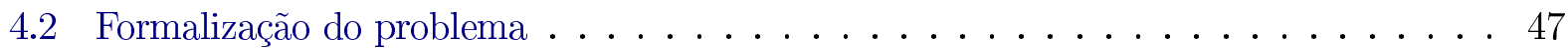

4.3 Propriedades de uma alocação . . . . . . . . . . . . . . . . . . . . . . . 48

4.4 Grafo do leilão e posição geral . . . . . . . . . . . . . . . . . . . . 50

4.5 Grafo de uma alocação . . . . . . . . . . . . . . . . . . . . . . . . 51

4.6 Algoritmo StableMatch . . . . . . . . . . . . . . . . . . . 52

4.7 Exemplo passo a passo do algoritmo . . . . . . . . . . . . . . . . 54

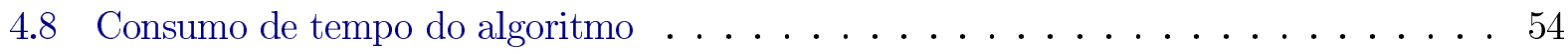

4.9 Correção do algoritmo: viabilidade e estabilidade . . . . . . . . . . . . . . . 55

4.9.1 Prova dos invariantes $(A 1),(A 2)$ e $(A 3) \ldots \ldots \ldots \ldots \ldots$

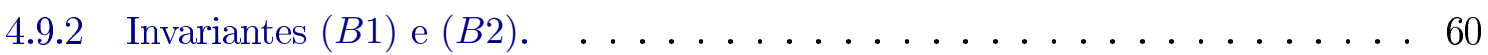

4.10 Propriedades de alocações viáveis e estáveis . . . . . . . . . . . . . . . 61

4.11 Correção do algoritmo: otimalidade da alocação produzida . . . . . . . . . . . . . . 63

4.11 .1 Prova da proposição $1 \ldots \ldots$. . . . . . . . . . . . . 66

4.11 .2 Prova da proposição $2 \ldots \ldots \ldots \ldots$. . . . . . . . . . 6 67

4.12 Detalhes de implementação sobre a posição geral . . . . . . . . . . . . . . . 67

4.13 Exemplos especiais . . . . . . . . . . . . . . . . . . 68

5 Conclusões e trabalhos futuros $\quad 73$

5.1 Considerações Finais . . . . . . . . . . . . . . . . . . . . . 74

$\begin{array}{ll}\text { Referências Bibliográficas } & 75\end{array}$ 


\section{Introdução}

O crescimento da Internet trouxe consigo uma variedade de problemas novos, muitos deles envolvendo aspectos de teoria dos jogos algorítmica. Essa área de pesquisa dedica-se a problemas que envolvem ciência da computação, teoria dos jogos, e teoria econômica. Neste trabalho estudaremos um tema da área de teoria dos jogos algorítmica conhecido como leilôes para publicidade na Internet. Exemplos de problemas dentro desse tema podem ser encontrados em [AGM06, AMPP09, NRTV07].

Em sites com mecanismo de busca, quando uma busca por uma palavra chave é realizada por um usuário de Internet (usuário), o resultado da busca é exibido. Além do resultado da busca, propagandas associadas à palavra chave são exibidas em locais específicos da página da Internet (locais), pré-determinados pelo dono da página (leiloeiro). Em muitas situações pode-se considerar que existem locais da página que têm maior visibilidade para os usuários, por exemplo, os locais mais próximos ao topo da página. Por isso, é importante que se utilize algum método para escolher qual propaganda será alocada a cada local, e também o preço que o anunciante daquela propaganda deverá pagar por aparecer em um local. O processo de determinação de quais propagandas serão exibidas, e seus respectivos preços e locais, é feito através de um leilão dentre os anunciantes interessados. Para isso, o dono da página deve especificar as regras do leilão, que estabelecem as informações necessárias para a realização do leilão e mecanismo que processará essas informações. Em seguida, os anunciantes interessados em ter suas propagandas exibidas na página podem informar suas ofertas ao dono da página e demais informações necessárias para o leilão.

Em 1994 eram negociadas verbalmente quais propagandas seriam exibidas em algumas páginas da Internet, e era utilizado o pagamento por impressão, de forma que os anunciantes pagavam uma quantidade fixa de dinheiro a cada mil vezes que suas propagandas eram exibidas nos sites com os quais eles tinham feito acordos.

Em 1996 surgiu também o conceito de pagamento por conversẫo, onde os sites exibiam anúncios de produtos como livros ou CDs de lojas, e se um usuário comprasse os produtos das lojas através desses anúncios, então as lojas pagavam aos sites uma quantia. Uma generalização do pagamento por conversão é o pagamento por ação, onde o anunciante especifica uma ação, por exemplo preencher um formulário, e se um usuário clica em sua propaganda e depois executa essa ação, então o anunciante irá pagar ao dono do site pela sua propaganda.

Em 1997, já utilizando-se um mecanismo automático para determinar os anunciantes que seriam exibidos na página, foi introduzido o pagamento por clique, e os anunciantes passaram a pagar apenas quando seus anúncios recebiam um clique de um usuário. Uma das principais vantagens do pagamento por clique sobre o pagamento por impressão é a precisão de atingir os usuários certos. Para um usuário que faz uma busca por muitas palavras, ou palavras que possuem mais de um significado, podem ser exibidas propagandas que não atraem a atenção do usuário, e este só clicará de fato nas propagandas que o interessam. Por isso o pagamento por clique é muito usado 
atualmente e é também a forma de pagamento utilizada em dois dos problemas estudados neste trabalho.

Muitos trabalhos envolvendo aspectos desse problema têm sido estudados nos últimos anos. Um dos motivos para isso é que é muito difícil modelar o comportamento dos usuários de Internet e dos anunciantes, sendo necessário estudar adaptações, simplificações e variantes do problema. Outro motivo se deve à grande quantidade de dinheiro envolvida em publicidade na Internet. Por exemplo, o lucro obtido pela Google em 2004 através de tais leilões superou o valor de 3 bilhões de dólares, e acredita-se que o lucro da Yahoo nesse mesmo período foi de aproximadamente 1,75 bilhões do dólares [EOS05]. No primeiro semestre de 2008, através de leilões para publicidade na Internet, o lucro da Yahoo foi superior a 1,8 bilhões de dólares, e o lucro da Google foi superior a 10 bilhões de dólares [Yua12].

Tanto o dono da página como muitos anunciantes têm interesse em maximizar seu lucro, e tais anunciantes são conhecidos como maximizadores de lucro. Existem também anunciantes que querem obter o melhor local da página possível que seja compatível com sua oferta, conhecidos como anunciantes de preço máximo. É favorável para o dono da página estabelecer regras para o leilão de forma a aumentar seus lucros, aumentar a estabilidade do leilão, e se possível evitar que os anunciantes ajam estrategicamente, falsificando suas ofertas. O foco deste trabalho é analisar essas regras, que são formadas pelas informações e mecanismos utilizados pelo leilão. 


\section{Capítulo 1}

\section{Preliminares sobre mecanismos e leilões}

\subsection{Notação}

O número de anunciantes em um leilão será denotado por $n$, e denotamos cada anunciante por um número em $[n]=\{1,2, \ldots, n\}$. Analogamente, o número de locais em um leilão será denotado por $k$, e cada local será denotado por um número em $[k]=\{1,2, \ldots, k\}$. Nos dois primeiros modelos de leilões apresentados utilizamos pagamento por clique, e no último modelo apresentado utilizamos pagamento por impressão.

Admitimos que cada anunciante $i \in[n]$ é capaz de mensurar a quantidade de dinheiro que receberá caso sua propaganda seja exibida em um local da página (ou caso receba um clique). Esse valor é chamado de valor verdadeiro do anunciante $i$, e será denotado ao longo do trabalho por $v_{i}$. Denotamos por $p_{i}$ o preço pago pelo anunciante $i$ caso a sua propaganda seja exibida (ou receba um clique). Caso sua propaganda não seja exibida (ou não receba cliques), $p_{i}=0$. A utilidade de um anunciante representa a sua satisfação diante da solução determinada pelo leilão (solução encontrada pelo mecanismo), e como nesse caso estamos considerando a utilização de dinheiro, a utilidade de um anunciante representa seu lucro. Dessa forma, muitas vezes definimos a utilidade de um anunciante $i$ como o valor $u_{i}=v_{i}-p_{i}$ se sua propaganda for exibida, e $u_{i}=0$ caso contrário.

Nos leilões estudados neste trabalho, os anunciantes devem informar ao leilão o valor máximo que estão dispostos a pagar caso sua propaganda seja exibida (ou receba um clique). Denotamos por $m_{i}$ o valor máximo declarado por um anunciante $i$. Ademais, consideraremos leilões onde o dono da página determina um valor mínimo de venda para cada local $j \in[k]$ que será denotado por $r_{j}$. Esse valor é usualmente chamado de preço de reserva.

\subsubsection{Taxa de cliques}

Muitos mecanismos levam em consideração a popularidade de um anunciante para decidir quais anunciantes serão exibidos em uma busca. De fato, é de interesse para o dono da página que as propagandas exibidas sejam clicadas, ou ele não recebe por tais exibições, quando o critério utilizado é o pagamento por clique. Por isso, é razoável que ele queira levar em conta tal popularidade das propagandas. Uma medida de popularidade é a chamada taxa de cliques de uma propaganda, e é uma tarefa do dono da página estimá-las. Isto é, estimar a fração de impressões (exibições) de uma propaganda em que ela recebe um clique, o que pode ser considerado como a frequência ou probabilidade de uma propaganda receber um clique. 
A taxa de cliques de uma propaganda $i$ exibida em um local $j$ será denotada por $t_{i, j}$. Nos modelos onde utilizam-se pagamento por clique definimos que a utilidade de um anunciante $i$ exibido no local $j$ é $u_{i}=t_{i, j}\left(v_{i}-p_{i}\right)$. Ou seja, sua utilidade é a utilidade que ele teria caso recebesse um clique vezes a probabilidade de receber um clique. Em alguns mecanismos apresentados neste trabalho utilizaremos taxas de cliques separáveis. As taxas de cliques são ditas separáveis se existem $\mu_{1}, \mu_{2}, \ldots, \mu_{n}>0$ relativos aos anunciantes e $\theta_{1} \geq \theta_{2} \geq \cdots \geq \theta_{k}>0$ relativos aos locais tais que a taxa de cliques $t_{i, j}$ do anunciante $i$ no local $j$ é dada por $t_{i, j}=\mu_{i} \theta_{j}$.

Para estimar o valor da taxa de cliques de uma propaganda, utilizam-se um dos seguintes métodos [IJMT05]:

- Média sobre uma janela de tempo: Fixada uma janela de tempo, sejam $x$ e $y$ o número de cliques que a propaganda recebeu e o número de impressões da propaganda, respectivamente, durante a janela de tempo fixada. Dessa maneira, estimamos que a taxa de cliques da propaganda é $t=\frac{x}{y}$.

- Média para um número fixo de impressões: Fixado um número $y$, seja $x$ a quantidade de cliques na propaganda para as últimas $y$ impressões. Estimamos $t=\frac{x}{y}$.

- Média para um número fixo de cliques: Fixado um número $x$, seja $y$ a menor quantidade de impressões mais recentes da propaganda onde tenham ocorrido exatamente $x$ cliques. Estimamos $t=\frac{x}{y}$.

Outros métodos podem ser utilizados para dar mais peso às impressões e cliques mais recentes [IJMT05], ou para estimar a taxa de cliques de um novo anunciante, que por sua vez não tem um histórico que possa ser utilizado para fazer as estimativas [Ric07].

\subsection{Informações e mecanismo de um leilão}

Uma solução de um leilão é constituída dos anunciantes que terão suas propagandas exibidas, os locais onde essas propagandas serão exibidas, e os preços que serão pagos pelos anunciantes caso suas propagandas recebam cliques. As informações necessárias para a realização de um leilão são tipicamente os valores que serão usados para encontrar uma solução para o leilão. Alguns desses valores são pré-determinados pelo leiloeiro e são publicamente acessíveis pelos anunciantes, por exemplo, os valores mínimos de venda dos locais da página. Outros desses valores são revelados ao leiloeiro por cada anunciante e não são acessíveis aos demais anunciantes, por exemplo, os valores máximos que os anunciantes estão dispostos a pagar. Existem também valores que são intrínsecos a cada anunciante, e que não são revelados nem ao leiloeiro e nem aos demais anunciantes, por exemplo, o valor verdadeiro do anunciante.

Após definidas as informações que serão utilizadas pelo leilão, que formam uma instância do problema, é preciso definir como se alcançará uma solução para um leilão, o que será feito através de um mecanismo. O mecanismo de um leilão é simplesmente um algoritmo que recebe uma instância como entrada, e devolve uma solução. 


\subsection{Objetivos de um leilão}

O objetivo de cada anunciante é declarar um valor $m_{i}$ - a chamada oferta do anunciante $i$ que maximize a sua utilidade ao final do leilão. Por isso o valor $m_{i}$ declarado é chamado também de estratégia do anunciante $i$. Dizemos que uma estratégia $m_{i}$ é dominante para um anunciante $i$ se qualquer que seja a estratégia dos demais anunciantes, $m_{i}$ é uma oferta que maximiza a utilidade para o anunciante $i$. A formalização da definição de estratégia dominante é apresentada mais adiante, na seção 1.5.1.

O leiloeiro por sua vez tem vários objetivos, que formalizaremos a seguir. Existem essencialmente dois tipos de leiloeiros: os que querem maximizar o bem-estar social (o governo em geral se encaixa nesta categoria) e os que querem maximizar o seu lucro (empresas como a Google, Yahoo e outras). O bem estar social é representado pela soma dos valores verdadeiros dos anunciantes ganhadores, enquanto que o lucro do leiloeiro é a soma dos preços pagos pelos anunciantes que participam do leilão (ou o valor esperado dessa soma, no caso de pagamento por cliques). Neste trabalho estamos interessados em mecanismos adotados pelo segundo tipo de leiloeiros, ou seja, os que querem maximizar seu lucro.

Uma característica apreciada em leilões é que os anunciantes tomem como $m_{i}$ o seu valor verdadeiro $v_{i}$. Se os anunciantes fizerem a escolha de $m_{i}$ desta maneira, o leiloeiro tem mais controle sobre o leilão (pois tem informação de melhor qualidade sobre os anunciantes) e consegue ter uma ideia melhor de quão próximo está de seu objetivo. Assim, dizemos que um mecanismo é à prova de estratégia se, para todo anunciante $i$, vale que $m_{i}=v_{i}$ é uma estratégia dominante ao utilizar esse mecanismo.

\subsection{Dois exemplos de mecanismos}

Consideremos um simples leilão com um único local da página a ser leiloado onde cada anunciante declara ao leilão o valor máximo que está disposto a pagar pelo local. Ou seja, considere um leilão onde o número de anunciantes é $n>1$, o número de locais é $k=1$, e os preços máximos dos anunciantes são dados por $m=\left(m_{1}, m_{2}, \ldots, m_{n}\right)$. Sem perda de generalidade, considere que $m_{1} \geq m_{2} \geq \cdots \geq m_{n}$.

Vamos analisar dois mecanismos para esse leilão que escolhem da mesma maneira o anunciante ganhador do único local, mas que diferem na determinação do preço que tal anunciante deve pagar. Em ambos os mecanismos apresentados a seguir, o anunciante ganhador é aquele que tiver o maior preço máximo, ou seja, o anunciante $i=1$ é o ganhador. Utilizaremos o valor verdadeiro $v=\left(v_{1}, v_{2}, \ldots, v_{n}\right)$ dos anunciantes para realizar a análise, onde $v_{i}$ representa o lucro do anunciante $i$ caso sua propaganda seja exibida.

\section{Leilão do primeiro preço com lance selado}

O preço determinado pelo mecanismo do primeiro preço ao anunciante ganhador é igual à sua oferta, ou seja, $p_{1}=m_{1}$. Dessa forma, sua utilidade vale $u_{1}=v_{1}-m_{1}$, e a utilidade para os demais anunciantes vale zero. Seria de grande interesse tanto para os anunciantes quanto para o leiloeiro que, para cada anunciante $i$, determinar o valor ótimo para $m_{i}$ (ou seja, um valor de $m_{i}$ que maximize a utilidade $u_{i}$ do anunciante $i$ ) fosse uma tarefa fácil. Porém, este mecanismo não 
permite que os anunciantes tenham uma estratégia dominante, e consequentemente não é à prova de estratégia. De fato, ao pagar o preço $p_{1}=m_{1}$, o anunciante pode não estar maximizando sua utilidade, quando fixadas as ofertas dos demais anunciantes. Seria necessário para o anunciante 1 saber (ou estimar através de especulações) o valor das ofertas dos outros anunciantes para conseguir maximizar sua utilidade declarando um valor tão baixo quanto possível mas ainda suficiente para ganhar o leilão, ou seja, um valor $m_{2}+\epsilon$, para algum $\epsilon>0$ pequeno.

\section{Leilão do segundo preço com lance selado}

O preço determinado pelo mecanismo do segundo preço ao anunciante ganhador é igual à segunda maior oferta, ou seja, $p_{1}=m_{2}$. Nesse caso, uma estratégia dominante para cada anunciante é declarar $m_{i}=v_{i}$. Dessa forma, para um anunciante que declara $m_{i}=v_{i}$, quaisquer que sejam as ofertas dos demais anunciantes, não existe $m_{i}^{\prime} \neq m_{i}$ tal que o anunciante $i$ aumentaria sua utilidade se tivesse declarado $m_{i}^{\prime}$ em vez de $m_{i}$. Segue uma demonstração dessa afirmação.

Primeiro, considere que $i$ é o anunciante ganhador quando declara $m_{i}=v_{i}$, e consequentemente tem utilidade maior ou igual a zero. Logo, caso o anunciante tivesse declarado um valor $m_{i}>v_{i}$, então a sua utilidade não se alteraria, pois ele continuaria sendo ganhador e pagando o mesmo preço; e se declarasse $m_{i}<v_{i}$, então o anunciante $i$ ou continuaria sendo ganhador com a mesma utilidade, ou deixaria de ser ganhador, recebendo utilidade zero. Portanto o anunciante $i$ não tem incentivo em declarar $m_{i} \neq v_{i}$. Segundo, considere que $i$ não é o anunciante ganhador quando declara $m_{i}=v_{i}$, e dessa forma tem utilidade zero. Logo, caso o anunciante $i$ tivesse declarado um valor $m_{i}<v_{i}$, então ele continuaria sendo perdedor com utilidade zero; e se declarasse $m_{i}>v_{i}$, então o anunciante $i$ ou continuaria sendo perdedor com utilidade zero, ou seria o ganhador, recebendo utilidade menor ou igual a zero, e portanto o anunciante $i$ não tem incentivo em declarar $m_{i} \neq v_{i}$. Assim, neste mecanismo, declarar $m_{i}=v_{i}$ de fato é uma estratégia dominante para todo anunciante $i$. Concluímos que o mecanismo do leilão do segundo preço é à prova de estratégia quando temos apenas um local a ser leiloado.

\subsection{Formalização}

Em um leilão, cada anunciante $i \in[n]$ pode adotar uma estratégia $m_{i}$ dentro do seu conjunto de estratégias $V_{i}$. Assim, um vetor de estratégias $m=\left(m_{1}, \ldots, m_{n}\right)$ é tal que $m_{i} \in V_{i}$, para $i \in[n]$, e denotamos por $V=V_{1} \times \cdots \times V_{n}$ o conjunto de todos os possíveis vetores de estratégias dos anunciantes.

Seja $T$ o conjunto de todas as possíveis saídas de um leilão, onde uma saída de um leilão é geralmente uma alocação dos objetos do leilão (locais) aos compradores (anunciantes). Por exemplo, nos exemplos acima, uma saída $S$ é constituída apenas pelo anunciante ganhador do único local da página. Para cada saída $S \in T$, cada anunciante $i \in[n]$ associa um valor verdadeiro $v_{i}(S)$. Por exemplo, nos exemplos acima, para cada anunciante $i \in[n]$ e para cada saída $S \in T$, o valor verdadeiro $v_{i}(S)$ é $v_{i}$ se ele é ganhador na saída $S$, e é zero caso contrário. Nos leilões apresentados neste trabalho, a estratégia $m_{i}(S) \in V_{i}$ é a oferta do anunciante $i$ para cada possível saída $S \in T$. Em geral, essas informações são representadas de uma forma bem concisa, como nos exemplos acima, onde $v_{i}(S)$ vale $v_{i}$ e $m_{i}(S)$ vale $m_{i}$ se $i$ é o ganhador em $S$, e valem zero caso contrário.

Considere também a notação $v_{-i}$ que representa os valores verdadeiros de todos os anunciantes 
com exceção de $i$, isto é, $v_{-i}=\left(v_{1}, v_{2}, \ldots, v_{i-1}, v_{i+1}, \ldots, v_{n}\right)$, e portanto temos que $v=\left(v_{i}, v_{-i}\right)$. Analogamente, utilizaremos as notações $m_{-i}$ e $V_{-i}$. Definiremos a seguir o que são estratégia dominante, equilíbrio, e mecanismo Vickrey-Clarke-Groves.

As notações e as definições apresentadas nesta seção podem ser utilizadas para leilões arbitrários (e podem ser estendidas para jogos em geral), mas cada uma delas pode ser entendida mais claramente para um leilão bem definido, como para os exemplos dos leilões com lance selado apresentados acima, e serão apresentadas de uma maneira mais simples e direta para cada um dos problemas estudados neste trabalho. Portanto, grande parte da notação apresentada acima, que diz respeito a leilões numa forma abstrata, será utilizada apenas para descrever as propriedades a seguir, e não será mais mencionada ao longo do trabalho.

\subsubsection{Estratégia dominante e equilíbrio}

Seja $M$ um mecanismo que recebe as ofertas $\left(m_{1}, \ldots, m_{n}\right)$ dos anunciantes, produz uma saída $S=M\left(m_{1}, \ldots, m_{n}\right)$, e determina também o preço $p_{i}$ que cada anunciante $i$ deverá pagar ao leilão em função das ofertas, ou seja, $p_{i}=p_{i}\left(m_{1}, \ldots, m_{n}\right)=p_{i}\left(m_{i}, m_{-i}\right)$. Disso, temos que a utilidade de cada anunciante $i \in[n]$ é $u_{i}(S)=v_{i}(S)-p_{i}\left(m_{i}, m_{-i}\right)$.

Dizemos que uma estratégia $m_{i}$, para $i \in[n]$, é dominante para um mecanismo $M$, se vale que

$$
v_{i}(S)-p_{i}\left(m_{i}, m_{-i}\right) \geq v_{i}\left(S^{\prime}\right)-p_{i}\left(m_{i}^{\prime}, m_{-i}\right),
$$

para toda estratégia $m_{i}^{\prime} \in V_{i}$ do anunciante $i$, e para todo conjunto de estratégias $m_{-i} \in V_{-i}$ dos demais anunciantes, onde $S=M\left(m_{i}, m_{-i}\right)$ e $S^{\prime}=M\left(m_{i}^{\prime}, m_{-i}\right)$. Ou seja, $m_{i}$ é a estratégia que maximiza a utilidade para o anunciante $i$ quaisquer que sejam as ofertas dos demais anunciantes.

Dizemos que as ofertas $\left(m_{1}, \ldots, m_{n}\right)$ estão em equilıbrio para um mecanismo $M$ se, para todo $i \in[n]$, vale que

$$
v_{i}(S)-p_{i}\left(m_{i}, m_{-i}\right) \geq v_{i}\left(S^{\prime}\right)-p_{i}\left(m_{i}^{\prime}, m_{-i}\right),
$$

para toda estratégia $m_{i}^{\prime} \in V_{i}$, onde $S=M\left(m_{i}, m_{-i}\right)$ e $S^{\prime}=M\left(m_{i}^{\prime}, m_{-i}\right)$. Ou seja, nenhum anunciante tem incentivo em alterar sua oferta, pois isso não aumentará sua utilidade.

Em alguns casos, o mecanismo $M$ pode produzir mais do que uma única saída para um mesmo vetor de ofertas $m$ (isso pode ocorrer se dois anunciantes distintos ofertam o mesmo valor, o mecanismo ordena arbitrariamente). Sejam $S^{1}, \ldots, S^{\ell}$ todas as saídas que poderiam ser produzidas por $M(m)$, e sejam $p_{i}^{1}, \ldots p_{i}^{\ell}$ os respectivos preços que cada anunciante $i \in[n]$ paga para cada uma das possíveis saídas. Para cada $i \in[n]$, seja $j \in[\ell]$ um índice que minimiza o valor $v_{i}\left(S^{j}\right)-p_{i}^{j}\left(m_{i}, m_{-i}\right)$, e denote por $S_{i}$ uma pior saída para o anunciante $i$, ou seja, por exemplo $S_{i}=S^{j}$. Seja $p_{i}\left(m_{i}, m_{-i}\right)$ o preço correspondente, ou seja, $p_{i}\left(m_{i}, m_{-i}\right)=p_{i}^{j}\left(m_{i}, m_{-i}\right)$. Dizemos que as ofertas $\left(m_{1}, \ldots, m_{n}\right)$ estão em equilíbrio se, para todo $i \in[n]$, vale que

$$
v_{i}\left(S_{i}\right)-p_{i}\left(m_{i}, m_{-i}\right) \geq v_{i}\left(S_{i}^{\prime}\right)-p_{i}\left(m_{i}^{\prime}, m_{-i}\right),
$$

para toda estratégia $m_{i}^{\prime} \in V_{i}$. Ou seja, qualquer que seja a saída produzida por $M\left(m_{i}, m_{-i}\right)$, deve valer, para cada $i \in[n]$, que $m_{i}$ é uma oferta que garante utilidade maior ou igual ao pior caso da solução produzida quando $i$ oferta $m_{i}^{\prime}$, e os demais anunciantes não alteram suas ofertas.

Por exemplo, no leilão do segundo preço com lance selado, para dois anunciantes com valores 
verdadeiros $v_{1}=10$ e $v_{2}=4$, se ambos os anunciantes ofertam o valor 10 , independentemente de como o mecanismo irá de fato ordenar os anunciantes, dizemos que estas ofertas não estão em equilíbrio, pois, no pior caso, o anunciante 2 irá ter utilidade negativa, o que não aconteceria se ofertasse $m_{2}<m_{1}=10$. Ainda neste exemplo, se ambos os anunciantes ofertam o valor 4 , novamente não temos um equilíbrio, pois o anunciante 1 no, pior caso, não será o ganhador.

Note que se todos os anunciantes ofertam estratégias dominantes, então as estratégias estão em equilíbrio, enquanto que o contrário não é verdade. Por exemplo, considere o problema do leilão do segundo preço com lance selado com dois anunciantes com valores verdadeiros $v_{1}=10$ e $v_{2}=5$. Se o anunciante 2 ofertar $m_{2}=3$, então, para toda oferta $m_{1} \geq 5$ do anunciante 1 , temos ofertas em equilíbrio. Por outro lado, para $m_{2}=3$ e $m_{1}=4$, não temos um equilíbrio, pois o anunciante 2 poderia aumentar sua oferta, aumentando sua utilidade.

\subsubsection{Mecanismo Vickrey-Clarke-Groves}

Apresentaremos aqui as definições, que serão utilizadas mais adiante, de um mecanismo VickreyClarke-Groves, conhecido como VCG.

Um mecanismo $M$ é dito VCG se ele satisfaz duas condições. Seja $S$ a saída obtida pelo mecanismo $M$ para as ofertas dos anunciantes, ou seja, $S=M\left(m_{1}, m_{2}, \ldots, m_{n}\right)$. A primeira condição é que $S$ maximize o bem estar social (baseado nas ofertas informadas) dentre todas as possíveis saídas, ou seja, que $\sum_{i \in[n]} m_{i}(S) \geq \sum_{i \in[n]} m_{i}\left(S^{\prime}\right)$, para todo $S^{\prime} \in T$. A segunda condição é que o preço estipulado por $M$ para um anunciante $i$ ganhador tenha a forma $p_{i}=h_{i}\left(m_{-i}\right)-\sum_{j \neq i} m_{j}(S)$, onde $h_{i}$ é uma função que não depende da oferta do anunciante $i$, e será discutida mais adiante.

Essas condições garantem que todo mecanismo VCG é à prova de estratégia, incentivando os anunciantes a ofertarem seus valores verdadeiros. Segue uma demonstração dessa afirmação.

Quando o anunciante $i$ oferta $m_{i}$, e o VCG encontra uma saída $S$, sabemos que

$$
m_{i}(S)+\sum_{j \neq i} m_{j}(S) \geq m_{i}\left(S^{\prime}\right)+\sum_{j \neq i} m_{j}\left(S^{\prime}\right), \forall S^{\prime} \in T
$$

Para $m_{i}=v_{i}$, vale que

$$
v_{i}(S)+\sum_{j \neq i} m_{j}(S) \geq v_{i}\left(S^{\prime}\right)+\sum_{j \neq i} m_{j}\left(S^{\prime}\right), \forall S^{\prime} \in T
$$

Ao subtrairmos $h_{i}\left(m_{-i}\right)$ em ambos os lados da desigualdade, obtemos exatamente a utilidade para o anunciante para as saídas $S$ e $S^{\prime}$, respectivamente. Portanto, concluímos que o mecanismo é à prova de estratégia, pois ofertar $v_{i}$ maximiza a utilidade para o anunciante $i$, qualquer que sejam as ofertas dos demais anunciantes.

A escolha da função $h_{i}$ deve satisfazer duas propriedades. A primeira é que nenhum anunciante tenha utilidade negativa, o que é conhecido como racionalidade individual. Caso contrário o anunciante não participaria do leilão. A segunda propriedade é que os preços determinados sejam todos não negativos. Uma escolha de $h_{i}$ que respeita essas duas propriedades é tomar $h_{i}$ como o $\max _{S^{\prime} \in T} \sum_{j \neq i} m_{j}\left(S^{\prime}\right)$. Dessa forma, temos que

$$
p_{i}=\max _{S^{\prime} \in T} \sum_{j \neq i} m_{j}\left(S^{\prime}\right)-\sum_{j \neq i} m_{j}(S),
$$


onde o primeiro termo refere-se ao bem estar social sem a participação do anunciante $i$ no leilão, e o segundo termo refere-se ao bem estar social com a participação de $i$ menos a oferta do anunciante $i$, e portanto dizemos que se trata do bem estar social dos anunciantes com exceção de $i$. Ou seja, o preço pago pelo anunciante $i$ é a diferença entre o bem estar social dos demais anunciantes sem a participação do anunciante $i$ no leilão, e com a participação dele.

Nos modelos estudados levamos em consideração as taxas de cliques, e a utilidade de um anunciante $i$ exibido em uma posição $j$ é da forma $u_{i}=t_{i, j}\left(v_{i}-p_{i}\right)$. Dessa forma, adaptamos o VCG substituindo $v_{i}$ por $t_{i, j} v_{i}$, e $p_{i}$ por $t_{i, j} p_{i}$, para todo $i \in[n]$. Ou seja, neste caso $u_{i}$ é a utilidade esperada do anunciante $i$ se este aparecer na posição $j$. 


\section{Capítulo 2}

\section{Leilões simplificados para publicidade na Internet}

\subsection{Introdução}

Este capítulo descreve o trabalho de Gagan Aggarwal, Ashish Goel e Rajeev Motwani [AGM06], um dos primeiros trabalhos publicados sobre o tema de leilões para publicidade na Internet.

Em um leilão simplificado, cada anunciante deve informar ao leiloeiro apenas o valor máximo que está disposto a pagar caso um usuário clique em sua propaganda, ou seja, utilizamos o pagamento por clique. Nesta versão do problema, há vários locais para propaganda na página e assume-se que quanto mais próxima do topo da página uma propaganda for exibida, maior será sua visibilidade para o usuário de Internet. Ademais, por questões de simplicidade, e incentivo aos anunciantes, o leiloeiro estabelece que os anunciantes sejam ordenados conforme uma função de classificação definida por ele.

\subsection{Formalização do problema}

Neste problema, que chamaremos de leilão simplificado, abreviado para LS, utilizaremos a notação descrita previamente na seção 1.1, desconsiderando os preços mínimos. Há ainda duas informações adicionais.

A primeira delas é uma informação relativa ao pagamento por clique. O leiloeiro deve estabelecer a taxa de cliques da propaganda do anunciante $i \in[n]$ quando exibida no local $j \in[k]$ da página, denotada por $t_{i, j}$. A taxa de cliques de uma propaganda é a fração de impressões (exibições) dessa propaganda em que ela é clicada. Como os locais do topo da página têm maior visibilidade, assumimos que $t_{i, j} \geq t_{i, j+1}>0$, para $1 \leq j<k$, e consideramos que $t_{i, j}=0$, para $j>k$.

A segunda delas é a função de classificação, utilizada pelo leiloeiro, dada por um vetor de pesos $w=\left(w_{1}, w_{2}, \ldots, w_{n}\right)$. O valor $w_{i}$ indica a importância do anunciante $i$ para o leilão. A função de classificação é usada para estabelecer uma ordem entre os anunciantes. Especificamente, dadas uma função de classificação $w$ e a oferta $m_{i}$ de cada anunciante $i \in[n]$, exige-se que o mecanimo utilizado para encontrar uma solução para o leilão atribua o primeiro local da página ao anunciante 1, o segundo local da página ao anunciante 2, e assim por diante, quando consideramos que os anunciantes estão ordenados de modo que $w_{1} m_{1} \geq w_{2} m_{2} \geq \cdots \geq w_{n} m_{n}$. As duas funções de 
classificação mais populares são:

- método Overture (direct ranking): $w_{1}=1$ para todo $i \in[n]$.

- método Google (revenue ranking): $w_{i}=t_{i, 1}$ para todo $i \in[n]$.

Portanto, uma instância do problema do leilão simplificado consiste em $(n, k, m, t, w)$, onde

- $n$ é o número de anunciantes e $[n]$ é o conjunto de anunciantes, e uma propaganda $i \in[n]$ refere-se à propaganda do anunciante $i$.

- $k$ é o número de locais da página e $[k]$ é o conjunto de locais, ordenados decrescentemente pela visibilidade na página.

- $m=\left(m_{1}, m_{2}, \ldots, m_{n}\right)$ é o vetor com o valor máximo (ou seja, a oferta) que cada anunciante está disposto a pagar por cada clique em sua propaganda.

- $t_{i, j}$ é a taxa de cliques da propaganda $i$ quando exibida no local $j$ da página, para todo par $(i, j) \in[n] \times[k]$.

- $w=\left(w_{1}, w_{2}, \ldots, w_{n}\right)$, onde o número $w_{i}$ é um valor não negativo chamado de peso do anunciante $i$.

Dada uma instância $(n, k, m, t, w)$, o problema do leilão simplificado consiste em determinar, para cada anunciante $i$ exibido, apenas o preço $p_{i} \leq m_{i}$ que será pago por $i$ quando sua propaganda for clicada. Um anunciante $i$ que tem sua propaganda exibida em um local $j$ tem utilidade $u_{i}=$ $t_{i, j}\left(v_{i}-p_{i}\right)$, mas note que o valor verdadeiro $v_{i}$ do anunciante $i$ não é revelado ao leiloeiro e será utilizado apenas para a análise dos mecanismos.

Ao longo de todo o capítulo, podemos assumir que $k<n$. Primeiro, porque se $k>n$, então podemos eliminar os locais de menor visibilidade, até que tenhamos $k=n$. Segundo, porque se $k=n$, então podemos adicionar um anunciante fictício $n+1 \operatorname{com} v_{n+1}=m_{n+1}=w_{n+1}=t_{n+1, j}=0$, para todo $j \in[k]$. A presença de tal anunciante não alterará a solução obtida pelos mecanismos apresentados neste trabalho, pois podemos assumir que ele sempre será classificado em último, e sua participação no leilão no alterará os preços determinados para os demais anunciantes.

\subsection{Mecanismo próximo preço}

Dada uma instância do leilão simplificado, o mecanismo próximo preço (next price auction) primeiramente realiza a classificação, ou seja, ordena os anunciantes decrescentemente por $w_{i} m_{i}$. Em seguida, a determinação do preço $p_{i}$ para um anunciante $i \leq k$ que tem sua propaganda exibida é dada pelo menor valor que $i$ poderia oferecer como $m_{i}$ tal que $i$ manteria sua posição na ordenação definida pela função de classificação, ou seja, $p_{i}=\frac{w_{i+1} m_{i+1}}{w_{i}}$.

Como veremos logo adiante, esse simples mecanismo não é à prova de estratégia. Por isso, Aggarwal et al. [AGM06, Agg05] propõem um novo mecanismo chamado leilão gradual (laddered auction), que é à prova de estratégia, e depois analisam o impacto no lucro do leiloeiro ao utilizar o leilão gradual em vez do próximo preço.

Considere uma instância $(n, k, m, t, w)$ do leilão simplificado, com $n \geq 3 \mathrm{e} k \geq 2$, já ordenada conforme a função de classificação, ou seja, $w_{i} m_{i} \geq w_{i+1} m_{i+1}$, para $1 \leq i<n$. Para mostrar que o mecanismo próximo preço não é à prova de estratégia, basta mostrar que um anunciante $i$ que oferece $m_{i}=v_{i}$ pode oferecer $m_{i} \neq v_{i}$ e aumentar sua utilidade. Suponha que o anunciante 
$\ell$ ofereceu $m_{\ell}=v_{\ell}$. Vamos mostrar que sob certas condições o anunciante $\ell$ pode aumentar sua utilidade ao declarar um valor $m_{\ell} \neq v_{\ell}$.

Primeiro, observe que o anunciante $\ell$ não tem incentivo em aumentar sua oferta para obter uma classificação melhor. Isso porque o anunciante $\ell$ pagaria um valor maior ou igual ao seu valor verdadeiro, caso recebesse uma classificação melhor do que $\ell$. De fato, ao receber uma classificação $j_{\ell}<\ell$, o anunciante $\ell$ pagaria $\frac{w_{j_{\ell}} m_{j_{\ell}}}{w_{\ell}} \geq \frac{w_{\ell} v_{\ell}}{w_{\ell}}=v_{\ell}$. Logo, se $\ell$ é um anunciante que não tem sua propaganda exibida quando declara $m_{\ell}=v_{\ell}$, então $\ell$ não tem incentivo em alterar sua oferta. Note também que se $\ell=k$, então $\ell$ também não tem incentivo em alterar sua oferta. Portanto, se $\ell \geq k$, então $\ell$ não tem incentivo em ofertar um valor diferente de seu valor verdadeiro.

Porém, se $\ell<k$ e sob certas condições, o anunciante $\ell$ tem incentivo de diminuir sua oferta para receber uma posição pior na classificação e assim obter uma utilidade maior. Sabemos que a utilidade para o anunciante $\ell$ quando declara $m_{\ell}=v_{\ell}$ é $t_{\ell, \ell}\left(v_{\ell}-p_{\ell}\right)$, onde $p_{\ell}=\frac{w_{\ell+1} m_{\ell+1}}{w_{\ell}}$. Para que seja possível para o anunciante $\ell$ diminuir sua oferta e obter uma utilidade maior é necessário que exista uma oferta que permita que o anunciante $\ell$ receba uma posição $j_{\ell}>\ell$, ou seja, que $w_{j_{\ell}} m_{j_{\ell}}>w_{j_{\ell}+1} m_{j_{\ell}+1}$, e que ele tenha lucro com isso, ou seja, que

$$
t_{\ell, j_{\ell}}\left(v_{\ell}-\frac{w_{j_{\ell}+1} m_{j_{\ell}+1}}{w_{\ell}}\right)>u_{\ell}=t_{\ell, \ell}\left(v_{\ell}-p_{\ell}\right)=t_{\ell, \ell}\left(v_{\ell}-\frac{w_{\ell+1} m_{\ell+1}}{w_{\ell}}\right) .
$$

Isolando $m_{j_{\ell}+1}$, podemos concluir que é vantajoso para o anunciante $\ell$ oferecer um valor $m_{\ell}$ tal que $w_{j_{\ell}} m_{j_{\ell}}>w_{\ell} m_{\ell}>w_{j_{\ell}+1} m_{j_{\ell}+1}$, se

$$
m_{j_{\ell}+1}<\frac{w_{\ell}}{w_{j_{\ell}+1}}\left(v_{\ell}-\frac{t_{\ell, \ell}}{t_{\ell, j_{\ell}}}\left(v_{\ell}-\frac{w_{\ell+1} m_{\ell+1}}{w_{\ell}}\right)\right) .
$$

Vejamos como o anunciante $\ell=1$ pode se beneficiar em um exemplo concreto. Considere uma instância com $n=3, k=2, t_{i, 1}=0.5, t_{i, 2}=0.4, w_{i}=1$, para $1 \leq i \leq 3$, com $m_{1}=v_{1}=200$, $m_{2}=180, m_{3}=100$. Utilizaremos tabelas como abaixo para representar uma instância, utilizando o símbolo "-" para representar valores que não nos interessam.

Tabela 2.1: Exemplo de utilização do mecanismo próximo preço.

\begin{tabular}{|c|c|c|c|c|c|c|c|c|}
\hline$i$ & $t_{i, 1}$ & $t_{i, 2}$ & $v_{i}$ & $m_{i}$ & $w_{i}$ & $w_{i} m_{i}$ & $p_{i}$ & $u_{i}$ \\
\hline \hline 1 & 0.5 & 0.4 & 200 & 200 & 1 & 200 & 180 & 10 \\
\hline 2 & 0.5 & 0.4 & - & 180 & 1 & 180 & 100 & - \\
\hline 3 & 0.5 & 0.4 & - & 100 & 1 & 100 & 0 & - \\
\hline
\end{tabular}

Nesse exemplo, o anunciante $\ell=1$ pode alterar sua oferta $m_{\ell}$ para um valor entre 100 e 180 , e assim receber a posição 2 na classificação, pagando apenas 100, e aumentando sua utilidade para $0,4(200-100)=40$. Portanto, o mecanismo próximo preço não é à prova de estratégia. Note que, se o preço dado ao anunciante $\ell=1$ por estar na posição 1 da classificação fosse menor ou igual a 120, então ele não teria incentivo em alterar sua oferta, já que sua utilidade seria $0,5(200-120)=$ 40 neste caso. 


\subsection{Mecanismo leilão gradual}

Como o mecanismo próximo preço não é à prova de estratégia, cada anunciante, ao tentar determinar uma oferta de maneira a maximizar o seu lucro, acaba tendo que especular as ofertas dos demais anunciantes e as taxas de cliques. Isso nem sempre é uma tarefa fácil para os anunciantes, o que pode acabar afastando possíveis anunciantes, ou fazer com que estes contratem consultores para auxiliá-los. Por outro lado, ao utilizarmos um mecanismo à prova de estratégia, o processo de realização das ofertas dos anunciantes torna-se mais simples, porque o valor ótimo para suas ofertas passa a ser um valor intrínseco a cada anunciante. Com essa motivação, foi proposto na literatura o mecanismo leilão gradual, que poderá vir a substituir o mecanismo próximo preço.

Dada uma instância do leilão, o mecanismo leilão gradual primeiramente realiza a classificação, ou seja, ordena os anunciantes decrescentemente por $w_{i} m_{i}$. Em seguida, a determinação do preço $p_{i}$ para um anunciante $i \leq k$ que tem sua propaganda exibida é

$$
p_{i}=\sum_{j=i}^{k}\left(\frac{t_{i, j}-t_{i, j+1}}{t_{i, i}}\right) \frac{w_{j+1}}{w_{i}} m_{j+1} .
$$

Perceba que $\sum_{j=i}^{k}\left(\frac{t_{i, j}-t_{i, j+1}}{t_{i, i}}\right)=1$ e que $\frac{w_{j+1}}{w_{i}} m_{j+1}$ é não crescente. Logo, vale que o preço determinado pelo leilão gradual é menor ou igual ao preço determinado pelo próximo preço.

Após um pequeno exemplo ilustrativo do mecanismo leilão gradual, demonstraremos os seguintes teoremas.

Teorema 2.4.1. O mecanismo leilão gradual é à prova de estratégia e é o único mecanismo à prova de estratégia dentre os que ordenam os anunciantes conforme a função de classificação $w$.

Teorema 2.4.2. Existe um equilíbrio de Nash tal que o lucro do leilão simplificado ao usar o mecanismo próximo preço é igual ao lucro do leilão simplificado ao usar o mecanismo leilão gradual, se as taxas de cliques forem separáveis.

\subsection{Exemplo utilizando o mecanismo leilão gradual}

Vamos aplicar o mecanismo leilão gradual para a mesma instância mostrada anteriormente, onde o anunciante $\ell=1$ tinha incentivo em diminuir sua oferta para aumentar sua utilidade quando o mecanismo utilizado era o próximo preço. Segue a tabela com os valores do exemplo anterior, e os preços obtidos agora pelo mecanismo leilão gradual.

Tabela 2.2: Exemplo de utilização do mecanismo leilão gradual.

\begin{tabular}{|c|c|c|c|c|c|c|c|c|}
\hline$i$ & $t_{i, 1}$ & $t_{i, 2}$ & $v_{i}$ & $m_{i}$ & $w_{i}$ & $w_{i} m_{i}$ & $p_{i}$ & $u_{i}$ \\
\hline \hline 1 & 0.5 & 0.4 & 200 & 200 & 1 & 200 & 116 & 42 \\
\hline 2 & 0.5 & 0.4 & - & 180 & 1 & 180 & 100 & - \\
\hline 3 & 0.5 & 0.4 & - & 100 & 1 & 100 & 0 & - \\
\hline
\end{tabular}

Utilizando o mecanismo leilão gradual, o anunciante $\ell=1$ não tem incentivo em diminuir sua oferta, pois ao receber a classificação 2 e preço igual a 100, sua utilidade seria de 40. Note também que o preço determinado para o anunciante 1 na posição 1 não é 120, o que deixaria a utilidade 
para o anunciante 1 exatamente igual a 40. Isso ocorre porque o mecanismo não sabe o valor verdadeiro do anunciante 1, que poderia ser, por exemplo, 182. Se esse fosse o caso, mantendo o preço $p_{1}=116$, mesmo assim o anunciante teria incentivo em oferecer $m_{1}=v_{1}$. Por outro lado, se o preço $p_{1}$ determinado pelo mecanismo fosse $p_{1}=120$, caso valesse que $v_{1}=182$, então o anunciante 1 teria utilidade 31 na solução encontrada pelo mecanismo, tendo incentivo a receber a classificação 2 pelo preço 100, obtendo utilidade 32.8 .

\subsection{Análise do mecanismo leilão gradual}

Mostraremos que o mecanismo leilão gradual é à prova de estratégia e, além disso, que é o único mecanismo à prova de estratégia que ordena os anunciantes conforme a função de classificação.

Considere uma instância do leilão $(n, k, m, t, w)$, para um vetor $m$ arbitrário. Vamos mostrar que o anunciante 1 não tem incentivo a escolher $m_{1} \neq v_{1}$. Como o anunciante 1 é um anunciante arbitrário, isso implica que o mecanismo é à prova de estratégia.

Seja $j^{*}$ a posição do anunciante 1 na classificação feita pelo mecanismo. Nas demonstrações a seguir iremos considerar que o anunciante 1 poderá alterar sua posição na classificação (alterando sua oferta $m_{1}$ ) para tentar se beneficiar. Por questão de conveniência e facilidade para realizar as demonstrações a seguir, considere que os demais anunciantes estão ordenados de modo que $w_{i} m_{i} \geq w_{i+1} m_{i+1}$, para $2 \leq i<n$.

Denotamos por $p_{L}(i)$ o preço dado ao anunciante 1 pelo mecanismo leilão gradual caso ele fique na posição $i$ da classificação, onde $p_{L}(i)=0$ para $i>k$, e para $1 \leq i \leq k$, pela determinação de preços do leilão,

$$
p_{L}(i)=\sum_{\ell=i}^{k}\left(\frac{t_{1, \ell}-t_{1, \ell+1}}{t_{1, i}}\right) \frac{w_{\ell+1}}{w_{1}} m_{\ell+1} .
$$

Equivalentemente,

$$
p_{L}(i) t_{1, i}=\sum_{\ell=i}^{k}\left(t_{1, \ell}-t_{1, \ell+1}\right) \frac{w_{\ell+1}}{w_{1}} m_{\ell+1} .
$$

Disso podemos deduzir que

$$
p_{L}(i) t_{1, i}-p_{L}(i+1) t_{1, i+1}=\left(t_{1, i}-t_{1, i+1}\right) \frac{w_{i+1}}{w_{1}} m_{i+1} .
$$

Ademais, seja $u_{L}(i)=t_{1, i}\left(v_{1}-p_{L}(i)\right)$ a utilidade para o anunciante 1 ao receber o local $i$, para $1 \leq i \leq k$, e $u_{L}(i)=0$ para $i>k$.

\subsubsection{Exemplo das estratégias de um anunciante}

Considere a instância descrita na tabela 2.3 abaixo, onde $n=4$ e $k=3$.

Veja que o anunciante escolhido $i=1$ receberia a classificação 2 durante a utilização do leilão gradual. Por outro lado, o anunciante 1 poderia ter feito uma outra oferta, o que faria com que ele pudesse receber uma outra classificação na ordenação por $w_{i} m_{i}$ usada no mecanismo leilão gradual. Por exemplo, o preço dado ao anunciante 1 caso recebesse a classificação 3, ou seja, caso ele optasse 
Tabela 2.3: Um exemplo.

\begin{tabular}{|c|c|c|c|c|c|c|}
\hline$i$ & $t_{i, 1}$ & $t_{i, 2}$ & $t_{i, 3}$ & $m_{i}$ & $w_{i}$ & $w_{i} m_{i}$ \\
\hline \hline 1 & 0.5 & 0.25 & 0.2 & 40 & 50 & 2000 \\
\hline 2 & 0.4 & 0.3 & 0.2 & 30 & 80 & 2400 \\
\hline 3 & 0.35 & 0.2 & 0.15 & 35 & 40 & 1400 \\
\hline 4 & 0.25 & 0.2 & 0.1 & 50 & 10 & 500 \\
\hline
\end{tabular}

por $m_{1}$ tal que $500<w_{1} m_{1}<1400\left(10<m_{1}<28\right)$, é

$$
\begin{aligned}
p_{L}(3) & =\sum_{j=3}^{3}\left(\frac{t_{1, j}-t_{1, j+1}}{t_{1,3}}\right) \frac{w_{j+1} m_{j+1}}{w_{1}} \\
& =\left(\frac{t_{1,3}-t_{1,4}}{t_{1,3}}\right) \frac{w_{4} m_{4}}{w_{1}} \\
& =10.0 .
\end{aligned}
$$

Analogamente, o preço dado ao anunciante 1 caso recebesse a classificação 2, ou seja, caso ele optasse por $m_{1}$ tal que $1400<w_{1} m_{1}<2400\left(28<m_{1}<48\right)$, é

$$
\begin{aligned}
p_{L}(2) & =\sum_{j=2}^{3}\left(\frac{t_{1, j}-t_{1, j+1}}{t_{1,2}}\right) \frac{w_{j+1} m_{j+1}}{w_{1}} \\
& =\left(\frac{t_{1,2}-t_{1,3}}{t_{1,2}}\right) \frac{w_{3} m_{3}}{w_{1}}+\left(\frac{t_{1,3}-t_{1,4}}{t_{1,2}}\right) \frac{w_{4} m_{4}}{w_{1}} \\
& =5.6+8 \\
& =13.6 .
\end{aligned}
$$

Analogamente, o preço dado ao anunciante 1 caso recebesse a classificação 1 , ou seja, caso ele optasse por $m_{1}$ tal que $2400<w_{1} m_{1}\left(48<m_{1}\right)$, é

$$
\begin{aligned}
p_{L}(1) & =\sum_{j=1}^{3}\left(\frac{t_{1, j}-t_{1, j+1}}{t_{1,1}}\right) \frac{w_{j+1} m_{j+1}}{w_{1}} \\
& =\left(\frac{t_{1,1}-t_{1,2}}{t_{1,1}}\right) \frac{w_{2} m_{2}}{w_{1}}+\left(\frac{t_{1,2}-t_{1,3}}{t_{1,1}}\right) \frac{w_{3} m_{3}}{w_{1}}+\left(\frac{t_{1,3}-t_{1,4}}{t_{1,1}}\right) \frac{w_{4} m_{4}}{w_{1}} \\
& =24+2.8+4 \\
& =30.8 .
\end{aligned}
$$

Para determinar qual a melhor oferta que o anunciante 1 poderia ter dado, temos que considerar o valor verdadeiro do anunciante 1 . Lembrando que $p_{L}(3)=10, p_{L}(2)=13.6, p_{L}(1)=30.8$, vejamos o que aconteceria com a utilidade para o anunciante 1 em função do seu valor verdadeiro, dada uma classificação do anunciante, que depende de sua oferta. 


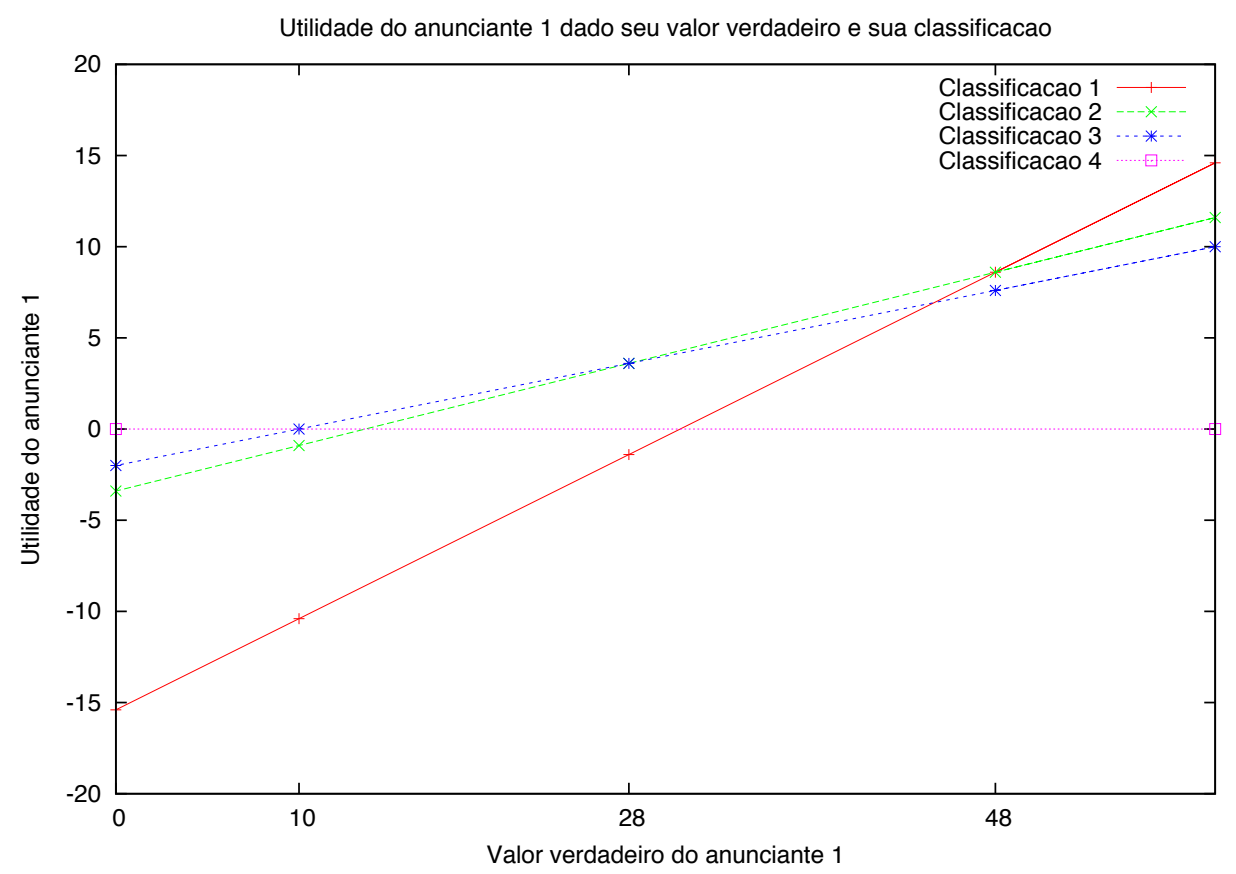

Observe que qualquer que seja o valor verdadeiro do anunciante 1, para obter a classificação que maximiza sua utilidade basta oferecer seu valor verdadeiro, ou seja, optar por $m_{1}=v_{1}$ é uma estratégia dominante. Mostraremos que esse resultado é válido para uma instância qualquer.

\subsubsection{Mecanismo leilão gradual é à prova de estratégia}

Para mostrar que o mecanismo leilão gradual é à prova de estratégia, basta mostrar que o anunciante 1 não se beneficia ao declarar um valor $m_{1} \neq v_{1}$. Note que a utilidade para o anunciante 1 não depende diretamente do lance $m_{1}$ dado, mas depende apenas de sua posição na classificação, dado que os lances dos outros anunciantes estão fixos.

Seja $j^{*}$ a posição do anunciante 1 ao declarar seu valor verdadeiro. Se o anunciante 1 não for alocado ao declarar seu valor verdadeiro, ou seja, se $j^{*}>k$, então ele não consegue se beneficiar ao declarar um valor maior. Isso porque se $j^{*}>k$, então ao obter a posição $k$ o preço dado ao anunciante 1 é exatamente $p_{L}(k)=\frac{w_{k+1} m_{k+1}}{w_{1}}$. Assim, se $j^{*}>k$, vale que $w_{1} v_{1} \leq w_{k+1} m_{k+1}=$ $w_{1} p_{L}(k)$, ou seja, ao obter a posição $k$, o anunciante 1 irá pagar um preço maior ou igual ao seu valor verdadeiro, obtendo utilidade menor ou igual a zero. Ao obter uma posição $j<k$, temos que $p_{L}(j) \geq p_{L}(k)$, e a mesma conclusão vale. Portanto, podemos nos restringir aos casos em que $j^{*} \leq k$.

Dentre todas as posições onde a utilidade para o anunciante 1 é a maior possível, tome $r$ sendo a posição mais próxima da posição $j^{*}$, ou seja, tome $r$ tal que a diferença $\left|r-j^{*}\right|$ é mínima. Suponha que o anunciante 1 possa se beneficiar ao declarar $m_{1} \neq v_{1}$, ou seja, temos que $r \neq j^{*}$. Mostraremos que se o anunciante se aproximar da posição $j^{*}$, sua utilidade não diminui, concluindo que essa suposição não é válida. Para isso, vamos mostrar que se $r>j^{*}$, então a variação em sua utilidade ao receber a posição $r-1$ é $\left(t_{1, r-1}-t_{1, r}\right)\left(v_{1}-\frac{w_{r}}{w_{1}} m_{r}\right) \geq 0$. Analogamente, se $r<j^{*}$, então a variação em sua utilidade ao receber a posição $r+1$ é $\left(t_{1, r+1}-t_{1, r}\right)\left(v_{1}-\frac{w_{r+1}}{w_{1}} m_{r+1}\right) \geq 0$. 
Primeiramente, vamos verificar que a variação da utilidade para o anunciante 1 pode ser expressa pelos valores mostrados acima, e depois verificaremos que essa variação é não negativa. Denote por $\delta\left(u_{L}\right)(r, r-1)=u_{L}(r-1)-u_{L}(r)$ a variação da utilidade para o anunciante ao trocar da posição $r$ para a posição $r-1$. Dessa forma, temos que

$$
\begin{aligned}
\delta\left(u_{L}\right)(r, r-1) & =t_{1, r-1}\left(v_{1}-p_{L}(r-1)\right)-t_{1, r}\left(v_{1}-p_{L}(r)\right) \\
& =\left(t_{1, r-1}-t_{1, r}\right) v_{1}-\left(p_{L}(r-1) t_{1, r-1}-p_{L}(r) t_{1, r}\right) \\
& =\left(t_{1, r-1}-t_{1, r}\right) v_{1}-\left(t_{1, r-1}-t_{1, r}\right)\left(\frac{w_{r}}{w_{1}} m_{r}\right) \\
& =\left(t_{1, r-1}-t_{1, r}\right)\left(v_{1}-\frac{w_{r}}{w_{1}} m_{r}\right) .
\end{aligned}
$$

Ademais, temos que a variação na utilidade $\left(t_{1, r-1}-t_{1, r}\right)\left(v_{1}-\frac{w_{r}}{w_{1}} m_{r}\right)$, no caso $r>j^{*}$, é de fato não negativa pois vale que $t_{1, r-1}-t_{1, r} \geq 0$ devido à maior visibilidade dos locais que estão mais no topo da página, e como $r>j^{*}$, então vale que $w_{1} v_{1} \geq w_{r} m_{r}$, e segue que $v_{1}-\frac{w_{r}}{w_{1}} m_{r} \geq 0$.

Analogamente, a variação da utilidade ao trocar da posição $r$ para a posição $r+1$ é

$$
\begin{aligned}
\delta\left(u_{L}\right)(r, r+1) & =t_{1, r+1}\left(v_{1}-p_{L}(r+1)\right)-t_{1, r}\left(v_{1}-p_{L}(r)\right) \\
& =\left(t_{1, r+1}-t_{1, r}\right) v_{1}+\left(p_{L}(r) t_{1, r}-p_{L}(r+1) t_{1, r+1}\right) \\
& =\left(t_{1, r+1}-t_{1, r}\right) v_{1}+\left(t_{1, r}-t_{1, r+1}\right)\left(\frac{w_{r+1}}{w_{1}} m_{r+1}\right) \\
& =\left(t_{1, r+1}-t_{1, r}\right)\left(v_{1}-\frac{w_{r+1}}{w_{1}} m_{r+1}\right) .
\end{aligned}
$$

Neste caso também vale que a variação da utilidade é não negativa, pois vale que $t_{1, r+1}-t_{1, r} \leq 0$ e que $v_{1}-\frac{w_{r+1}}{w_{1}} m_{r+1} \leq 0$.

Apenas para ilustrar as contas demonstradas acima, podemos, por exemplo, verificar que ao trocar a posição do anunciante 1 de $r=3$ para a posição 4 , a variação na sua utilidade é de $\left(t_{1, r+1}-t_{1, r}\right)\left(v_{1}-\frac{w_{r+1}}{w_{1}} m_{r+1}\right)=\left(t_{1,4}-t_{1,3}\right)\left(v_{1}-\frac{w_{4}}{w_{1}} m_{4}\right)$. Também podemos verificar que a variação de utilidade ao trocar da posição $r=4$ para a posição $r=3$ tem o mesmo valor mas sinal contrário, dada por $\left(t_{1, r-1}-t_{1, r}\right)\left(v_{1}-\frac{w_{r}}{w_{1}} m_{r}\right)=\left(t_{1,3}-t_{1,4}\right)\left(v_{1}-\frac{w_{4}}{w_{1}} m_{4}\right)$.

\subsubsection{Leilão gradual é o único mecanismo à prova de estratégia}

Seja $M$ um mecanismo para encontrar uma solução para o problema do leilão simplificado. Mostraremos que se $M$ é à prova de estratégia e define os ganhadores na mesma ordem do leilão gradual, então $M$ deve determinar preços iguais aos determinados pelo mecanismo leilão gradual.

Como na seção anterior, fixemos nossa atenção no anunciante 1 , e suponhamos que $w_{2} m_{2} \leq$ $\cdots \leq w_{n} m_{n}$. Denote por $p_{M}(j)$ o preço dado ao anunciante 1 pelo mecanismo $M$ caso ele seja alocado a um local $j$ qualquer, onde $p_{M}(j)=0$, para $j>k$. Analogamente, denote por $u_{M}(j)$ a utilidade para o anunciante 1 quando alocado a um local $j$ pelo mecanismo $M$. Vamos mostrar que se $M$ é de fato à prova de estratégia, então, para $1 \leq i \leq k$, vale que

$$
p_{M}(i)=p_{L}(i)
$$

Fixe uma instância $(n, k, m, t, w)$, exceto pelo valor de $m_{1}$, e suponha que $w_{i} m_{i}>w_{i+1} m_{i+1}$, 
para $2 \leq i<n$. Mostraremos, por indução em $j$, que vale que $p_{M}(j)=p_{L}(j)$, para $1 \leq j \leq n$. Como base da indução, para $j>k$, vale que $p_{M}(j)=p_{L}(j)=0$. Tome $j \leq k$, e por hipótese de indução suponha que $p_{M}(j+1)=p_{L}(j+1)$.

Primeiramente, mostraremos que se o anunciante 1 optar por $m_{1}=v_{1}$ obtendo o local $j$, então existe $v_{1}$ tal que se valesse que $p_{M}(j)>p_{L}(j)$, o anunciante 1 teria incentivo em diminuir sua oferta e receber o local $j+1$. Em seguida, mostraremos que se o anunciante 1 optar por $m_{1}=v_{1}$ obtendo o local $j+1$, então existe $v_{1}$ tal que se valesse que $p_{M}(j)<p_{L}(j)$, o anunciante 1 teria incentivo em aumentar sua oferta e receber o local $j$.

Suponha que $v_{1}=\frac{w_{j+1}}{w_{1}} m_{j+1}+\epsilon$. Então ao oferecer $m_{1}=v_{1}$, para um $\epsilon>0$ suficientemente pequeno, o anunciante 1 recebe o local $j$. Se $p_{M}(j)>p_{L}(j)$, então podemos escolher $\epsilon>0$ tal que $\delta\left(u_{M}\right)(j, j+1)>0$, o que contraria o fato do mecanismo $M$ ser à prova de estratégia. De fato, temos que

$$
\delta\left(u_{L}\right)(j, j+1)-\delta\left(u_{M}\right)(j, j+1)=t_{1, j}\left(p_{L}(j)-p_{M}(j)\right)
$$

ou seja,

$$
\delta\left(u_{M}\right)(j, j+1)=\delta\left(u_{L}\right)(j, j+1)+t_{1, j}\left(p_{M}(j)-p_{L}(j)\right)
$$

Como $\delta\left(u_{L}\right)(j, j+1)<0$ pode ser arbitrariamente próximo de zero pela escolha de $\epsilon$, se $p_{M}(j)>$ $p_{L}(j)$, existe $\epsilon>0$ tal que o valor de $\delta\left(u_{M}\right)(j, j+1)$ é positivo. Logo, deve valer que

$$
p_{M}(j) \leq p_{L}(j)
$$

Analogamente, suponha que $v_{1}=\frac{w_{j+1}}{w_{1}} m_{j+1}-\epsilon$. Então ao oferecer $m_{1}=v_{1}$, para um $\epsilon>0$ suficientemente pequeno, o anunciante 1 recebe o local $j+1$. Se $p_{M}(j)<p_{L}(j)$, então podemos escolher $\epsilon>0$ tal que $\delta\left(u_{M}\right)(j+1, j)>0$, o que contraria o fato do mecanismo $M$ ser à prova de estratégia. De fato, temos que

$$
\delta\left(u_{L}\right)(j+1, j)-\delta\left(u_{M}\right)(j+1, j)=t_{1, j}\left(p_{M}(j)-p_{L}(j)\right)
$$

ou seja,

$$
\delta\left(u_{M}\right)(j+1, j)=\delta\left(u_{L}\right)(j+1, j)+t_{1, j}\left(p_{L}(j)-p_{M}(j)\right)
$$

Como $\delta\left(u_{L}\right)(j+1, j)<0$ pode ser arbitrariamente próximo de zero pela escolha de $\epsilon$, se $p_{M}(j)<$ $p_{L}(j)$, existe $\epsilon>0$ tal que o valor de $\delta\left(u_{M}\right)(j+1, j)$ é positivo. Logo, deve valer que

$$
p_{M}(j) \geq p_{L}(j)
$$

De (2.3) e (2.4) concluímos que $p_{M}(j)=p_{L}(j)$. Logo, por indução, concluímos que $p_{M}(j)=p_{L}(j)$ para todo $j \leq n$. 


\subsection{Comparação entre o leilão gradual e o próximo preço}

Nesta seção utilizaremos taxa de cliques separáveis definidas na subseção 1.1.1. Relembrando, as taxas de cliques são ditas separáveis se existem $\mu_{1}, \mu_{2}, \ldots, \mu_{n}>0$ relativos aos anunciantes e $\theta_{1} \geq \theta_{2} \geq \cdots \geq \theta_{k}>0$ relativos aos locais tais que a taxa de cliques $t_{i, j}$ do anunciante $i$ no local $j$ é dada por $t_{i, j}=\mu_{i} \theta_{j}$.

Sabemos que o leilão gradual determina preços menores ou iguais aos preços determinados pelo mecanismo próximo preço para uma mesma instância. Portanto, para fazer uma comparação justa entre o lucro obtido pelo leiloeiro ao utilizar o mecanismo próximo preço e ao utilizar o mecanismo leilão gradual, consideraremos instâncias onde as ofertas dos anunciantes estão em equilíbrio de Nash para o mecanismo próximo preço, conforme descrito a seguir.

Dada uma instância $(n, k,-, t, w)$ sem as ofertas dos anunciantes, onde os anunciantes tem valores verdadeiros arbitrários, determinaremos valores para as ofertas dos anunciantes de forma a obter um equilíbrio de Nash ao utilizar o mecanismo próximo preço. Ou seja, determinaremos valores para a oferta $m_{i}$ de cada anunciante $i$ de forma que nenhum anunciante possa aumentar sua utilidade ao alterar sua oferta $m_{i}$ quando o mecanismo próximo preço é usado para determinar os preços. Mostraremos que o lucro obtido pelo leiloeiro ao utilizar o mecanismo próximo preço para essa instância é igual ao lucro obtido ao utilizar o mecanismo leilão gradual para a mesma instância, mas com $m_{i}=v_{i}$, para todo $i \in[n]$.

Considere uma instância $(n, k,-, t, w)$ do leilão simplificado sem as ofertas dos anunciantes, tal que $w_{i} v_{i} \geq w_{i+1} v_{i+1}$, para $1 \leq i<n$. Considere que as taxas de cliques são separáveis, onde vale que $t_{i, j}=\mu_{i} \theta_{j}$, para $i \in[n]$ e $j \in[k]$. Construíremos as ofertas dos anunciantes de forma a obter um equilíbrio de Nash para o mecanismo próximo preço da seguinte maneira. Primeiro, tomemos $m_{i}=v_{i}$ para $i=1$ e para $i>k$. Para $i=k, k-1, \ldots, 2$, tomemos $m_{i}$ tal que

$$
w_{i} m_{i}=\frac{1}{\theta_{i-1}} \sum_{\ell=i-1}^{k}\left(\left(\theta_{\ell}-\theta_{\ell+1}\right) w_{\ell+1} v_{\ell+1}\right) \text {. }
$$

Primeiramente, mostraremos que as ofertas determinadas por (2.5) respeitam a função classificação. Em seguida, mostraremos que, para ofertas construídas conforme descrito em (2.5), o lucro do leiloeiro ao utilizar o mecanismo próximo preço é igual ao lucro do leiloeiro ao utilizar o mecanismo leilão gradual quando os anunciantes ofertam seus valores verdadeiros. Por fim, mostraremos que essas ofertas de fato definem um equilíbrio de Nash.

Por (2.5) temos que $w_{i} m_{i}$ é uma combinação convexa de $w_{\ell} v_{\ell}$ para $\ell=i, i+1, \ldots, k+1$. Como vale que $w_{j} v_{j} \geq w_{j+1} v_{j+1}$ para $1 \leq j<n$, temos que $w_{i} v_{i} \geq w_{i+1} m_{i+1}$. Além disso, de (2.5) deduzimos que

$$
\begin{aligned}
w_{i} m_{i} & =\frac{1}{\theta_{i-1}} \sum_{\ell=i-1}^{k}\left(\left(\theta_{\ell}-\theta_{\ell+1}\right) w_{\ell+1} v_{\ell+1}\right) \\
& =\frac{1}{\theta_{i-1}}\left(\left(\theta_{i-1}-\theta_{i}\right) w_{i} v_{i}+\sum_{\ell=i}^{k}\left(\left(\theta_{\ell}-\theta_{\ell+1}\right) w_{\ell+1} v_{\ell+1}\right)\right) \\
& =\left(1-\frac{\theta_{i}}{\theta_{i-1}}\right) w_{i} v_{i}+\left(\frac{\theta_{i}}{\theta_{i-1}}\right) w_{i+1} m_{i+1} .
\end{aligned}
$$


Logo, $w_{i} m_{i}$ é uma combinação convexa de $w_{i} v_{i}$ e $w_{i+1} m_{i+1}$, e portanto vale que $w_{i} m_{i} \geq w_{i+1} m_{i+1}$ e as ofertas determinadas por (2.5) respeitam a função de classificação.

Como o preço determinado pelo mecanismo próximo preço a um anunciante $i \leq k$ é $\frac{w_{i+1} m_{i+1}}{w_{i}}$, então, por (2.5), vale que $p_{i}=\frac{1}{\theta_{i}} \sum_{\ell=i}^{k}\left(\left(\theta_{\ell}-\theta_{\ell+1}\right) \frac{w_{\ell+1} v_{\ell+1}}{w_{i}}\right)$. Portanto, o preço determinado pelo mecanismo próximo preço quando as ofertas satisfazem (2.5) é igual ao preço determinado pelo mecanismo leilão gradual quando as ofertas são os valores verdadeiros dos anunciantes. Logo, o lucro do leiloeiro é o mesmo em ambos os casos.

\subsubsection{As ofertas determinadas estão em equilíbrio}

Para verificar que as ofertas determinadas por (2.5) estão em equílibrio de Nash, basta mostrar que nenhum anunciante consegue aumentar sua utilidade ao oferecer uma oferta diferente, considerando fixadas todas as outras ofertas. Primeiro, veja que como vale que $p_{i} \leq m_{i}$ para um anunciante ganhador $i \leq k$, nenhum anunciante ganhador tem incentivo em diminuir sua oferta a ponto de receber uma classificação pior do que $k$. Ademais, nenhum anunciante $i>k$ perdedor tem incentivo em oferecer um valor suficiente para receber uma posição melhor ou igual a $k$ dado que ele pagaria um valor maior do que seu valor verdadeiro. Portanto, podemos nos concentrar apenas nos anunciantes ganhadores que tentam receber um outro local da página para aumentar sua utilidade.

Para um anunciante $i \leq k$ que oferta $m_{i}$ recebendo a posição $i$, sua utilidade é

$$
\begin{aligned}
u_{i} & =\mu_{i} \theta_{i}\left(v_{i}-p_{i}\right) \\
& =\mu_{i} \theta_{i}\left(v_{i}-\frac{w_{i+1} m_{i+1}}{w_{i}}\right) \\
& =\mu_{i} \theta_{i} v_{i}-\frac{\mu_{i} \theta_{i}}{w_{i}} \frac{1}{\theta_{i}} \sum_{\ell=i}^{k}\left(\left(\theta_{\ell}-\theta_{\ell+1}\right) w_{\ell+1} v_{\ell+1}\right) \\
& =\mu_{i} v_{i} \sum_{\ell=i}^{k}\left(\theta_{\ell}-\theta_{\ell+1}\right)-\frac{\mu_{i}}{w_{i}} \sum_{\ell=i}^{k}\left(\left(\theta_{\ell}-\theta_{\ell+1}\right) w_{\ell+1} v_{\ell+1}\right) \\
& =\mu_{i} \sum_{\ell=i}^{k}\left(\theta_{\ell}-\theta_{\ell+1}\right)\left(v_{i}-\frac{w_{\ell+1} v_{\ell+1}}{w_{i}}\right) .
\end{aligned}
$$

Analogamente, a utilidade de um anunciante $i \leq k$ quando oferta um valor diferente de $m_{i}$ recebendo uma posição $j \leq k$ é

$$
\begin{aligned}
u_{i} & =\mu_{i} \theta_{j}\left(v_{i}-\frac{w_{j+1} m_{j+1}}{w_{i}}\right) \\
& =\mu_{i} \theta_{j} v_{i}-\frac{\mu_{i} \theta_{j}}{w_{i}} \frac{1}{\theta_{j}} \sum_{\ell=j}^{k}\left(\left(\theta_{\ell}-\theta_{\ell+1}\right) w_{\ell+1} v_{\ell+1}\right) \\
& =\mu_{i} v_{i} \sum_{\ell=j}^{k}\left(\theta_{\ell}-\theta_{\ell+1}\right)-\frac{\mu_{i}}{w_{i}} \sum_{\ell=j}^{k}\left(\left(\theta_{\ell}-\theta_{\ell+1}\right) w_{\ell+1} v_{\ell+1}\right) \\
& =\mu_{i} \sum_{\ell=j}^{k}\left(\theta_{\ell}-\theta_{\ell+1}\right)\left(v_{i}-\frac{w_{\ell+1} v_{\ell+1}}{w_{i}}\right) .
\end{aligned}
$$

Dessa forma, a alteração na utilidade de um anunciante $i<k$ que oferta um valor diferente de 
$m_{i}$ recebendo uma posição $j$ tal que $i<j \leq k$ é

$$
-\mu_{i} \sum_{\ell=i}^{j-1}\left(\theta_{\ell}-\theta_{\ell+1}\right)\left(v_{i}-\frac{w_{\ell+1} v_{\ell+1}}{w_{i}}\right) .
$$

Como vale que $\theta_{\ell} \geq \theta_{\ell+1}$ para $1 \leq \ell \leq k$ e que $w_{\ell} v_{\ell} \geq w_{\ell+1} v_{\ell+1}$ para $1 \leq \ell<n$, então essa variação na utilidade não é positiva.

Analogamente, a alteração na utilidade de um anunciante $i \leq k$ que oferta um valor diferente de $m_{i}$ recebendo uma posição $j$ tal que $1 \leq j<i$ é

$$
\mu_{i} \sum_{\ell=j}^{i-1}\left(\theta_{\ell}-\theta_{\ell+1}\right)\left(v_{i}-\frac{w_{\ell+1} v_{\ell+1}}{w_{i}}\right) .
$$

Novamente, como vale que $\theta_{\ell} \geq \theta_{\ell+1}$ para $1 \leq \ell \leq k$ e que $w_{\ell} v_{\ell} \geq w_{\ell+1} v_{\ell+1}$ para $1 \leq \ell<n$, então essa variação na utilidade não é positiva.

Portanto, as ofertas determinadas por (2.5) de fato estão em equilíbrio quando utilizamos o mecanismo próximo preço. O mecanismo do próximo preço tem outros equilíbrios além do descrito acima, onde o lucro do leiloeiro pode ser maior ou menor.

\subsubsection{Exemplos de ofertas em equilíbrio para o próximo preço}

Considere um exemplo para o leilão simplificado com 3 anunciantes que têm valores verdadeiros $v_{1}=500, v_{2}=480$ e $v_{3}=100$, com 2 locais na página, onde é utilizada a função de classificação revenue ranking, onde $w_{i}=t_{i, 1}$ para $i \in[n]$, e que possui taxas de cliques separáveis tais que $\mu_{1}=\mu_{2}=\mu_{3}=1$ e $\theta_{1}=0.2$ e $\theta_{2}=0.15$. Assim, temos que $w_{i}=0.2$ para $i \in[n]$.

Ao utilizar o mecanismo próximo preço, se os anunciantes ofertarem seus valores verdadeiros, então o lucro esperado do leiloeiro seria de $0.2 \cdot 480+0.15 \cdot 100=96+15=111$. Porém nesse caso ofertar o valor verdadeiro não é um equilíbrio.

Podemos atingir um equilíbrio nesse exemplo ao alterar a oferta do anunciante 1 para $m_{1}=110$, aumentando sua utilidade, de forma que o lucro do leiloeiro passaria a ser $15+22=37$. Podemos também atingir um equilíbrio nesse exemplo ao alterar a oferta do anunciante 2 para $m_{2}=200$, obtendo um lucro para o leiloeiro de valor $15+40=55$. Veja que se o anunciante 2 oferecer um valor $m_{2}>200$, então o anunciante 1 tem incentivo em diminuir sua oferta para receber a segunda classificação. Caso contrário, ou seja, se $m_{2} \leq 200$, então o anunciante 1 não se beneficia ao receber a segunda classificação.

Veja que as ofertas em equilíbrio obtidas por (2.5) são $m_{1}=v_{1}, m_{3}=v_{3} \mathrm{e}$

$$
\begin{aligned}
w_{2} m_{2} & =\frac{1}{0.2}((0.2-0.15)(0.2)(480)+(0.15-0)(0.2)(100)) \\
& =24+15=39
\end{aligned}
$$

Assim, com oferta $m_{2}=195$, obtida da equação acima, o lucro esperado do leiloeiro é de 54 , que é igual ao lucro esperado do leiloeiro ao utilizar o leilão gradual quando os anunciantes ofertam seus valores verdadeiros. De fato, ao utilizarmos o leilão gradual, obtemos os valores mostrados na tabela abaixo, onde o lucro do leiloeiro é $0.2(120+75)+0.15(100)=54$. 
Tabela 2.4: Utilizando o leilão gradual.

\begin{tabular}{|c|c|c|c|c|c|c|c|}
\hline$i$ & $t_{i, 1}$ & $t_{i, 2}$ & $v_{i}$ & $w_{i}$ & $w_{i} v_{i}$ & $p_{i}$ & $u_{i}$ \\
\hline \hline 1 & 0.2 & 0.15 & 500 & 0.2 & 100 & $120+75$ & 61 \\
\hline 2 & 0.2 & 0.15 & 480 & 0.2 & 96 & 100 & 57 \\
\hline 3 & 0.2 & 0.15 & 100 & 0.2 & 20 & 0 & 0 \\
\hline
\end{tabular}

\subsection{Cenário dinâmico dos leilões simplificados}

Neste capítulo apresentamos os leilões simplificados considerando uma única ocorrência do leilão, sem considerar o fato de que os leilões ocorrem ao longo do tempo, a cada vez que um usuário de Internet realiza uma busca em um site com mecanimo de busca. Em especial, para várias buscas por uma mesma palavra chave, os mesmos anunciantes competirão várias vezes entre si. Fixando uma palavra chave específica, podemos tentar analisar o comportamento dos anunciantes que competirão entre si várias vezes por essa palavra chave ao longo de um período de tempo. Nesse cenário, podemos esperar que esses anunciantes irão ajustar suas ofertas ao longo do tempo, tentando estimar as ofertas dos outros anunciantes, o que pode levar a um equilíbrio, como, por exemplo, o equilíbrio apresentado acima na seção 2.7 .

Porém, na prática, outros comportamentos também podem ser observados. Um anunciante pode agir estrategicamente para fazer seus competidores gastarem muito dinheiro. Tais anunciantes são conhecidos como vingativos. Para isso, basta um tal anunciante ofertar um valor grande suficiente que não altere sua posição na ordenação, e portanto não altere sua utilidade, mas faz com que o anunciante acima pague mais. Essa estratégia é conhecida como bid jamming e é muito usada na prática [Yua09]. Esse comportamento pode trazer uma grande complexidade ao leilão, em especial quando os gastos dos anunciantes estão limitados às suas reservas monetárias (budgets). Um resumo sobre os comportamentos dos anunciantes e como isso influencia o leilão pode ser encontrado em $\left[\mathrm{MMN}^{+} 10\right]$. 


\section{Capítulo 3}

\section{Leilões com exclusividade para publicidade na Internet}

\subsection{Introdução}

Os leilões simplificados apresentados no capítulo anterior não levam em consideração algumas particularidades que podem ser interessantes na prática, levando-nos ao estudo de modelos mais sofisticados para atender às necessidades dos anunciantes. Com essa motivação, apresentamos neste capítulo o trabalho de Arpita Ghosh e Amin Sayedi [GS10], que busca dar mais expressividade ao leilão, mantendo grande parte das características já presentes nos atuais leilões (que por sua vez são parecidos com os leilões simplificados apresentados no capítulo anterior) utilizados por grandes empresas como Google, Yahoo e Microsoft.

A competição entre os anúncios exibidos na página não se restringe ao ato de receber um clique. O clique é apenas o primeiro passo que pode levar o anúncio a trazer de fato algum lucro ao anunciante. Após receber o clique, o anúncio precisa agradar o usuário, e fazer com que este realize alguma compra, ou mais genericamente, uma conversão para o anunciante. Um cenário que parece bastante natural é um usuário de Internet clicar em mais de um dos anúncios antes de decidir onde realizará a conversão. Dessa maneira, podemos dizer que dependendo dos anunciantes rivais que aparecem na página, a chance de conversão pode variar bastante, enquanto a taxa de clique não varia tanto, quando consideramos o cenário exposto acima. Com essa motivação, Ghosh e Sayedi [GS10] propõem um modelo que é uma extensão dos leilões simplificados, mas onde os anunciantes têm a opção, dependendo do pagamento, de aparecerem com exclusividade na região onde os anúncios são exibidos, aumentando a chance de que uma conversão seja realizada quando o anúncio receber um clique.

Apresentaremos dois mecanismos que são extensões dos leilões simplificados, e analisaremos o lucro e o bem estar social obtidos em soluções em equilíbrio por esses mecanismos quando comparados a um mecanismo à prova de estratégia para o modelo proposto, que é um mecanismo VCG. Os mecanismos apresentados foram patenteados pela Yahoo, que atualmente estuda as possibilidades de implementação desses mecanismos [JS11]. 


\subsection{Formalização do problema}

Neste problema, que chamaremos de leilâo com exclusividade, abreviado por LE, utilizaremos a notação descrita previamente na seção 1.1, desconsiderando os preços mínimos. Há ainda duas informações adicionais.

A primeira delas é uma informação relativa à exclusividade. Para que os leilões com exclusividade sejam apenas uma pequena modificação dos leilões simplificados e permitam que um anunciante possa aparecer com exclusividade, um anunciante $i$ deve ofertar dois valores $\left(m_{i}, m_{i}^{\prime}\right)$. O primeiro valor, $m_{i}$, refere-se ao valor máximo que o anunciante $i$ está disposto a pagar caso seja exibido com exclusividade na página, enquanto que o valor $m_{i}^{\prime}$ é o valor máximo que o anunciante $i$ está disposto a pagar caso seja exibido em uma lista junto com outros anunciantes. Além disso, o anunciante $i$ tem também o seu valor verdadeiro $v_{i}$ caso apareça exclusivamente, e tem o seu valor verdadeiro $v_{i}^{\prime}$ caso apareça junto com outros anunciantes. Um anunciante sempre prefere aparecer exclusivamente do que junto com outros anunciantes, e portanto vale que $v_{i} \geq v_{i}^{\prime}$, para todo $i \in[n]$.

A segunda informação é a simplificação das taxas de cliques. Neste modelo teremos apenas taxas de cliques associadas às posições, sendo $\theta_{1}$ a taxa de cliques da primeira posição, $\theta_{2}$ a taxa de cliques da segunda posição, e assim por diante, sendo que $\theta_{1} \geq \cdots \geq \theta_{k}$, onde $k$ é o número de locais na página. Ou seja, utilizamos taxas de cliques separáveis descritas na seção 1.1.1, mas com $\mu_{1}=\cdots=\mu_{n}=1$, onde $n$ é o número de anunciantes. Ademais, quando o mecanismo decide exibir um anunciante exclusivamente, a taxa de cliques $\hat{\theta}$ é maior do que as taxas de cliques obtidas quando são exibidos múltiplos anúncios, ou seja, $\hat{\theta} \geq \theta_{1}$. Dessa forma, a utilidade $u_{i}$ de um anunciante $i \in[n]$ que é exibido em um local $j \in[k]$ pagando $p_{i}$ passa a ser definida como $u_{i}=\theta_{j}\left(v_{i}^{\prime}-p_{i}\right)$. Analogamente, um anunciante $i$ que é exibido exclusivamente pagando $p_{i}$ tem utilidade $u_{i}=\hat{\theta}\left(v_{i}-p_{i}\right)$.

Uma instância do problema do leilão com exclusividade consiste em $\left(n, k, m, m^{\prime}, \theta\right)$, onde

- $n$ é o número de anunciantes e $[n]$ é o conjunto de anunciantes, e uma propaganda $i \in[n]$ refere-se à propaganda do anunciante $i$.

- $k$ é o número de locais da página e $[k]$ é o conjunto de locais, ordenados decrescentemente pela visibilidade na página.

- $\left.\left(m, m^{\prime}\right)=\left(\left(m_{1}, m_{1}^{\prime}\right),\left(m_{2}, m_{2}^{\prime}\right)\right), \ldots,\left(m_{n}, m_{n}^{\prime}\right)\right)$ é o par de vetores com os valores máximos (ou seja, as ofertas) que cada anunciante está disposto a pagar por cada clique em sua propaganda para exibições exclusivas e múltiplas, respectivamente.

- $\theta_{j}$ é a taxa de cliques do local $j$ da página, para todo $j \in[k]$, e $\hat{\theta}$ é a taxa de cliques do local exclusivo, $\operatorname{com} \hat{\theta} \geq \theta_{1} \geq \cdots \geq \theta_{k}$.

Note que os valores verdadeiros $\left(v_{i}, v_{i}^{\prime}\right)$ do anunciante $i$ não são revelados ao leiloeiro e serão utilizados apenas para a análise do bem estar social e lucro esperado dos mecanismos. O bem estar social para múltiplos anúncios é $\sum_{i=1}^{k} \theta_{i} v_{i}$, onde cada anunciante $i$, para $1 \leq i \leq k$, é exibido no $i$-ésimo local da página, e o lucro esperado pelo leiloeiro é $\sum_{i=1}^{k} \theta_{i} p_{i}$. No caso de um anunciante $i$ ser exibido exclusivamente, o bem estar social é $\hat{\theta} v_{i}$, e o lucro esperado é $\hat{\theta} p_{i}$.

A solução do problema do leilão com exclusividade, para uma instância $\left(n, k, m, m^{\prime}, \theta\right)$, consiste em determinar se a exibição dos anúncios será múltipla ou com exclusividade, e determinar os anunciantes ganhadores e o preço que eles deverão pagar quando sua propaganda receber um clique. Ao longo de todo o capítulo vamos considerar que os anunciantes estão ordenados pelas suas ofertas 
para exibição múltipla, de forma que $m_{1}^{\prime} \geq m_{2}^{\prime} \geq \cdots \geq m_{n}^{\prime}$, e que $\theta_{j}=0$ para $j>k$. Para simplificar, sem perda de generalidade, podemos normalizar todas as taxas de cliques ao multiplicar cada uma delas por $\frac{1}{\hat{\theta}}$, e assim considerar que $\hat{\theta}=1$. Ademais, sem perda de generalidade, vamos considerar que $n \geq k$. Se $n<k$, podemos remover os locais com menor taxas de cliques, de forma a obter $n=k$. Consideramos também que $v_{n+1}=v_{n+2}=m_{n+1}=m_{n+2}=v_{n+1}^{\prime}=v_{n+2}^{\prime}=m_{n+1}^{\prime}=m_{n+2}^{\prime}=0$, o que não altera o funcionamento dos mecanismos e dos resultados obtidos, mas esses índices podem ser acessados em algumas demonstrações.

\subsection{Notação}

Para facilitar a distinção entre soluções onde um anunciante é exibido exclusivamente, ou vários anunciantes são exibidos juntos, dizemos que a exibição exclusiva é uma E-solução, e a exibição de múltiplos anúncios é uma M-solução. Além disso, a E-oferta e a M-oferta de um anunciante $i$ são as ofertas $m_{i}$ e $m_{i}^{\prime}$, respectivamente. Analogamente, o E-valor e o M-valor de um anunciante $i$ são os valores $v_{i}$ e $v_{i}^{\prime}$, respectivamente.

Os anunciantes são indexados em ordem descrescente de suas M-ofertas, e vamos adotar índices especiais para os dois anunciantes com os maiores E-valores, que são os índices evmax e evmax 2 . Ou seja, temos que $v_{\text {evmax }} \geq v_{i}$, para todo $i \in[n]$, e $v_{\text {evmax } 2} \geq v_{i}$, para todo $i \in[n]$ e $i \neq$ evmax. Ademais, usaremos uma notação comumente usada para expressar a ausência do anunciante $i$, dada por $v_{\text {evmax }}$. Assim, vale que $v_{\text {evmax }}$. $=v_{\text {evmax }}$ se $i \neq$ evmax, e $v_{\text {evmax }}=v_{\text {evmax } 2}$ se $i=$ evmax. Analogamente, usaremos a notação eomax e eomax 2 para indexar os anunciantes com maiores Eofertas. Note que se $m_{i}=v_{i}$ para todo $i \in[n]$, então vale que evmax = eomax e evmax $2=$ eomax 2 .

Outra notação utilizada é a indexação por M-valores decrescentes. Como a indexação padrão utilizada é definida pelas M-ofertas, ou seja, $m_{1}^{\prime} \geq \cdots \geq m_{n}^{\prime}$, definiremos uma segunda indexação usada para auxiliar em algumas demonstrações, dada por $d$ tal que $v_{d_{1}}^{\prime} \geq \cdots \geq v_{d_{n}}^{\prime}$.

\subsection{Mecanismo $\mathrm{GSP}_{2 D}$}

Vamos apresentar um mecanismo que chamaremos de $\mathrm{GSP}_{2 D}$ (generalized second price), onde o $2 D$ refere-se ao fato de que o mecanismo recebe um vetor com duas ofertas de cada anunciante. Depois analisaremos o lucro e o bem estar social obtidos pelo $\mathrm{GSP}_{2 D}$ quando as soluções encontradas pelo GSP $_{2 D}$ estão em certos tipos de equilíbrios, comparados ao lucro e bem estar social obtidos pelo mecanismo $\mathrm{VCG}_{2 D}$ que apresentaremos na seção 3.5.

Dada uma instância $\left(n, k, m, m^{\prime}, \theta\right)$ dos leilões com exclusividade onde $m_{1}^{\prime} \geq \cdots \geq m_{n}^{\prime}$, o mecanismo $\mathrm{GSP}_{2 D}$ primeiro determina se deve produzir uma E-solução ou uma M-solução, e depois determina os anunciantes ganhadores e os preços. Para uma M-solução, o GSP $_{2 D}$ estabelece a ordem dos anunciantes e os preços da mesma maneira que o mecanismo para os leilões simplificados estabelece quando as ofertas são dadas pelo vetor $m^{\prime}$. Assim, não há diferença para os anunciantes entre os atuais mecanismos utilizados na prática e o $\mathrm{GSP}_{2 D}$ quando a solução exibe múltiplos anúncios, facilitando então a aceitação desse mecanismo pelos anunciantes, caso ele venha a ser utilizado.

Resta determinar quando o mecanismo escolhe uma M-solução ou uma E-solução, e para o caso exclusivo, onde o ganhador é o anunciante com maior E-oferta, determinar o preço que o anunciante 
ganhador deve pagar. Para isso, o mecanismo $\mathrm{GSP}_{2 D}$ compara a maior E-oferta com o pagamento esperado da melhor M-solução da seguinte maneira.

Saída exclusiva: Se $m_{\text {eomax }}>\sum_{i=2}^{k+1} \theta_{i-1} m_{i}^{\prime}$, o $\operatorname{GSP}_{2 D}$ produz uma E-solução, e o preço por clique do anunciante ganhador eomax é

$$
p_{\text {eomax }}=\max \left\{m_{\text {eomax }_{2}}, \sum_{i=2}^{k+1} \theta_{i-1} m_{i}^{\prime}\right\} .
$$

Saída múltipla: Se $m_{e o m a x} \leq \sum_{i=2}^{k+1} \theta_{i-1} m_{i}^{\prime}$, o GSP $2 D$ produz uma M-solução, e os anunciantes são exibidos na mesma ordem que estão indexados, decrescentemente por suas M-ofertas, e o preço por clique de um anunciante $i \leq k$ é

$$
p_{i}=m_{i+1}^{\prime} .
$$

Uma observação sobre o critério de decisão para o tipo de saída é que comparar a maior E-oferta com as $k$ maiores M-ofertas não é uma boa escolha, dada a escolha de preços de uma M-solução. Se o anunciante 1 com maior M-oferta for diferente do anunciante eomax com maior E-oferta, então o anunciante 1 poderia forçar que ocorresse uma M-solução, ofertando $m_{1}^{\prime}=m_{\text {eomax }} / \theta_{1}$, sem ter nenhum prejuízo com isso, pois o preço pago pelo anunciante $1 \mathrm{em}$ uma M-solução continuaria sendo a oferta $m_{2}^{\prime}$.

Fixados $n$ anunciantes, a quantidade $k$ de locais na página, e suas taxas de cliques $\theta_{j}$, para $j \in[k]$, utilizaremos a notação $\operatorname{GSP}_{2 D}\left(m, m^{\prime}\right)$ para denotar a utilização do $\mathrm{GSP}_{2 D}$ para a instância $\left(n, k, m, m^{\prime}, \theta\right)$.

\subsubsection{Exemplos do $\mathrm{GSP}_{2 D}$}

O mecanismo $\mathrm{GSP}_{2 D}$ não é à prova de estratégia, e possui equilíbrios bastante complexos, analisados mais adiante na seção 3.7. Veja dois exemplos.

\section{Exemplo 1}

Primeiramente, considere um leilão onde $n=4, k=3$ e os valores verdadeiros e taxas de cliques são exibidos na tabela 3.1.

Tabela 3.1: Valores verdadeiros.

\begin{tabular}{|c|c|c|c|}
\hline$i$ & $v_{i}$ & $v_{i}^{\prime}$ & $\theta_{i}$ \\
\hline \hline 1 & 100 & 100 & 1 \\
\hline 2 & 10 & 10 & 0.5 \\
\hline 3 & 10 & 10 & 0.5 \\
\hline 4 & 10 & 10 & 0 \\
\hline
\end{tabular}

Caso os anunciantes ofertem seus valores verdadeiros, o anunciante 1 é ganhador com exclusividade. De fato, $v_{\text {evmax }}=100>1 \cdot 10+0.5 \cdot 10+0.5 \cdot 10=20$. Porém, ele paga 20 para aparecer exclusivamente, que resulta em $u_{1}=1 \cdot(100-20)=80$, enquanto pagaria apenas 10 na saída múltipla, com utilidade maior $u_{1}=1 \cdot(100-10)=90$. Por outro lado, as ofertas exibidas na tabela 3.2 estão em equilíbrio. 
Tabela 3.2: Ofertas em equilibrio.

\begin{tabular}{|c|c|c|c|}
\hline$i$ & $m_{i}$ & $m_{i}^{\prime}$ & $\theta_{i}$ \\
\hline \hline 1 & 20 & 20 & 1 \\
\hline 2 & 10 & 10 & 0.5 \\
\hline 3 & 10 & 10 & 0.5 \\
\hline 4 & 10 & 10 & 0 \\
\hline
\end{tabular}

De fato, para essas ofertas, o mecanismo escolhe saída múltipla, pois $m_{\text {eomax }}=20 \ngtr 20$, e temos $u_{1}=1 \cdot(100-10)=90, u_{2}=u_{3}=0.5 \cdot(10-10)=0$. Observe que as ofertas estão em equilíbrio, pois nenhum anunciante tem incentivo em aumentar ou diminuir suas E-ofertas ou M-ofertas. Se o anunciante 2 ou 3 diminuir sua oferta, ele deixa de ser exibido, mantendo sua utilidade igual a zero.

\section{Exemplo 2}

Veja um exemplo em que a saída múltipla é pior do que a saída exclusiva para o anunciante com maior E-valor. Os valores são exibidos na tabela 3.3. Neste caso, sua M-oferta igual a zero será um equilíbrio.

Tabela 3.3: Valores verdadeiros.

\begin{tabular}{|c|c|c|c|}
\hline$i$ & $v_{i}$ & $v_{i}^{\prime}$ & $\theta_{i}$ \\
\hline \hline 1 & 10 & 9 & 1 \\
\hline 2 & 5 & 5 & 1 \\
\hline 3 & 3 & 3 & 1 \\
\hline 4 & 1 & 1 & 0 \\
\hline
\end{tabular}

Neste exemplo, ao ofertar verdadeiramente, o anunciante 1 paga $9=1 \cdot 5+1 \cdot 3+1 \cdot 1$ para ser exibido exclusivamente, e a sua utilidade é 1. Mais interessante para o anunciante 1 seria ele aparecer em primeiro na saída múltipla, pagando 5 por isso, e obtendo utilidade 4 . Ele poderia obter isso selecionando ofertas $m_{1}=m_{1}^{\prime}=9$. Porém, existe uma estratégia que aumenta ainda mais sua utilidade, dada pelas ofertas exibidas na tabela 3.4.

Tabela 3.4: Ofertas em equilibrio.

\begin{tabular}{|c|c|c|c|}
\hline$i$ & $m_{i}$ & $m_{i}^{\prime}$ & $\theta_{i}$ \\
\hline \hline 1 & 5 & 5 & 1 \\
\hline 2 & 3 & 3 & 1 \\
\hline 3 & 1 & 1 & 1 \\
\hline 4 (era o 1 ) & 10 & 0 & 0 \\
\hline
\end{tabular}

Diminuindo sua M-oferta, o anunciante 1 passa a ser o anunciante 4 (devido à ordenação), mas ele continua aparecendo exclusivamente, pagando agora 5, e aumentando sua utilidade para 5. Essas ofertas estão em equilíbrio pois nenhum anunciante tem incentivo em alterar sua E-oferta ou sua M-oferta. 


\subsubsection{Exemplos não intuitivos do $\mathrm{GSP}_{2 D}$}

Mostraremos mais dois exemplos do $\mathrm{GSP}_{2 D}$ onde as ofertas em equilíbrio são mais sutis.

\section{Exemplo 3}

Considere um leilão onde $n=3, k=2$ e os valores verdadeiros, ofertas e taxas de cliques estão exibidos na tabela 3.5. Com essas ofertas, o $\operatorname{GSP}_{2 D}\left(m, m^{\prime}\right)$ produz uma E-solução onde o

Tabela 3.5: Exemplo em equilibrio.

\begin{tabular}{|c|c|c|c|c|c|}
\hline$i$ & $v_{i}$ & $v_{i}^{\prime}$ & $m_{i}$ & $m_{i}^{\prime}$ & $\theta_{i}$ \\
\hline \hline 1 & 100 & 100 & 100 & 100 & 1 \\
\hline 2 & 1 & 1 & 1 & 1 & 1 \\
\hline 3 & 99 & 0 & 99 & 0 & 0 \\
\hline
\end{tabular}

anunciante 1 é ganhador, e paga $99=\max \{99,1 \cdot 1+1 \cdot 0\}$. Como o anunciante 3 não tem interesse nenhum em uma M-solução, o anunciante 1 não tem alternativa senão ofertar de forma a ser ganhador exclusivo. Note que se o anunciante 2 ofertar $m_{2}^{\prime}=100$, a saída passa a ser múltipla, e ele pode tanto ser exibido na segunda posição pagando zero, ou ser exibido na primeira posição pagando 100. Conforme definido um equilíbrio na seção 1.5.1, o anunciante sempre deve considerar o pior caso quando ocorrem empates, e portanto, o anunciante 2 também não tem incentivo em alterar sua oferta.

\section{Exemplo 4}

Considere um leilão onde $n=4, k=3$ e os valores verdadeiros, ofertas e taxas de cliques estão exibidos na tabela 3.6. Com essas ofertas, o $\operatorname{GSP}_{2 D}\left(m, m^{\prime}\right)$ produz uma E-solução onde o

Tabela 3.6: Exemplo em equilibrio.

\begin{tabular}{|c|c|c|c|c|c|}
\hline$i$ & $v_{i}$ & $v_{i}^{\prime}$ & $m_{i}$ & $m_{i}^{\prime}$ & $\theta_{i}$ \\
\hline \hline 1 & 100 & 100 & 100 & 100 & 1 \\
\hline 2 & 1 & 1 & 1 & 1 & 1 \\
\hline 3 & 1 & 1 & 1 & 1 & 1 \\
\hline 4 & 99 & 0 & 99 & 0 & 0 \\
\hline
\end{tabular}

anunciante 1 é ganhador, e paga $99=\max \{99,1 \cdot 1+1 \cdot 1\}$. Como o anunciante 4 não tem interesse nenhum em uma M-solução, o anunciante 1 não tem alternativa senão ofertar de forma a ser ganhador exclusivo. Note que se o anunciante 2 ofertar $m_{2}^{\prime}=100-\epsilon$, a saída passa a ser múltipla, e ele é exibido na segunda posição pagando 1, e portanto mantendo sua utilidade igual a zero. Logo, nenhum anunciante consegue aumentar sua utilidade ao alterar sua oferta, e portanto as ofertas estão em equilíbrio.

\subsection{Mecanismo $\mathrm{VCG}_{2 D}$}

Utilizando as definições da seção 1.5.2, vamos descrever um mecanismo VCG para o problema dos leilões com exclusividade, que será chamado de $\mathrm{VCG}_{2 D}$, onde o $2 D$ refere-se ao fato de que o me- 
canismo recebe um vetor com duas ofertas de cada anunciante. Para uma instância $\left(n, k, m, m^{\prime}, \theta\right)$, onde os anunciantes estão ordenados decrescentemente por suas M-ofertas, o mecanismo $\mathrm{VCG}_{2 D}$ é definido da seguinte forma.

Saída exclusiva: Se $m_{\text {eomax }}>\sum_{i=1}^{k} \theta_{i} m_{i}^{\prime}$, o $\mathrm{VCG}_{2 D}$ produz uma E-solução, e apenas o anunciante eomax é exibido. O preço por clique do anunciante eomax é

$$
p_{\text {eomax }}=\max \left\{m_{\text {eomax } 2}, \sum_{i=1}^{\text {eomax }-1} \theta_{i} m_{i}^{\prime}+\sum_{i=\text { eomax }}^{k} \theta_{i} m_{i+1}^{\prime}\right\} \text {. }
$$

Saída múltipla: Se $m_{\text {eomax }} \leq \sum_{i=1}^{k} \theta_{i} m_{i}^{\prime}$, o $\mathrm{VCG}_{2 D}$ produz uma M-solução, e os $k$ primeiros anunciantes são exibidos. Para cada anunciante $i \leq k$, o preço por clique $p_{i}$ do anunciante $i$ é dado por

$$
\theta_{i} p_{i}=\max \left\{\sum_{j=i}^{k}\left(\theta_{j}-\theta_{j+1}\right) m_{j+1}^{\prime}, m_{e^{o m a x}-i}-\sum_{j=1, j \neq i}^{k} \theta_{j} m_{j}^{\prime}\right\} .
$$

De fato, pela definição do VCG na seção 1.5.2, o preço para um anuciante $i$ é determinado pela variação do bem estar social (baseado nas ofertas informadas) dos demais anunciantes ao remover o anunciante $i$ do leilão. A seguir calculamos o valor desta variação para confirmarmos (3.1) e (3.2).

Assim, no caso exclusivo, a ausência do anunciante eomax no leilão pode fazer o mecanismo manter-se devolvendo uma E-solução, onde o anunciante eomax2 é o ganhador com bem estar social $m_{\text {eomax } 2}$, ou mudar para uma M-solução, onde os $k$ anunciantes com maiores M-ofertas são exibidos, com bem estar social $\sum_{i=1}^{e o m a x}-1 \theta_{i} m_{i}^{\prime}+\sum_{i=e o m a x}^{k} \theta_{i} m_{i+1}^{\prime}$. Note que se eomax $>k$, como $\theta_{i}=0$ para $i>k$, alguns termos serão nulos. Como nenhum outro anunciante além de eomax é exibido no caso exclusivo, a variação do bem estar social dos demais anunciantes com a ausência do anunciante eomax é $m_{\text {eomax } 2}$ se a saída continuar exclusiva, e é $\sum_{i=1}^{e o m a x-1} \theta_{i} m_{i}^{\prime}+\sum_{i=\text { eomax }}^{k} \theta_{i} m_{i+1}^{\prime}$ se a saída mudar para múltipla. Portanto, o valor $p_{\text {eomax }}$ é simplesmente o bem estar social obtido sem a presença do anunciante eomax, dado por (3.1). Note que, neste caso, a ausência de qualquer outro anunciante não altera o bem estar social, e portanto seu pagamento é zero.

No caso da saída múltipla, para cada anunciante $i \leq k$, a sua ausência no leilão pode fazer a saída manter-se múltipla, fazendo todos os anunciantes abaixo subirem uma posição, ou mudar a saída para exclusiva, dependendo de qual destas duas possibilidades maximiza o bem estar social no leilão sem o anunciante $i$. Se a ausência de um anunciante $i \leq k$ mantiver a saída múltipla, então a variação no bem estar social é $\sum_{j=i}^{k}\left(\theta_{j}-\theta_{j+1}\right) m_{j+1}^{\prime}$. Caso contrário, a variação no bem estar social é $v_{e o m a x}-\sum_{j=1, j \neq i}^{k} \theta_{j} m_{j}^{\prime}$. Dessa forma, conforme descrito na seção 1.5 .2 , o valor $\theta_{i} p_{i}$ para um anunciante $i \leq k$ é dado por (3.2). Neste caso, a ausência de um anunciante $i>k$ no leilão não altera o bem estar social, e portanto seu pagamento é zero.

Como o mecanismo $\mathrm{VCG}_{2 D}$ é à prova de estratégia, podemos assumir que os anunciantes ofertam os seus valores verdadeiros, ou seja, $m_{i}=v_{i}$ e $m_{i}^{\prime}=v_{i}^{\prime}$ para todo $i \in[n]$. Os preços da forma como apresentados a seguir não dependem da ordem em que os anunciantes estão indexados, pois vamos utilizar a indexação por M-valores. Isso facilitará todas as demonstrações que seguem. Porém, note que como $m_{i}=v_{i}$, temos que o anunciante eomax com maior E-oferta é também o anunciante evmax com maior E-valor. Assim, para uma E-solução, e tomando $q$ de forma que evmax $=d_{q}(q$ é a posição do anunciante de maior E-valor quando os anunciantes estão indexados por M-valores), 
temos que

$$
p_{\text {evmax }}=\max \left\{v_{\text {evmax } 2}, \sum_{i=1}^{q-1} \theta_{i} v_{d_{i}}^{\prime}+\sum_{i=q}^{k} \theta_{i} v_{d_{i+1}}^{\prime}\right\},
$$

e, para uma M-solução, tomando $q$ de forma que $i=d_{q}$ ( $q$ é a posição do anunciante $i$ quando os anunciantes estão indexados por M-valores), o preço $p_{i}$ que o anunciante $i$ paga por clique é dado (para $q \leq k$ ) por

$$
\theta_{q} p_{i}=\max \left\{\sum_{j=i}^{k}\left(\theta_{j}-\theta_{j+1}\right) v_{d_{j+1}}^{\prime}, v_{e v m a x_{-i}}-\sum_{j=1, j \neq q}^{k} \theta_{j} v_{d_{j}}^{\prime}\right\}
$$

De fato, como o mecanismo $\mathrm{VCG}_{2 D}$ é à prova de estratégia, então ofertar verdadeiramente é uma estratégia dominante para os anunciantes. Assim, as ofertas $\left(m_{i}=v_{i}, m_{i}^{\prime}=v_{i}^{\prime}\right)$, para $i \in[n]$, estão em equilíbrio no $\mathrm{VCG}_{2 D}$. Ou seja, nenhum anunciante tem incentivo em alterar sua oferta, pois isso não traria aumento em sua utilidade. Fixados $n$ anunciantes, a quantidade $k$ de locais na página, e suas taxas de cliques $\theta_{j}$, para $j \in[k]$, utilizaremos a notação $\operatorname{VCG}_{2 D}\left(m, m^{\prime}\right)$ para denotar a utilização do $\mathrm{VCG}_{2 D}$ para a instância $\left(n, k, m, m^{\prime}, \theta\right)$.

\subsection{Comparação entre $\mathrm{GSP}_{2 D}$ e $\mathrm{VCG}_{2 D}$}

Vamos considerar fixados $n$ anunciantes e seus valores verdadeiros $v_{i}$ e $v_{i}^{\prime}$, para $i \in[n]$, a quantidade $k$ de locais de páginas, e suas taxas de cliques $\theta_{j}$, para $j \in[k]$, ao longo de toda esta seção de comparação entre os mecanismos.

Iremos comparar o lucro e o bem estar social obtidos em equilíbrios "bons" e "livres de inveja" do $\mathrm{GSP}_{2 D}$ com o lucro e bem estar social obtidos pelo $\mathrm{VCG}_{2 D}\left(v, v^{\prime}\right)$.

Definimos que um equilíbrio $\left(m, m^{\prime}\right)$ é bom se todo anunciante que não foi exibido oferta (pelo menos) seu valor verdadeiro, pois, caso contrário, ele pode perder a oportunidade de ser exibido e aumentar sua utilidade. Portanto, para todo anunciante $i$ que não é exibido em um equilíbrio bom, deve valer que $m_{i}^{\prime} \geq v_{i}^{\prime}$ e $m_{i} \geq v_{i}$.

Ademais, vamos nos restringir apenas a equilíbrios que levam o $\mathrm{GSP}_{2 D}$ a produzir uma solução livre de inveja, ou seja, soluções onde cada anunciante $i$ não "inveja" a posição e preço dos demais anunciantes. Formalmente, uma solução é livre de inveja se vale que

$$
\theta_{i}\left(v_{i}^{\prime}-p_{i}\right) \geq \theta_{j}\left(v_{i}^{\prime}-p_{j}\right) \text { para todo } i, j \in[n] \text { (onde } \theta_{j}=0 \text { e } p_{j}=0 \text { para } j>k \text { ). }
$$

Equivalentemente,

$$
v_{i}^{\prime}\left(\theta_{i}-\theta_{j}\right) \geq p_{i} \theta_{i}-p_{j} \theta_{j} \quad \text { para todo } i, j \in[n] .
$$

Observe que a condição de livre de inveja é uma pequena variação da própria definição de equilíbrio neste mecanismo, que é dada por

$$
\begin{aligned}
& \theta_{i}\left(v_{i}^{\prime}-p_{i}\right) \geq \theta_{j}\left(v_{i}^{\prime}-p_{j}\right) \quad \text { para todo } i, j \in[n], \text { tal que } i \leq j, \text { e } \\
& \theta_{i}\left(v_{i}^{\prime}-p_{i}\right) \geq \theta_{j}\left(v_{i}^{\prime}-p_{j-1}\right) \quad \text { para todo } i, j \in[n], \text { tal que } i>j .
\end{aligned}
$$

As demonstrações sobre o $\mathrm{GSP}_{2 D}$ a seguir serão feitas apenas para equilíbrios bons e livres de 
inveja, e também mostraremos que equilíbrios bons sempre existem. Os resultados são que o valor do bem estar social do $\operatorname{GSP}_{2 D}$ é pelo menos $\frac{1}{3}$ do valor do bem estar social obtido pelo $\operatorname{VCG}_{2 D}\left(v, v^{\prime}\right)$, enquanto o lucro do $\mathrm{GSP}_{2 D}$ é pelo menos pelo menos $\frac{1}{2}$ do lucro obtido pelo $\operatorname{VCG}_{2 D}\left(v, v^{\prime}\right)$. A vantagem ao utilizar o $\mathrm{GSP}_{2 D}$ é sua simplicidade, comparado ao $\mathrm{VCG}_{2 D}$, e sua semelhança com os atuais mecanismos utilizados.

Utilizaremos os seguintes lemas e teorema nas demonstrações das propriedades do $\operatorname{GSP}_{2 D}$.

Lema 3.6.1. Em todo equilíbrio $\left(m, m^{\prime}\right)$ do $\mathrm{GSP}_{2 D}$ com $\mathrm{M}$-solução, vale que $m_{i+1}^{\prime} \leq v_{i}^{\prime}$, para $1 \leq i \leq k$.

Esse lema segue do fato que o anunciante $i$, em uma M-solução, irá pagar $m_{i+1}^{\prime}$. Logo, se $m_{i+1}^{\prime}>v_{i}^{\prime}$, o anunciante $i$ terá utilidade negativa, e portanto as ofertas $\left(m, m^{\prime}\right)$ não serão um equilíbrio.

Lema 3.6.2. Seja eomax o anunciante com maior E-oferta, e seja q sua posição quando ordenamos os anunciantes por ordem decrescente de M-valores, ou seja, eomax $=d_{q}$. Em todo equilibrio bom $\left(m, m^{\prime}\right)$ do $\mathrm{GSP}_{2 D}$ com E-solução vale que $m_{i}^{\prime} \geq v_{d_{i}}^{\prime}$, para $1 \leq i<q$, e $m_{i}^{\prime} \geq v_{d_{i+1}}^{\prime}$, para $q \leq i<n$. Demonstração. Por hipótese, vale que $m_{1}^{\prime} \geq m_{2}^{\prime} \geq \cdots \geq m_{n}^{\prime}$. Como os anunciantes perdedores ofertam pelo menos seus valores verdadeiros, vale que $m_{i}^{\prime} \geq v_{i}^{\prime}$ para todo $i \in[n]$ e $i \neq$ eomax. Assim, temos que $m_{i}^{\prime} \geq \max \left\{v_{i}^{\prime}, v_{i+1}^{\prime}, \ldots, v_{\text {eomax }-1}^{\prime}, v_{\text {eomax }+1}^{\prime}, \ldots, v_{n}^{\prime}\right\}$. Ou seja, $m_{i}^{\prime}$ é maior ou igual a pelo menos $n-i$ M-valores (e menor que no máximo $i$ M-valores), e portanto $m_{i}^{\prime} \geq v_{d_{i+1}}^{\prime}$. Porém, para $i<q$, como $m_{i}^{\prime}$ é menor que no máximo $i$ M-valores, $m_{i}^{\prime}$ não pode ser menor do que o $v_{d_{q}}^{\prime}$, e portanto $m_{i}^{\prime} \geq v_{\text {eomax }}^{\prime}$, donde concluímos que $m_{i}^{\prime} \geq v_{d_{i}}^{\prime}$.

Teorema 3.6.1. Se o $\mathrm{VCG}_{2 D}\left(v, v^{\prime}\right)$ produz uma E-solução, então o único equilíbrio do $\mathrm{GSP}_{2 D}$ também produz uma E-solução com o anunciante evmax como ganhador, e não existe equilibrio do $\mathrm{GSP}_{2 D}$ com uma M-solução.

Demonstração. Suponha que existam ofertas $\left(m, m^{\prime}\right)$ em equilíbrio tais que o mecanismo $\mathrm{GSP}_{2 D}$ devolve uma M-solução para a instância $\left(n, k, m, m^{\prime}, \theta\right)$. Mostraremos uma contradição.

Pelo fato do $\operatorname{VCG}_{2 D}\left(v, v^{\prime}\right)$ devolver uma E-solução, temos que

$$
v_{\text {evmax }}>\sum_{i=1}^{k} \theta_{i} v_{d_{i}}^{\prime} \geq \sum_{i=1}^{k} \theta_{i} v_{i}^{\prime}
$$

e pelo lema 3.6.1 temos que $\sum_{i=1}^{k} \theta_{i} v_{i}^{\prime} \geq \sum_{i=1}^{k} \theta_{i} m_{i+1}^{\prime}$. Logo, se o anunciante evmax declarar $m_{\text {evmax }}=v_{\text {evmax }}$ o $\mathrm{GSP}_{2 D}$ produzirá uma E-solução com evmax como ganhador e a utilidade de evmax será positiva. Como as ofertas $\left(m, m^{\prime}\right)$ estão em equilíbrio no $\mathrm{GSP}_{2 D}$, deve valer que evmax é exibido, ou seja, evmax $\leq k$. Caso contrário ele teria utilidade nula, e poderia aumentar sua utilidade ao declarar $m_{\text {evmax }}=v_{\text {evmax }}$, o que implicaria que $\left(m, m^{\prime}\right)$ não é um equilíbrio.

Resta mostrar que a utilidade para o anunciante evmax, com evmax $\leq k$, em uma E-solução é maior que sua utilidade na M-solução, o que contradiz o equilíbrio. Vamos utilizar o índice $j=$ evmax, para simplificar a notação.

Pelo lema 3.6.1, que diz que $m_{i+1}^{\prime} \leq v_{i}^{\prime}$, podemos substituir $v_{i}^{\prime}$ por $m_{i+1}^{\prime}$ para todo $i \neq j$ em (3.3), obtendo

$$
v_{j}>\theta_{1} m_{2}^{\prime}+\cdots+\theta_{j-1} m_{j}^{\prime}+\theta_{j} v_{j}^{\prime}+\theta_{j+1} m_{j+2}^{\prime}+\cdots+\theta_{k} m_{k+1}^{\prime} .
$$


Isolando $\theta_{j} v_{j}^{\prime}$ do lado direito da desigualdade, e subtraindo $\theta_{j} m_{j+1}^{\prime}$ de ambos os lados, obtemos que

$$
v_{j}-\left(\theta_{1} m_{2}^{\prime}+\cdots+\theta_{k} m_{k+1}^{\prime}\right)>\theta_{j}\left(v_{j}^{\prime}-m_{j+1}^{\prime}\right) .
$$

Isso contraria o fato de a solução do $\operatorname{GSP}_{2 D}$ estar em equilíbrio. De fato, note que o lado esquerdo da desigualdade é exatamente a utilidade que o anunciante evmax teria se fosse exibido exclusivamente, pois estamos supondo que $\operatorname{GSP}_{2 D}\left(m, m^{\prime}\right)$ produz uma M-solução, e portanto vale que $\sum_{j=2}^{k+1} \theta_{j-1} m_{j}^{\prime} \geq m_{e o m a x} \geq m_{\text {eomax } 2}$. Ademais, o lado direito da desigualdade é exatamente a utilidade para o anunciante evmax na M-solução. Portanto, chegamos a uma contradição, já que as ofertas não estão em equilíbrio, pois o anunciante evmax pode aumentar sua utilidade ao fazer uma E-oferta suficientemente grande para que a solução produzida seja exclusiva.

Portanto, quando o $\operatorname{VCG}_{2 D}\left(v, v^{\prime}\right)$ devolve uma E-solução, não existem ofertas $\left(m, m^{\prime}\right)$ em equilíbrio tais que o $\operatorname{GSP}_{2 D}\left(m, m^{\prime}\right)$ produz uma M-solução. Ademais, neste caso a única solução em equilíbrio para o $\mathrm{GSP}_{2 D}$ exibe o anunciante evmax exclusivamente.

\subsubsection{Eficiência do $\mathrm{GSP}_{2 D}$}

Analisaremos a eficiência do $\mathrm{GSP}_{2 D}$ para ofertas em equilíbrio bom e livre de inveja, ou seja, como é o bem estar social da solução produzida pelo $\operatorname{GSP}_{2 D}\left(m, m^{\prime}\right)$ onde $\left(m, m^{\prime}\right)$ é um equilíbrio bom e livre de inveja do $\mathrm{GSP}_{2 D}$, se comparado com o bem estar social ótimo, que é o bem estar social da solução produzida pelo $\operatorname{VCG}_{2 D}\left(v, v^{\prime}\right)$. Mostraremos que o valor do bem estar social em uma solução em um tal equilíbrio do $\operatorname{GSP}_{2 D}$ é maior ou igual a $\frac{1}{3}$ do valor do bem estar social obtido pelo $\operatorname{VCG}_{2 D}\left(v, v^{\prime}\right)$.

Dividiremos a demonstração em três casos. O primeiro caso é quando o $\mathrm{VCG}_{2 D}\left(v, v^{\prime}\right)$ devolve uma E-solução. Neste caso, o teorema 3.6.1 acima garante que o $\operatorname{GSP}_{2 D}\left(m, m^{\prime}\right)$ devolve uma Esolução, e exibe o mesmo anunciante ganhador que o $\operatorname{VCG}_{2 D}\left(v, v^{\prime}\right)$, obtendo, portanto, o mesmo bem estar social. Os outros dois casos são apresentados a seguir.

\section{Caso 2: $\operatorname{VCG}_{2 D}\left(v, v^{\prime}\right)$ devolve M-solução e $\operatorname{GSP}_{2 D}\left(m, m^{\prime}\right)$ devolve M-solução.}

Sejam $i, j \in[n]$ tais que $\theta_{i}>\theta_{j}$. Como o equilíbrio $\left(m, m^{\prime}\right)$ é livre de inveja, temos que

$$
\begin{aligned}
v_{i}^{\prime}\left(\theta_{i}-\theta_{j}\right) & \geq p_{i} \theta_{i}-p_{j} \theta_{j}, \mathrm{e} \\
v_{j}^{\prime}\left(\theta_{j}-\theta_{i}\right) & \geq p_{j} \theta_{j}-p_{i} \theta_{i} .
\end{aligned}
$$

Somando as duas desigualdades, temos que

$$
\left(v_{i}^{\prime}-v_{j}^{\prime}\right)\left(\theta_{i}-\theta_{j}\right) \geq 0,
$$

donde concluímos que vale que $v_{i}^{\prime} \geq v_{j}^{\prime}$.

Isso implica que o $\operatorname{GSP}_{2 D}\left(m, m^{\prime}\right)$ obtém o mesmo bem estar social que o $\mathrm{VCG}_{2 D}\left(v, v^{\prime}\right)$. De fato, a ordem dos anunciantes na saída do $\mathrm{GSP}_{2 D}$ será a mesma ordem dos anunciantes na saída do $\mathrm{VCG}_{2 D}\left(v, v^{\prime}\right)$, exceto pelos locais da página com mesma taxa de cliques, o que não altera o bem estar social, já que cada anunciante em ambos os mecanismos será alocado a um local com mesma 
taxa de cliques. De fato, se $i$ é a posição de um anunciante na saída do $\operatorname{GSP}_{2 D}\left(m, m^{\prime}\right)$ e $d_{i}$ é sua posição na saída do $\operatorname{VCG}_{2 D}\left(v, v^{\prime}\right)$, então vale que

$$
\theta_{i}=\theta_{d_{i}}
$$

\section{Caso 3: $\operatorname{VCG}_{2 D}\left(v, v^{\prime}\right)$ devolve M-solução e $\operatorname{GSP}_{2 D}\left(m, m^{\prime}\right)$ devolve E-solução.}

Dentre todos os casos, esse é o único em que o mecanismo $\mathrm{GSP}_{2 D}$ tem perda de eficiência quando comparado ao mecanismo $\mathrm{VCG}_{2 D}$.

Seja eomax o anunciante com maior E-oferta, e seja $q$ sua posição quando ordenamos os anunciantes por ordem decrescente de M-valores, ou seja, eomax $=d_{q}$. Como o $\operatorname{GSP}_{2 D}\left(m, m^{\prime}\right)$ devolve uma E-solução e como $\left(m, m^{\prime}\right)$ é um equilíbrio bom, pelo lema 3.6.2, e porque $\theta_{i-1} \geq \theta_{i}$ para todo $i>1$, para $q=1$, temos que

$$
v_{\text {eomax }} \geq \sum_{i=2}^{k+1} \theta_{i-1} m_{i}^{\prime} \geq \sum_{i=2}^{k+1} \theta_{i-1} v_{d_{i+1}}^{\prime} \geq \sum_{i=3}^{k} \theta_{i} v_{d_{i}}^{\prime},
$$

e para $q>1$, temos que

$$
v_{\text {eomax }} \geq \sum_{i=2}^{k+1} \theta_{i-1} m_{i}^{\prime} \geq \sum_{i=2}^{q-1} \theta_{i-1} v_{d_{i}}^{\prime}+\sum_{i=q}^{k+1} \theta_{i-1} v_{d_{i+1}}^{\prime} \geq \sum_{i=2}^{q-1} \theta_{i} v_{d_{i}}^{\prime}+\sum_{i=q+1}^{k} \theta_{i} v_{d_{i}}^{\prime} .
$$

Ademais, como o $\operatorname{GSP}_{2 D}\left(m, m^{\prime}\right)$ devolve E-solução e $\left(m, m^{\prime}\right)$ é um equilíbrio bom, vale que $v_{\text {eomax }} \geq m_{\text {eomax } 2} \geq v_{\text {eomax } 2}$, e portanto temos que eomax $=$ evmax, e vale que

$$
v_{\text {eomax }} \geq \theta_{1} v_{d_{1}}^{\prime}
$$

Portanto, neste caso, para mostrar que o bem estar social do $\mathrm{GSP}_{2 D}$ é pelo menos um terço do bem estar social do $\mathrm{VCG}_{2 D}$ basta mostrar que $3 \cdot v_{\text {eomax }} \geq \sum_{i=1}^{k} \theta_{i} v_{d_{i}}^{\prime}$. Para o caso $q=1$, os dois termos ausentes na somatória da parte direita da equação (3.5) são $\theta_{1} v_{d_{1}}^{\prime}$ e $\theta_{2} v_{d_{2}}^{\prime}$. Então, para $q=1$, por (3.5) e por (3.7), temos que

$$
v_{\text {eomax }}+v_{\text {eomax }}+v_{\text {eomax }} \geq \theta_{1} v_{d_{1}}^{\prime}+\theta_{1} v_{d_{1}}^{\prime}+\sum_{i=3}^{k} \theta_{i} v_{d_{i}}^{\prime} \geq \sum_{i=1}^{k} \theta_{i} v_{d_{i}}^{\prime} .
$$

Analogamente, para $q>1$, os dois termos ausentes na somatória da parte direita da equação (3.6) são $\theta_{1} v_{d_{1}}^{\prime}$ e $\theta_{q} v_{d_{q}}^{\prime}$. Portanto, para $q>1$, por (3.6) e por (3.7), obtemos que $3 \cdot v_{\text {eomax }} \geq \sum_{i=1}^{k} \theta_{i} v_{d_{i}}^{\prime}$.

\section{Exemplo onde o fator do bem estar social é justo}

Para mostrar que o fator 3 é justo, vejamos um exemplo. Considere um leilão onde $n=4, k=3$, $\theta_{i}=1$ para $i \in[k]$, e os seguintes anunciantes e valores verdadeiros da tabela 3.7:

Nesse caso, o $\operatorname{VCG}_{2 D}\left(v, v^{\prime}\right)$ produz uma M-solução onde o bem estar social vale 3 . De fato, pois $m_{\text {eomax }}=1+\epsilon \leq 3$. Considere as ofertas em equilíbrio para o $\mathrm{GSP}_{2 D}$ exibidas na tabela 3.8.

Para essas ofertas, o $\mathrm{GSP}_{2 D}$ produz uma E-solução, pois $m_{\text {eomax }}=1+\epsilon>1$. Logo, o anunciante $A$ é exibido exclusivamente, e o bem estar social obtido pelo $\operatorname{GSP}_{2 D}$ vale $1+\epsilon$. Note que este equilíbrio é bom, pois os anunciantes perdedores ofertam seus valores verdadeiros. 
Tabela 3.7: Exemplo justo.

\begin{tabular}{|c|c|c|c|}
\hline Nome & $i$ & $v_{i}$ & $v_{i}^{\prime}$ \\
\hline \hline$A$ & 1 & $1+\epsilon$ & 1 \\
\hline$B$ & 2 & 1 & 1 \\
\hline$C$ & 3 & 1 & 1 \\
\hline$D$ & 4 & 0 & 0 \\
\hline
\end{tabular}

Tabela 3.8: Ofertas em equilibrio para o $\mathrm{GSP}_{2 D}$.

\begin{tabular}{|c|c|c|c|}
\hline Nome & $i$ & $m_{i}$ & $m_{i}^{\prime}$ \\
\hline \hline$B$ & 1 & 1 & 1 \\
\hline$C$ & 2 & 1 & 1 \\
\hline$A$ & 3 & $1+\epsilon$ & 0 \\
\hline$D$ & 4 & 0 & 0 \\
\hline
\end{tabular}

\subsubsection{Lucro do GSP $2 D$}

Analisaremos o lucro do $\operatorname{GSP}_{2 D}\left(m, m^{\prime}\right)$ para ofertas $\left(m, m^{\prime}\right)$ em equilíbrio bom e livre de inveja comparado ao lucro do $\mathrm{VCG}_{2 D}\left(v, v^{\prime}\right)$. Mostraremos que o lucro para ofertas em equilíbrio do $\mathrm{GSP}_{2 D}\left(m, m^{\prime}\right)$ é maior ou igual a $\frac{1}{2}$ do lucro obtido pelo $\operatorname{VCG}_{2 D}\left(v, v^{\prime}\right)$. Para isso, analisaremos três casos.

\section{Caso 1: $\operatorname{VCG}_{2 D}\left(v, v^{\prime}\right)$ devolve saída E.}

Pelo teorema 3.6.1, sabemos que o único equilíbrio do $\operatorname{GSP}_{2 D}\left(m, m^{\prime}\right)$ exibe o anunciante evmax exclusivamente, e portanto o lucro do leilão é $\max \left\{m_{\text {eomax } 2}, \sum_{i=2}^{k+1} \theta_{i-1} m_{i}^{\prime}\right\}$. Lembre-se que o lucro do $\operatorname{VCG}_{2 D}\left(v, v^{\prime}\right)$ é $\max \left\{v_{\text {evmax } 2}, \sum_{i=1}^{\text {evmax }}-1 \theta_{i} v_{i}^{\prime}+\sum_{i=\text { evmax }}^{k} \theta_{i} v_{i+1}^{\prime}\right\}$. Vamos mostrar que $m_{\text {eomax } 2}+$ $\sum_{i=2}^{k+1} \theta_{i-1} m_{i}^{\prime}$ é maior que o lucro do $\mathrm{VCG}_{2 D}\left(v, v^{\prime}\right)$. Como $m_{\text {eomax } 2} \geq m_{\text {evmax } 2}$, pois eomax 2 não é exibido e o equilíbrio é bom, basta mostrar que $m_{\text {evmax } 2}+\sum_{i=2}^{k+1} \theta_{i-1} m_{i}^{\prime}$ é maior que o lucro do $\operatorname{VCG}_{2 D}\left(v, v^{\prime}\right)$.

Seja $q$ a posição do anunciante evmax ao ordenarmos os anunciantes por M-valor, ou seja, evmax $=d_{q}$. Vamos separar a demonstração em dois casos. No primeiro caso, vamos considerar que o anunciante evmax com maior E-valor não é o anunciante $d_{1}$ com maior M-valor, ou seja, $q \neq 1$. Sendo assim, como anunciantes perdedores ofertam pelo menos seus valores verdadeiros, para o anunciante evmax 2 com segundo maior E-valor, vale que $m_{\text {evmax } 2} \geq v_{\text {evmax } 2}$. Como $v_{i}^{\prime} \leq v_{i}$ para todo $i \in[n]$ e $v_{\text {evmax } 2} \geq v_{i}$ para todo $i \in[n] \operatorname{com} i \neq \operatorname{evmax}$, temos que $v_{\text {evmax } 2} \geq v_{d_{1}} \geq v_{d_{1}}^{\prime} \geq \theta_{1} v_{d_{1}}^{\prime}$. Ou seja, temos que

$$
m_{\text {evmax } 2} \geq \theta_{1} v_{d_{1}}^{\prime}
$$

Ademais, pelo lema 3.6.2, para $z=\min \{q, k+2\}$, vale que

$$
\sum_{i=2}^{k+1} \theta_{i-1} m_{i}^{\prime} \geq \sum_{i=2}^{z-1} \theta_{i-1} v_{d_{i}}^{\prime}+\sum_{i=z}^{k+2} \theta_{i-1} v_{d_{i+1}}^{\prime}
$$


O lucro do $\operatorname{VCG}_{2 D}\left(v, v^{\prime}\right)$, para $\ell=\min \{q, k+1\}$, onde $q$ é tal que $d_{q}=$ evmax, é dado por

$$
\max \left\{v_{\text {evmax } 2}, \sum_{i=1}^{\ell-1} \theta_{i} v_{d_{i}}^{\prime}+\sum_{i=\ell+1}^{k+1} \theta_{i-1} v_{d_{i}}^{\prime}\right\}
$$

Portanto, é suficiente mostrar que

$$
m_{\text {evmax } 2}+\sum_{i=2}^{z-1} \theta_{i-1} v_{d_{i}}^{\prime}+\sum_{i=z}^{k+2} \theta_{i-1} v_{d_{i+1}}^{\prime} \geq \max \left\{v_{\text {evmax } 2}, \sum_{i=1}^{\ell-1} \theta_{i} v_{d_{i}}^{\prime}+\sum_{i=\ell+1}^{k+1} \theta_{i-1} v_{d_{i}}^{\prime}\right\}
$$

Se o termo dominante no lado direito da desigualdade for o $v_{\text {evmax } 2}$, então a desigualdade vale pois $m_{\text {evmax } 2} \geq v_{\text {evmax } 2}$ já que estamos num equilíbrio bom do $\mathrm{GSP}_{2 D}$. Caso contrário, precisamos verificar que

$$
m_{\text {evmax } 2}+\sum_{i=2}^{z-1} \theta_{i-1} v_{d_{i}}^{\prime}+\sum_{i=z}^{k+2} \theta_{i-1} v_{d_{i+1}}^{\prime} \geq \sum_{i=1}^{\ell-1} \theta_{i} v_{d_{i}}^{\prime}+\sum_{i=\ell+1}^{k+1} \theta_{i-1} v_{d_{i}}^{\prime} .
$$

Por (3.8), e separando o primeiro termo da somatória da parte direita da desigualdade, basta verificar que

$$
\theta_{1} v_{d_{1}}^{\prime}+\sum_{i=2}^{z-1} \theta_{i-1} v_{d_{i}}^{\prime}+\sum_{i=z}^{k+2} \theta_{i-1} v_{d_{i+1}}^{\prime} \geq \theta_{1} v_{d_{1}}^{\prime}+\sum_{i=2}^{\ell-1} \theta_{i} v_{d_{i}}^{\prime}+\sum_{i=\ell+1}^{k+1} \theta_{i-1} v_{d_{i}}^{\prime} .
$$

Por comparação termo a termo, como $z \geq \ell$, é possível verificar que a desigualdade é válida.

Para finalizar, resta mostrar o caso em que evmax $=d_{1}$, ou seja, $q=1$. Nesse caso, vale que $m_{\text {evmax } 2} \geq v_{\text {evmax } 2} \geq v_{d_{2}}^{\prime}$, as somatórias de $i=2$ até $z-1$ e até $\ell-1$ são vazias, pois $z=\ell=1$, e a segunda somatória começa de 2. Portanto, neste caso, pelo lema 3.6.2, basta verificar que

$$
m_{\text {evmax } 2}+\sum_{i=z}^{k+2} \theta_{i-1} v_{d_{i+1}}^{\prime} \geq \max \left\{v_{\text {evmax } 2}, \sum_{i=2}^{k+1} \theta_{i-1} v_{d_{i}}^{\prime}\right\}
$$

Novamente, a desigualdade é trivialmente satisfeita se o termo dominante do lado direito for o $v_{\text {evmax } 2}$. Caso contrário, podemos verificar termo a termo que a desigualdade abaixo vale

$$
\theta_{2} v_{d_{2}}^{\prime}+\sum_{i=2}^{k+2} \theta_{i-1} v_{d_{i+1}}^{\prime} \geq \theta_{2} v_{d_{2}}^{\prime}+\sum_{i=3}^{k+1} \theta_{i-1} v_{d_{i}}^{\prime}
$$

Concluímos que o lucro do $\mathrm{GSP}_{2 D}$ é pelo menos metade do lucro do $\operatorname{VCG}_{2 D}\left(v, v^{\prime}\right)$ em uma E-solução.

\section{Caso 2: $\operatorname{VCG}_{2 D}\left(v, v^{\prime}\right)$ devolve M-solução e $\operatorname{GSP}_{2 D}\left(m, m^{\prime}\right)$ devolve M-solução.}

Neste caso, como veremos, o lucro do $\operatorname{GSP}_{2 D}\left(m, m^{\prime}\right)$ é maior ou igual ao lucro do $\operatorname{VCG}_{2 D}\left(v, v^{\prime}\right)$.

Sabemos que o preço pago no $\operatorname{VCG}_{2 D}\left(v, v^{\prime}\right)$ por um anunciante $i \leq k$, tal que $i=d_{q}$, é

$$
p_{i}=\max \left\{\sum_{j=q}^{k}\left(\theta_{j}-\theta_{j+1}\right) v_{d_{j+1}}^{\prime}, v_{\text {evmax }_{-i}}-\sum_{j=1, j \neq q}^{k} \theta_{j} v_{d_{j}}^{\prime}\right\} / \theta_{q},
$$

pois em particular vale que $\theta_{q}=\theta_{i}$ por 3.4 . 
Vamos mostrar que o preço $m_{i+1}^{\prime}$ pago pelo anunciante $i$ no $\operatorname{GSP}_{2 D}\left(m, m^{\prime}\right)$ é maior ou igual ao preço $p_{i}$ acima pago no $\operatorname{VCG}_{2 D}\left(v, v^{\prime}\right)$.

Caso 2.1: $\sum_{j=q}^{k}\left(\theta_{j}-\theta_{j+1}\right) v_{d_{j+1}}^{\prime} \leq v_{e v m a x-i}-\sum_{j=1, j \neq q}^{k} \theta_{j} v_{d_{j}}^{\prime}$.

Neste caso, queremos mostrar que $\theta_{i} m_{i+1}^{\prime} \geq v_{\text {evmax }}-\sum_{j=1, j \neq q}^{k} \theta_{j} v_{d_{j}}^{\prime}$.

Primeiramente, por (3.4), vale que $\sum_{j=1, j \neq q}^{k} \theta_{j} v_{d_{j}}^{\prime}=\sum_{j=1, j \neq i}^{k} \theta_{j} v_{j}^{\prime}$ para todo $i$. Suponha que $\theta_{i} m_{i+1}^{\prime}<v_{\text {evmax }_{-i}}-\sum_{j=1, j \neq i}^{k} \theta_{j} v_{j}^{\prime}$, e chegaremos a uma contradição, mostrando que a saída não está em equilíbrio.

De fato, seja $\ell$ o anunciante com maior E-oferta desconsiderando a E-oferta do anunciante $i$, ou seja, $v_{\ell}=v_{e \max _{-i}}$. Se $\ell$ não é exibido na saída múltipla, as ofertas não estão em equilíbrio, pois $\ell$ pode aumentar sua utilidade ao declarar $\left(v_{\ell}, m_{\ell}^{\prime}\right)$, mudando a saída para exclusiva, já que $v_{\ell}>\sum_{j=1, j \neq i}^{k} \theta_{j} v_{j}^{\prime}+\theta_{i} m_{i+1}^{\prime} \geq \sum_{j=1}^{k} \theta_{j} m_{j+1}^{\prime}$, pelo lema 3.6.1.

Se $\ell$ é exibido na saída múltipla, as ofertas não estão em equilíbrio, pois

$$
\begin{aligned}
\theta_{i} m_{i+1}^{\prime} & <v_{\ell}-\sum_{j=1, j \neq i}^{k} \theta_{j} v_{j}^{\prime}, \\
0 & <-\theta_{i} m_{i+1}^{\prime}+v_{\ell}-\theta_{\ell} v_{\ell}^{\prime}-\sum_{j=1, j \neq i, \ell}^{k} \theta_{j} v_{j}^{\prime}, \\
\theta_{\ell} v_{\ell}^{\prime} & <v_{\ell}-\left(\theta_{i} m_{i+1}^{\prime}+\sum_{j=1, j \neq i, \ell}^{k} \theta_{j} v_{j}^{\prime}\right), \\
\theta_{\ell}\left(v_{\ell}^{\prime}-m_{\ell+1}^{\prime}\right) & <v_{\ell}-\left(\theta_{\ell} m_{\ell+1}^{\prime}+\theta_{i} m_{i+1}^{\prime}+\sum_{j=1, j \neq i, \ell}^{k} \theta_{j} v_{j}^{\prime}\right) .
\end{aligned}
$$

Note que o lado esquerdo da última desigualdade é exatamente a utilidade para o anunciante $\ell$ no GSP $_{2 D}$ com saída múltipla, enquanto que o lado direito da desigualdade é a utilidade para o anunciante $\ell$ no $\operatorname{GSP}_{2 D}$ em uma saída exclusiva pagando o valor que está entre parênteses. Pelo lema 3.6.1, temos que $\theta_{\ell} m_{\ell+1}^{\prime}+\theta_{i} m_{i+1}^{\prime}+\sum_{j=1, j \neq i, \ell}^{k} \theta_{j} v_{j}^{\prime} \geq \sum_{j=1}^{k} \theta_{j} m_{j+1}^{\prime}$, e como $\sum_{j=1}^{k} \theta_{j} m_{j+1}^{\prime} \geq m_{\text {eomax }}$, pois o mecanismo $\mathrm{GSP}_{2 D}$ exibe saída múltipla, vale que o termo entre parênteses do lado direito da desigualdade é uma delimitação superior para o preço do anunciante $\ell$ ao ser exibido exclusivamente. $\mathrm{O}$ anunciante $\ell$ é exibido exclusivamente ao ofertar $\left(v_{\ell}, m_{\ell}^{\prime}\right)$. Portanto, as ofertas não estão em equilíbrio.

Concluímos que, neste caso, o preço pago por cada anunciante $i$ no $\mathrm{GSP}_{2 D}$ é maior ou igual ao preço pago no $\operatorname{VCG}_{2 D}\left(v, v^{\prime}\right)$.

Caso 2.2: $\sum_{j=q}^{k}\left(\theta_{j}-\theta_{j+1}\right) v_{d_{j+1}}^{\prime}>v_{e v m a x-i}-\sum_{j=1, j \neq q}^{k} \theta_{j} v_{d_{j}}^{\prime} \cdot$

Neste caso, queremos mostrar que $\theta_{i} m_{i+1}^{\prime} \geq \sum_{j=q}^{k}\left(\theta_{j}-\theta_{j+1}\right) v_{d_{j+1}}^{\prime}$. Primeiro, vamos mostrar que $\theta_{i} m_{i+1}^{\prime} \geq \sum_{j=i}^{k}\left(\theta_{j}-\theta_{j+1}\right) v_{j+1}^{\prime}$, e depois vamos mostrar que isso implica a desigualdade anterior.

Da definição de equilíbrio livre de inveja, temos que o anunciante $i+1$ não inveja o anunciante $i$, ou seja,

$$
\theta_{i+1}\left(v_{i+1}^{\prime}-m_{i+2}^{\prime}\right) \geq \theta_{i}\left(v_{i+1}^{\prime}-m_{i+1}^{\prime}\right) \text {. }
$$


Disso, temos que

$$
\begin{aligned}
\theta_{i+1} v_{i+1}^{\prime}-\theta_{i+1} m_{i+2}^{\prime}-\theta_{i} v_{i+1}^{\prime} & \geq-\theta_{i} m_{i+1}^{\prime} \\
\theta_{i+1} m_{i+2}^{\prime}+\left(\theta_{i}-\theta_{i+1}\right) v_{i+1}^{\prime} & \leq \theta_{i} m_{i+1}^{\prime}
\end{aligned}
$$

Dessa desigualdade, obtemos que

$$
\theta_{i} m_{i+1}^{\prime} \geq \sum_{j=i}^{k}\left(\theta_{j}-\theta_{j+1}\right) v_{j+1}^{\prime}
$$

Portanto, vale que o preço pago no $\operatorname{GSP}_{2 D}\left(m, m^{\prime}\right)$ é pelo menos o preço no $\operatorname{VCG}_{2 D}\left(v, v^{\prime}\right)$ se os anunciantes estiverem ordenados por seus valores verdadeiros. Porém, em um equilíbrio livre de inveja, os anunciantes estão ordenados pelos valores verdadeiros, a menos de locais da página com a mesma taxa de cliques. Mas em locais com uma mesma taxa de cliques, os preços pagos pelos anunciantes no $\mathrm{GSP}_{2 D}$ são todos os mesmos, caso contrário haveria "inveja". Portanto, dado um equilíbrio livre de inveja do $\mathrm{GSP}_{2 D}$, ao ordenar os anunciantes pelos valores verdadeiros, incluindo os anunciantes associados a locais com mesma taxa de cliques, não altera o valor pago, e mantém o equilíbrio. Logo, se vale $\theta_{i} m_{i+1}^{\prime} \geq \sum_{\ell=i}^{k}\left(\theta_{\ell}-\theta_{\ell+1}\right) v_{\ell+1}^{\prime}$, vale também que $\theta_{i} m_{i+1}^{\prime} \geq \sum_{j=q}^{k}\left(\theta_{j}-\right.$ $\left.\theta_{j+1}\right) v_{d_{j+1}}^{\prime}$.

Concluímos que o lucro do $\operatorname{GSP}_{2 D}$ é maior ou igual ao lucro do $\operatorname{VCG}_{2 D}\left(v, v^{\prime}\right)$, neste caso.

\section{Caso 3: $\operatorname{VCG}_{2 D}\left(v, v^{\prime}\right)$ devolve M-solução e $\operatorname{GSP}_{2 D}\left(m, m^{\prime}\right)$ devolve E-solução.}

Neste caso, o lucro esperado do $\operatorname{GSP}_{2 D}\left(m, m^{\prime}\right)$ é $\max \left\{m_{\text {eomax } 2}, \sum_{i=2}^{k+1} \theta_{i-1} m_{i}^{\prime}\right\}$, e o lucro esperado do $\operatorname{VCG}_{2 D}\left(v, v^{\prime}\right)$ é $\sum_{i=1}^{k} c_{i}$, onde $c_{i}=\max \left\{\theta_{i} p_{i}^{1}, \theta_{i} p_{i}^{2}\right\}, \operatorname{com} \theta_{i} p_{i}^{1}=\sum_{j=i}^{k}\left(\theta_{j}-\theta_{j+1}\right) v_{d_{j}}^{\prime}$, e $\theta_{i} p_{i}^{2}=$ $v_{\text {evmax }-d_{i}}-\sum_{j=1, j \neq i}^{k} \theta_{j} v_{d_{j}}^{\prime}$. Vamos mostrar que o lucro esperado do $\operatorname{GSP}_{2 D}\left(m, m^{\prime}\right)$ é maior ou igual a metade do lucro esperado do $\operatorname{VCG}_{2 D}\left(v, v^{\prime}\right)$.

Como temos um equilíbrio bom com E-solução do $\operatorname{GSP}_{2 D}\left(m, m^{\prime}\right)$, podemos assumir que evmax = eomax, pois vale que $m_{\text {eomax }} \geq m_{\text {evmax }}$ e $v_{\text {eomax }} \geq m_{\text {evmax }}$, pois sua utilidade não é negativa. Como o equilíbrio é bom, vale que $m_{\text {evmax }} \geq v_{\text {evmax }}$. Logo, temos que que $v_{\text {eomax }} \geq v_{\text {evmax }}$.

Como $m_{\text {eomax } 2} \geq m_{\text {evmax } 2}$, é suficiente mostrar que vale que

$$
m_{\text {evmax } 2}+\sum_{i=2}^{k+1} \theta_{i-1} m_{i}^{\prime} \geq \sum_{i=1}^{k} c_{i} .
$$

Primeiro, note que

$$
c_{i} \leq \theta_{i} v_{d_{i}}^{\prime}
$$

pois o preço por clique de um anunciante para ofertas em equilíbrio não pode ser maior do que seu valor verdadeiro. Note que vale que

$$
p_{i}^{1} \leq \theta_{i} v_{d_{i+1}}^{\prime},
$$

pois $\sum_{j=i}^{k}\left(\theta_{j}-\theta_{j+1}\right)=\theta_{j} \leq 1$, e $\theta_{j} \geq \theta_{j+1}$ e $v_{d_{j}}^{\prime} \geq v_{d_{j+1}}^{\prime}$, para $1 \leq j \leq k$. Vamos separar a demonstração em três casos. Seja $q$ a posição do anunciante evmax quando ordenamos os anunciantes por M-valores, ou seja, evmax $=d_{q}$.

Caso 3.1: $q>k$. 
Neste caso, pelo lema 3.6.2, vale que $m_{i}^{\prime} \geq v_{d_{i}}^{\prime}$, para $i \leq k<q$. Então, observando o lado esquerdo da inequação em 3.9 e ignorando o último termo da somatória, vale que o lucro esperado do $\operatorname{GSP}_{2 D}\left(m, m^{\prime}\right)$ é pelo menos $\max \left\{v_{\text {evmax } 2}, \sum_{i=2}^{k} \theta_{i-1} v_{d_{i}}^{\prime}\right\}$. Ademais, por (3.10), o lucro esperado do $\operatorname{VCG}_{2 D}\left(v, v^{\prime}\right)$ neste caso é no máximo $\sum_{i=1}^{k} \theta_{i} v_{d_{i}}^{\prime}$. Como evmax $\neq d_{1}$, vale que $v_{\text {evmax } 2} \geq v_{d_{1}} \geq$ $v_{d_{1}}^{\prime} \geq \theta_{1} v_{d_{1}}^{\prime}$, e portanto (3.9) é válida neste caso, pois temos

$$
v_{\text {evmax } 2}+\sum_{i=2}^{k} \theta_{i-1} v_{d_{i}}^{\prime} \geq \theta_{1} v_{d_{1}}^{\prime}+\sum_{i=2}^{k} \theta_{i} v_{d_{i}}^{\prime} .
$$

Caso 3.2: $2 \leq q \leq k$.

Neste caso, pelo lema 3.6.2, vale que o lucro esperado do $\operatorname{GSP}_{2 D}\left(m, m^{\prime}\right)$ é maior ou igual a

$$
\max \left\{v_{\text {evmax } 2}, \sum_{i=2}^{q-1} \theta_{i-1} v_{d_{i}}^{\prime}+\sum_{i=q}^{k+1} \theta_{i-1} v_{d_{i+1}}^{\prime}\right\} .
$$

Vamos considerar dois subcasos.

Caso 3.2.1: $p_{q}^{2} \geq p_{q}^{1}$.

Se $p_{q}^{2} \geq p_{q}^{1}$, então o lucro esperado do $\operatorname{VCG}_{2 D}\left(v, v^{\prime}\right)$ é

$$
\begin{aligned}
\sum_{j=1}^{k} c_{j} & =p_{q}^{2}+\sum_{j=1, j \neq q}^{k} c_{j} \\
& \leq p_{q}^{2}+\sum_{j=1, j \neq q} \theta_{j} v_{d_{j}}^{\prime} \\
& =v_{\text {evmax } 2}-\sum_{j=1, j \neq q}^{k} \theta_{j} v_{d_{j}}^{\prime}+\sum_{j=1, j \neq q}^{k} \theta_{j} v_{d_{j}}^{\prime} \\
& =v_{\text {evmax } 2} .
\end{aligned}
$$

e portanto (3.9) é válida neste caso.

Caso 3.2.2: $p_{q}^{2}<p_{q}^{1}$.

Se $p_{q}^{2}<p_{q}^{1}$, então o lucro esperado do $\operatorname{VCG}_{2 D}\left(v, v^{\prime}\right)$ é

$$
\begin{aligned}
\sum_{j=1}^{k} c_{j} & =p_{q}^{1}+\sum_{j=1, j \neq q}^{k} c_{j} \\
& \leq \sum_{j=q}^{k}\left(\theta_{j}-\theta_{j+1}\right) v_{d_{j+1}}^{\prime}+\sum_{j=1, j \neq q}^{k} \theta_{j} v_{d_{j}}^{\prime} \\
& =\sum_{j=q}^{k} \theta_{j} v_{d_{j+1}}^{\prime}-\sum_{j=q}^{k} \theta_{j+1} v_{d_{j+1}}^{\prime}+\sum_{j=1, j \neq q}^{k} \theta_{j} v_{d_{j}}^{\prime} \\
& \leq \sum_{j=q}^{k} \theta_{j} v_{d_{j+1}}^{\prime}+\sum_{j=1}^{q-1} \theta_{j} v_{d_{j}}^{\prime} .
\end{aligned}
$$

Como evmax $\neq d_{1}$, então vale que $v_{\text {evmax } 2} \geq v_{d_{1}} \geq v_{d_{1}}^{\prime} \geq \theta_{1} v_{d_{1}}^{\prime}$, e concluímos que (3.9) é válida neste caso. 
Caso 3.3: $q=1$.

Neste caso, pelo lema 3.6.2, vale que o lucro esperado do $\operatorname{GSP}_{2 D}\left(m, m^{\prime}\right)$ é maior ou igual a

$$
\max \left\{v_{\text {evmax } 2}, \sum_{i=2}^{k+1} \theta_{i-1} v_{d_{i+1}}^{\prime}\right\} .
$$

Este caso é muito parecido com o caso anterior. Tanto para $p_{q}^{2} \geq p_{q}^{1}$ quanto para $p_{q}^{2}<p_{q}^{1}$, obtemos os resultados do caso anterior. Porém, para $p_{q}^{2}<p_{q}^{1}$, onde o lucro esperado do $\mathrm{VCG}_{2 D}\left(v, v^{\prime}\right)$ é $\sum_{j=q}^{k} \theta_{j} v_{d_{j+1}}^{\prime}+\sum_{j=1}^{q-1} \theta_{j} v_{d_{j}}^{\prime}$, observe o seguinte. Como evmax $=d_{1}$, então vale que $v_{\text {evmax } 2} \geq v_{d_{2}} \geq$ $v_{d_{2}}^{\prime} \geq \theta_{1} v_{d_{2}}^{\prime}$, e concluímos que (3.9) é válida neste caso.

\section{Exemplo onde o fator do lucro é justo}

Para mostrar que a análise do lucro é justa, vejamos um exemplo. Considere um leilão onde $n=3, k=2, \theta_{i}=1$ para $i \in[k]$, e anunciantes e valores verdadeiros como na tabela 3.9:

Tabela 3.9: Exemplo justo.

\begin{tabular}{|c|c|c|c|}
\hline Nome & $i$ & $v_{i}$ & $v_{i}^{\prime}$ \\
\hline \hline$A$ & 1 & $1+\epsilon$ & 1 \\
\hline$B$ & 2 & 1 & 1 \\
\hline$C$ & 3 & 1 & 1 \\
\hline
\end{tabular}

Nesse caso, o $\operatorname{VCG}_{2 D}\left(v, v^{\prime}\right)$ produz uma M-solução onde o lucro vale 2. Considere as ofertas em equilíbrio para o $\mathrm{GSP}_{2 D}$ exibidas na tabela 3.10 .

Tabela 3.10: Ofertas em equilíbrio para o $\mathrm{GSP}_{2 D}$.

\begin{tabular}{|c|c|c|c|}
\hline Nome & $i$ & $m_{i}$ & $m_{i}^{\prime}$ \\
\hline \hline$B$ & 1 & 1 & 1 \\
\hline$C$ & 2 & 1 & 1 \\
\hline$A$ & 3 & $1+\epsilon$ & 0 \\
\hline
\end{tabular}

Com essas ofertas, o anunciante $A$ é exibido exclusivamente, e o lucro obtido pelo $\operatorname{GSP}_{2 D}\left(m, m^{\prime}\right)$ vale $1+\epsilon$.

\subsection{Equilíbrios bons do $\mathrm{GSP}_{2 D}$}

Vamos mostrar que sempre existem ofertas $\left(m, m^{\prime}\right)$ em equilíbrio bom para o $\mathrm{GSP}_{2 D}$, construindo essas ofertas com base nos valores verdadeiros dos anunciantes. Considere $n$ anunciantes e seus valores verdadeiros $v_{i}$ e $v_{i}^{\prime}$, para $i \in[n]$, a quantidade $k$ de locais de páginas, e suas taxas de cliques $\theta_{j}$, para $j \in[k]$, e que os anunciantes estão ordenados por seus M-valores, ou seja, $v_{1}^{\prime} \geq v_{2}^{\prime} \geq \cdots \geq v_{n}^{\prime}$. Seja evmax o anunciante com maior E-valor, e o vetor $\hat{v}^{\prime}=v_{- \text {evmax }}^{\prime}$, ou seja, $\hat{v}_{i}^{\prime}=v_{i}^{\prime}$ para $i<$ evmax, e $\hat{v}_{i}^{\prime}=v_{i+1}^{\prime}$ para evmax $\leq i<n$.

Vamos tomar como oferta de todo anunciante $i \neq$ evmax o seu valor verdadeiro, ou seja, $m_{i}=v_{i}$ e $m_{i}^{\prime}=v_{i}^{\prime}$, para todo $i \neq$ evmax. Para determinar a oferta do anunciante evmax de forma 
a obtermos um equilíbrio bom para o $\mathrm{GSP}_{2 D}$, precisamos determinar qual local da página maximiza sua utilidade, dado que estão fixadas as ofertas dos demais anunciantes. Para determinar os possíveis locais da página onde evmax pode ser exibido sem que a oferta $m_{\text {eomax } 2}$ seja grande o suficiente para ganhar exclusivamente, definimos $S_{0}=\infty, S_{1}=\sum_{i=1}^{k} \theta_{i} \hat{v}_{i}^{\prime}$, e $S_{\ell}=\sum_{i=2}^{\ell-1} \theta_{i-1} \hat{v}_{i}^{\prime}+\sum_{i=\ell}^{k} \theta_{i} \hat{v}_{i}^{\prime}+$ $\theta_{\ell-1} \hat{v}_{\ell-1}^{\prime}$, para $2 \leq \ell \leq k+1$. Ou seja, $S_{\ell}$ é exatamente $\sum_{i=2}^{k+1} \theta_{i-1} m_{i}^{\prime}$ quando o anunciante evmax oferta para $m_{\text {evmax }}^{\prime}$ o maior valor possível para obter a posição $\ell$ em uma M-solução (ofertando o mesmo valor que o anunciante acima dele), exceto para $\ell=1$, onde basta ofertar qualquer valor maior do que $\hat{v}_{1}^{\prime}$. Dessa forma, temos que $S_{0} \geq \cdots \geq S_{k+1}$.

Seja $j$, onde $0 \leq j \leq k+1$, tal que $S_{j}>v_{\text {evmax } 2}$ e $S_{j+1} \leq v_{\text {evmax } 2}($ ou $j=k+1)$. Em uma M-solução, o anunciante evmax pode apenas ser alocado a um local dentre os $j$ primeiros locais, caso contrário o anunciante evmax 2 seria exibido exclusivamente. Seja $t$ o local, dentre os $j$ primeiros locais, que maximiza a utilidade para o anunciante evmax em uma M-solução, ou seja, $t=\arg \max _{1 \leq i \leq j} \theta_{i}\left(v_{\text {evmax }}^{\prime}-\hat{v}_{i}^{\prime}\right)$. Sejam $u_{M}=\theta_{t}\left(v_{\text {evmax }}^{\prime}-\hat{v}_{t}^{\prime}\right)$ a utilidade para o anunciante evmax na M-solução e $u_{E}=v_{\text {evmax }}-\max \left\{v_{\text {evmax } 2}, \sum_{i=2}^{k+1} \theta_{i-1} \hat{v}_{i}^{\prime}\right\}$ a utilidade para o anunciante evmax na E-solução. Separemos em dois casos para construir ofertas em equilíbrio bom para o $\operatorname{GSP}_{2 D}$.

\section{Caso 1: Equilíbrio bom onde o $\mathrm{GSP}_{2 D}$ produz E-solução.}

Se $v_{\text {evmax } 2}>S_{1}$, ou seja, se $j=0$, então o $\mathrm{GSP}_{2 D}$ produzirá uma E-solução, independente da oferta do anunciante evmax. Neste caso, é vantajoso para o anunciante evmax ser exibido exclusivamente (em vez de deixar o anunciante evmax 2 ser o ganhador), ofertando $\left(m_{\text {evmax }}=\infty, m_{\text {evmax }}^{\prime}=0\right)$. Também, se $u_{E} \geq u_{M}$, então é vantajoso para o anunciante evmax ser exibido exclusivamente, ofertando $\left(m_{\text {evmax }}=\infty, m_{\text {evmax }}^{\prime}=0\right)$. Nesses dois casos, o anunciante evmax está maximizando sua utilidade, e os anunciantes perdedores nada podem fazer para serem exibidos, e portanto temos um equilíbrio bom.

\section{Caso 2: Equilíbrio bom onde o $\mathrm{GSP}_{2 D}$ produz M-solução.}

Por outro lado, se $u_{M}>u_{E}$, então se evmax ofertar $\left(m_{\text {evmax }}=S_{t}-\epsilon \theta_{t-1}, m_{\text {evmax }}^{\prime}=\hat{v}_{t-1}^{\prime}-\epsilon\right)$ (com $\hat{v}_{0}^{\prime}=\hat{v}_{1}^{\prime}+2 \epsilon, \theta_{0}=0$, e $\epsilon>0$ ) obtemos um equilíbrio bom com M-solução para o $\mathrm{GSP}_{2 D}$. De fato, para $t>1$, temos que

$$
\begin{aligned}
m_{\text {evmax }} & =S_{t}-\epsilon \theta_{t-1} \\
& =\sum_{i=2}^{t-1} \theta_{i-1} \hat{v}_{i}^{\prime}+\sum_{i=t}^{k} \theta_{i} \hat{v}_{i}^{\prime}+\theta_{t-1} \hat{v}_{t-1}^{\prime}-\epsilon \theta_{t-1} \\
& =\sum_{i=2}^{t-1} \theta_{i-1} \hat{v}_{i}^{\prime}+\sum_{i=t}^{k} \theta_{i} \hat{v}_{i}^{\prime}+\theta_{t-1}\left(\hat{v}_{t-1}^{\prime}-\epsilon\right) \\
& =\sum_{i=2}^{k+1} \theta_{i-1} m_{i}^{\prime} .
\end{aligned}
$$

Para $t=1$, temos que

$$
m_{\text {evmax }}=S_{1}=\sum_{i=1}^{k} \theta_{i} \hat{v}_{i}^{\prime}=\sum_{i=2}^{k+1} \theta_{i-1} m_{i}^{\prime} .
$$

Primeiro, note que $m_{\text {evmax }}=S_{t}-\epsilon \theta_{t-1}>v_{\text {evmax } 2}$, para $\epsilon$ suficientemente pequeno. Segundo, como $m_{\text {evmax }} \ngtr \sum_{i=2}^{k+1} \theta_{i-1} m_{i}^{\prime}$, obtemos uma M-solução. Ademais, como $u_{M}>u_{E}$, o anunciante 
evmax não tem incentivo em alterar sua oferta para que a solução produzida seja uma E-solução, e nem de ser exibido em um local diferente de $t$. Por último, para cada anunciante $i \neq e v m a x$, se $i$ diminuir sua M-oferta, então o anunciante evmax passa a ser ganhador exclusivo; e se $i$ aumentar sua M-oferta, ou mantém-se no mesmo local sem alterar sua utilidade, ou recebe um local superior, mas pagando a oferta do anunciante acima dele, que por sua vez oferta um valor maior ou igual a $v_{i}^{\prime}$, o que também não é lucrativo. Concluímos que, neste caso, obtemos um equilíbrio bom com Msolução se todos os anunciantes exceto evmax ofertam verdadeiramente e evmax oferta $\left(m_{\text {evmax }}=\right.$ $\left.S_{t}-\epsilon \theta_{t-1}, m_{\text {evmax }}^{\prime}=\hat{v}_{t-1}^{\prime}-\epsilon\right)$.

\subsection{Mecanismo $\mathrm{NP}_{2 D}$}

Vamos apresentar o mecanismo $\mathrm{NP}_{2 D}$ (next price) também proposto por Arpita Ghosh e Amin Sayedi [GS10] e enunciar as propriedades garantidas por este mecanismo. Quando o $\mathrm{NP}_{2 D}$ produz uma M-solução, o preço é definido de forma a ser o menor valor que não altera a solução encontrada. Ou seja, no caso de uma M-solução, o preço $p_{i}$ para um anunciante $i \in[k]$ deve ser grande o suficiente para que, tomando-se $m_{i}^{\prime}=p_{i}$, a posição do anunciante $i$ seja mantida na ordenação por M-ofertas, e ademais mantemos as condições necessárias para garantir uma M-solução. A decisão entre produzir uma E-solução e uma M-solução, e a determinação do preço no caso de uma E-solução são feitas como no $\mathrm{VCG}_{2 D}$. Formalmente, seja eomax o anunciante com maior E-oferta. A solução é definida da seguinte forma.

Saída exclusiva: Se $m_{\text {eomax }}>\sum_{j=1}^{k} \theta_{j} m_{j}^{\prime}$, o $\mathrm{NP}_{2 D}$ produz uma E-solução onde o preço do anunciante eomax é

$$
p_{\text {eomax }}=\max \left\{m_{\text {eomax } 2}, \sum_{i=1}^{\text {eomax }-1} \theta_{i} m_{i}^{\prime}+\sum_{i=\text { eomax }}^{k} \theta_{i} m_{i+1}^{\prime}\right\} .
$$

Saída múltipla: Se $m_{e o m a x} \leq \sum_{j=1}^{k} \theta_{j} m_{j}^{\prime}$, o $\mathrm{NP}_{2 D}$ produz uma M-solução onde o preço para todo anunciante $i$, onde $i \in[k]$, é dado por

$$
\theta_{i} p_{i}=\max \left\{\theta_{i} m_{i+1}^{\prime}, m_{\text {eomax }_{-i}}-\sum_{j=1, j \neq i}^{k} \theta_{j} m_{j}^{\prime}\right\}
$$

Para apresentar a seguir as propriedades garantidas pelo $\mathrm{NP}_{2 D}$, vamos considerar fixados $n$ anunciantes e seus valores verdadeiros $v_{i}$ e $v_{i}^{\prime}$, para $i \in[n]$, a quantidade $k$ de locais de páginas, e suas taxas de cliques $\theta_{j}$, para $j \in[k]$, ao longo de toda esta seção. Iremos comparar o lucro e o bem estar social obtidos em equilíbrios bons e livres de inveja do $\mathrm{NP}_{2 D}$ com o lucro e bem estar social obtidos pelo $\mathrm{VCG}_{2 D}\left(v, v^{\prime}\right)$. Os resultados apresentados a seguir, no entanto, não serão acompanhados de suas demonstrações, que podem ser encontradas na seção 4 do artigo [GS10].

\subsubsection{Eficiência do $\mathrm{NP}_{2 D}$}

Assim como no mecanismo $\mathrm{GSP}_{2 D}$, três teoremas resumem a análise da eficiência do $\mathrm{NP}_{2 D}$. Segue dos teoremas abaixo que o bem estar social do $\mathrm{NP}_{2 D}\left(m, m^{\prime}\right)$, para ofertas em equilíbrios bons e livres de inveja, é pelo menos metade do bem estar social do $\operatorname{VCG}_{2 D}\left(v, v^{\prime}\right)$, um fator melhor do que o obtido pelo $\mathrm{GSP}_{2 D}$. 
Antes de enunciar o primeiro teorema, precisamos de uma nova definição. Para um anunciante $i \in[n]$, uma estratégia $\left(m_{i}, m_{i}^{\prime}\right)$ é dita dominada se existem ofertas $\left(\bar{m}_{i}, \bar{m}_{i}^{\prime}\right)$ tais que $\bar{u}_{i} \geq u_{i}$ para todos os possíveis conjuntos de ofertas dos demais anunciantes, e $\bar{u}_{i}>u_{i}$ para pelo menos um conjunto de ofertas dos demais anunciantes, onde $u_{i}$ e $\bar{u}_{i}$ são as utilidades do anunciante $i$ quando este oferta $\left(m_{i}, m_{i}^{\prime}\right)$ e $\left(\bar{m}_{i}, \bar{m}_{i}^{\prime}\right)$, respectivamente.

Teorema 3.8.1. Se o $\mathrm{VCG}_{2 D}\left(v, v^{\prime}\right)$ produz uma E-solução, e se os anunciantes escolhem estratégias $\left(m, m^{\prime}\right)$ não dominadas no $\mathrm{NP}_{2 D}$, então toda E-solução em equilíbrio bom para o $\mathrm{NP}_{2 D}\left(m, m^{\prime}\right)$ tem o mesmo bem estar social que o $\mathrm{VCG}_{2 D}\left(v, v^{\prime}\right)$.

Em especial, as estratégias dominadas no $\mathrm{NP}_{2 D}$ são ofertas com valores maiores que os valores verdadeiros dos anunciantes. O teorema acima segue do fato de que quando o anunciante evmax oferta verdadeiramente, e o mecanismo $\mathrm{NP}_{2 D}$ produz uma E-solução, então o anunciante evmax não tem incentivo em alterar sua oferta.

Teorema 3.8.2. Se o $\operatorname{VCG}_{2 D}\left(v, v^{\prime}\right)$ produz uma M-solução, então para todo equilíbrio bom $\left(m, m^{\prime}\right)$ do $\mathrm{NP}_{2 D}$ com E-solução vale que o bem estar social do $\mathrm{NP}_{2 D}\left(m, m^{\prime}\right)$ é pelo menos metade do bem estar social do $\mathrm{VCG}_{2 D}\left(v, v^{\prime}\right)$.

Teorema 3.8.3. Se o $\operatorname{VCG}_{2 D}\left(v, v^{\prime}\right)$ produz uma M-solução, então para todo equilibrio livre de inveja $\left(m, m^{\prime}\right)$ do $\mathrm{NP}_{2 D}$ com M-solução, vale que o bem estar social do $\mathrm{NP}_{2 D}\left(m, m^{\prime}\right)$ é igual ao bem estar social do $\operatorname{VCG}_{2 D}\left(v, v^{\prime}\right)$.

\subsubsection{Lucro do $\mathrm{NP}_{2 D}$}

Similarmente, os resultados sobre o lucro do $\mathrm{NP}_{2 D}$ são capturados pelos três teoremas a seguir.

Teorema 3.8.4. Para todo equilíbrio bom $\left(m, m^{\prime}\right)$ do $\mathrm{NP}_{2 D}$ com E-solução vale que o lucro do $\mathrm{NP}_{2 D}\left(m, m^{\prime}\right)$ é maior ou igual ao lucro do $\mathrm{VCG}_{2 D}\left(v, v^{\prime}\right)$.

Apesar do bom resultado garantido pelo teorema acima, onde o $\mathrm{NP}_{2 D}$ se mostra melhor do que o $\mathrm{GSP}_{2 D}$, no caso em que o $\mathrm{VCG}_{2 D}\left(v, v^{\prime}\right)$ produz uma M-solução, o lucro do $\mathrm{NP}_{2 D}$ pode ser arbitrariamente menor do que o lucro do $\operatorname{VCG}_{2 D}\left(v, v^{\prime}\right)$. Isso acontece porque o mecanismo $\mathrm{NP}_{2 D}$ possui uma quantidade maior de equilíbrios do que o $\mathrm{GSP}_{2 D}$, mas os dois seguintes teoremas mostram que isso pode não ser um grande problema.

Teorema 3.8.5. Todo equilíbrio $\left(m, m^{\prime}\right)$ do $\mathrm{GSP}_{2 D}$ com M-solução é também um equilíbrio para o $\mathrm{NP}_{2 D}$ com M-solução, e o lucro obtido em ambos os mecanismos é o mesmo.

Para enunciar o próximo teorema, vamos nos lembrar do modelo unidimensional (leilão simplificado) apresentado no capítulo 3 , e do mecanismo à prova de estratégia para esse leilão, o leilão gradual apresentado na seção 2.4 .

Teorema 3.8.6. Sempre existe um equilíbrio bom $\left(m, m^{\prime}\right)$ do $\mathrm{NP}_{2 D}$ com lucro maior ou igual ao lucro obtido pelo leilão gradual (quando os anunciantes ofertam verdadeiramente $m^{\prime}=v^{\prime}$ ).

Além dos teoremas apresentados acima, o mecanismo $\mathrm{NP}_{2 D}$ possui a propriedade de que o lucro pode diminuir quando os anunciantes aumentam suas ofertas, o que chamamos de lucro não monótono. 


\subsection{Conclusões sobre o capítulo}

Apresentamos neste capítulo um modelo que permite mais expressividade ao leilão, e dois mecanismos que poderiam vir a substituir o atual mecanismo caso o modelo apresentado passasse a ser utilizado, apresentando também as propriedades garantidas por tais mecanismos. Por um lado, o $\mathrm{NP}_{2 D}$ garante, no pior caso, soluções com bem estar social maior do que o $\mathrm{GSP}_{2 D}$, e também garante soluções com lucro maior do que o do $\mathrm{GSP}_{2 D}$ em algumas situações. Por outro lado, em outras situações, o lucro do $\mathrm{NP}_{2 D}$ pode ser muito ruim, além de possuir a propriedade do lucro não monótono.

Uma outra maneira, na mesma direção do trabalho apresentado neste capítulo, para dar mais expressividade ao leilão, é discutida no trabalho de Muthukrishnan [Mut09]. Neste trabalho, cada anunciante $i$ deve informar dois valores ao leilão, a oferta $\left(m_{i}, n_{i}\right)$, onde o anunciante $i$ diz que está disposto a pagar no máximo $m_{i}$ contanto que não mais do que $n_{i}$ anunciantes sejam exibidos, e não está disposto a pagar nada caso mais do que $n_{i}$ anunciantes sejam exibidos na página. 


\section{Capítulo 4}

\section{Leilões genéricos}

\subsection{Introdução}

Aggarwal, Muthukrishnan, Pál e Pál [AMPP09] consideraram o seguinte problema, que chamaremos de leilão genérico: encontrar uma maneira de alocar os locais da página aos anunciantes de forma a maximizar a utilidade para os anunciantes, usando os conceitos de alocação estável e alocação ótima. Cada anunciante faz uma oferta ao leiloeiro com o valor que pretende pagar por cada local da página. O mecanismo proposto por estes autores para encontrar uma alocação nos permite especificar valores mínimos e máximos diferentes que cada anunciante poderá pagar por cada local da página, onde o valor mínimo é definido pelo leiloeiro, e o valor máximo pelo anunciante. Passamos a descrever tal mecanismo.

\subsection{Formalização do problema}

Um leilão genérico envolve um leiloeiro, um número $n$ de anunciantes e um número $k$ de locais. Identificamos cada anunciante com um número do conjunto $[n]=\{1,2, \ldots, n\}$ e cada local com um número do conjunto $[k]=\{1,2, \ldots, k\}$. Denotamos por $I$ o conjunto de anunciantes e por $J$ o conjunto de locais, ou seja, $I=[n]$ e $J=[k]$.

O leiloeiro especifica um número $r_{i, j} \geq 0$ para cada anunciante $i \in I$ e local $j \in J$, que representa o valor mínimo de venda do local $j$ para o anunciante $i$. Por outro lado, para cada local $j$, cada anunciante $i$ define um número $v_{i, j} \geq 0$, o qual chamaremos de valor verdadeiro, que expressa o valor que o local $j$ tem para $i$, e um número $m_{i, j} \leq v_{i, j}$ que representa o valor máximo que $i$ está disposto a pagar por $j$. Note que o valor máximo $m_{i, j}$ não deve exceder o valor verdadeiro $v_{i, j}$. Dizemos que $i$ está interessado em $j$ se $m_{i, j} \geq r_{i, j}$. Caso contrário, $i$ não está interessado em $j$ e estabelecemos que $m_{i, j}=-1$ neste caso.

Essas são as informações que definem um leilão genérico, ou seja, um leilão genérico é uma quíntupla $(v, m, r, n, k)$ onde

- $n$ é o número de anunciantes,

- $k$ é o número de locais,

- $v, m$ e $r$ são matrizes $n \times k$ que definem os valores $v_{i, j}, m_{i, j}$ e $r_{i, j}$ conforme descrito acima, para cada anunciante $i$ e local $j$. 
Uma atribuição para um leilão genérico $(v, m, r, n, k)$ é um emparelhamento $\mu$ no grafo $K_{n, k}$ (o grafo bipartido completo com $n$ vértices em um lado da bipartição e $k$ vértices do outro lado). Se $(i, j) \in \mu$, dizemos que $i$ e $j$ estão alocados (um ao outro). Para cada anunciante $i$ alocado, denotamos por $\mu(i)$ o local $j$ tal que $(i, j) \in \mu$. Analogamente, para cada local $j$ alocado, denotamos por $\mu(j)$ o anunciante $i$ tal que $(i, j) \in \mu$. Uma atribuição $\mu$ é válida se todo anunciante $i$ alocado está interessado no local $\mu(i)$.

Estamos interessados não apenas na atribuição para um leilão genérico, mas também nos preços que serão pagos por cada local vendido, pois o preço pago por cada local vendido determina a utilidade para o anunciante que recebe tal local. Por isso estendemos a definição de atribuição para acomodar os preços pagos e a utilidade para os anunciantes.

Uma alocação para um leilão genérico $(v, m, r, n, k)$ é um tripla $(\mu, p, u)$ onde $\mu$ é uma atribuição válida para $(v, m, r, n, k), p$ é um vetor indexado por $[k]$ e $u$ é um vetor indexado por $[n]$.

\subsection{Propriedades de uma alocação}

Alocação viável: Uma alocação $(\mu, p, u)$ é viável para um leilão genérico $(v, m, r, n, k)$ se

$$
\begin{aligned}
& r_{i, j} \leq p_{j} \leq m_{i, j} \text { e } u_{i}=v_{i, j}-p_{j} \text { para todo }(i, j) \text { em } \mu, \\
& p_{j}=0 \text { para todo local } j \text { não alocado e } \\
& u_{i}=0 \text { para todo anunciante } i \text { não alocado. }
\end{aligned}
$$

Ou seja, numa alocação $(\mu, p, u)$ viável, $\mu$ é uma atribuição válida, $p_{j}$ representa o preço pago pelo local $j$ e $u_{i}$ a utilidade para o anunciante $i$. Uma alocação $(\mu, p, u)$ é semi viável se valem (4.1) e (4.2).

Alocação estável: Uma alocação $(\mu, p, u)$ é estável para um leilão genérico $(v, m, r, n, k)$ se para todo $(i, j) \in I \times J$ pelo menos uma das seguintes desigualdades é válida:

$$
\begin{aligned}
& u_{i}+p_{j} \geq v_{i, j}, \\
& p_{j} \geq m_{i, j}, \\
& u_{i}+r_{i, j} \geq v_{i, j} .
\end{aligned}
$$

Um par $(i, j) \in I \times J$ que não satisfaz nenhuma das desigualdades é dito par bloqueador.

Explicitamente, para um par bloqueador $(i, j)$ vale que $u_{i}+p_{j}<v_{i, j}, p_{j}<m_{i, j}$ e $u_{i}+r_{i, j}<v_{i, j}$. Logo, vale que $j$ não está alocado a $i$, pois $u_{i}+p_{j} \neq v_{i, j}$, e vale que $i$ está interessado em $j$, pois como $p_{i, j} \geq 0$ segue que $m_{i, j}>0$. Ademais, $i$ pode oferecer um preço $p_{j}^{\prime}>p_{j}$ com $r_{i, j} \leq p_{j}^{\prime} \leq m_{i, j}$ de modo que sua nova utilidade $u_{i}^{\prime}=v_{i, j}-p_{j}^{\prime}$ seja maior que $u_{i}$, como será mostrado adiante. Ou seja, o anunciante $i$ tem um incentivo para oferecer um preço maior por $j$ do que seu preço corrente.

Para um par bloqueador $(i, j)$ vamos encontrar um preço $p_{j}^{\prime}$ tal que

$$
\begin{aligned}
& p_{j}^{\prime}>p_{j}, \\
& u_{i}^{\prime}>u_{i} \quad \mathrm{e} \\
& r_{i, j} \leq p_{j}^{\prime} \leq m_{i, j} .
\end{aligned}
$$


Primeiramente veja que se $p_{j}^{\prime}=p_{j}$, então $u_{i}^{\prime}=v_{i, j}-p_{j}^{\prime}=v_{i, j}-p_{j}>u_{i}$. Porém, queremos $p_{j}^{\prime}>p_{j}$. Por outro lado, caso o anunciante $i$ pague exatamente $v_{i, j}-u_{i}$ por $j$, sua utilidade não se altera. Logo, utilizaremos o meio termo entre esses valores. Tome $q=\frac{p_{j}+v_{i, j}-u_{i}}{2}$. Então, atribuindo $p_{j}^{\prime}=q$, temos que (4.7) é satisfeita, pois $p_{j}<q$, e (4.8) é satisfeita, pois temos $u_{i}^{\prime}=v_{i, j}-q=\frac{v_{i, j}-p_{j}+u_{i}}{2}$, e segue que $2 u_{i}^{\prime}=v_{i, j}-p_{j}+u_{i}>2 u_{i}$. Mas (4.9) não é necessariamente satisfeita. Analisaremos esses dois casos separadamente:

Caso 1: $r_{i, j}>q$. Tome $p_{j}^{\prime}=r_{i, j}$. Trivialmente, (4.7) e (4.9) são satisfeitas. Ademais, como temos que $u_{i}+r_{i, j}<v_{i, j}$, e $u_{i}^{\prime}=v_{i, j}-p_{j}^{\prime}=v_{i, j}-r_{i, j}$, vale que $u_{i}<u_{i}^{\prime}$, ou seja, (4.8).

Caso 2: $m_{i, j}<q$. Tome $p_{j}^{\prime}=m_{i, j}$. Trivialmente, (4.7) e (4.9) são satisfeitas. Dado que atribuindo $p_{j}^{\prime}=q$ vale que $u_{i}^{\prime}>u_{i}$, ao pagar um preço $p_{j}^{\prime}<q$, a utilidade $u_{i}^{\prime}$ continua maior do que $u_{i}$ e (4.8) também vale.

Ao atribuir o local $j$ ao anunciante $i$ pelo preço $p_{j}^{\prime}$ conforme descrito acima, o par $(i, j)$ deixa de ser bloqueador.

Por outro lado, se não há um par bloqueador em uma alocação, nenhum anunciante pode oferecer por um local mais do que seu preço corrente para aumentar sua utilidade, o que caracteriza a estabilidade da alocação. De fato, se pelo menos uma dentre (4.4), (4.5) e (4.6) for válida para um par $(i, j)$, então o anunciante $i$ não pode pagar um preço $p_{j}^{\prime}>p_{j}$, tal que $r_{i, j} \leq p_{j}^{\prime} \leq m_{i, j}$, e aumentar sua utilidade. Vejamos caso por caso:

Caso 1: $u_{i}+p_{j} \geq v_{i, j}$. Se $i$ pagar um valor $p_{j}^{\prime}>p_{j}$ pelo local $j$, sua utilidade diminui. Portanto o anunciante $i$ não tem incentivo em pagar um preço maior do que $p_{j}$ pelo local $j$.

Caso 2: $p_{j} \geq m_{i, j}$. O anunciante $i$ não pode oferecer um valor maior do que o preço corrente do local $j$.

Caso 3: $u_{i}+r_{i, j} \geq v_{i, j}$. Independente do valor corrente do local $j$, nem mesmo comprando o local $j$ pelo valor $r_{i, j}$ o anunciante $i$ aumentaria sua utilidade. Neste caso, o anunciante $i$ não tem incentivo em oferecer um valor $p_{j}^{\prime} \geq r_{i, j}$.

Com isso conclui-se a ideia de estabilidade do leilão genérico. Um leilão genérico é estável se e somente se, para todo local $j$, nenhum anunciante tem incentivo em oferecer um preço maior do que o preço corrente de $j$.

Alocação ótima: Para um leilão genérico $(v, m, r, n, k)$, uma alocação $(\mu, p, u)$ é ótima se ela é viável e estável e, para toda alocação $\left(\mu^{\prime}, p^{\prime}, u^{\prime}\right)$ viável e estável, vale que $u_{i}^{\prime} \leq u_{i}$ para todo anunciante $i$. Veremos a seguir, na seção 4.4, que nem sempre existe uma alocação ótima.

Problema do leilão genérico: Dado um leilão genérico $(v, m, r, n, k)$, encontrar, se existir, uma alocação ótima para $(v, m, r, n, k)$.

\section{Exemplo}

Considere um leilão genérico com $n=2, k=2$ e os valores verdadeiros, preços máximos e mínimos exibidos na tabela 4.1 .

Tabela 4.1: Exemplo 1.

\begin{tabular}{|c|c|c|}
\hline$v_{i, j}$ & $j=1$ & $j=2$ \\
\hline$i=1$ & 8 & 6 \\
\hline$i=2$ & 10 & 5 \\
\hline
\end{tabular}

\begin{tabular}{|c|c|c|}
\hline$m_{i, j}$ & $j=1$ & $j=2$ \\
\hline$i=1$ & 3 & 5 \\
\hline$i=2$ & 4 & 1 \\
\hline
\end{tabular}

\begin{tabular}{|c|c|c|}
\hline$r_{i, j}$ & $j=1$ & $j=2$ \\
\hline$i=1$ & 0 & 0 \\
\hline$i=2$ & 0 & 0 \\
\hline
\end{tabular}


Neste caso, a única solução ótima é alocar o anunciante 1 ao local 2, com preço 0, e alocar o anunciante 2 ao local $1 \mathrm{com}$ preço 2. Assim, o anunciante 1 tem utilidade 6 (e não tem incentivo em pagar mais do que 2 pelo local 1). Analogamente, o anunciante 2 tem utilidade 8 (e não tem incentivo em pagar mais do que 0 pelo local 2).

Veja outro exemplo do leilão genérico com $n=2, k=2$ e os valores verdadeiros, preços máximos e mínimos exibidos na tabela 4.2.

Tabela 4.2: Exemplo 2.

\begin{tabular}{|c|c|c|}
\hline$v_{i, j}$ & $j=1$ & $j=2$ \\
\hline$i=1$ & 9 & 6 \\
\hline$i=2$ & 10 & 7 \\
\hline
\end{tabular}

\begin{tabular}{|c|c|c|}
\hline$m_{i, j}$ & $j=1$ & $j=2$ \\
\hline$i=1$ & 4 & 5 \\
\hline$i=2$ & 3 & 6 \\
\hline
\end{tabular}

\begin{tabular}{|c|c|c|}
\hline$r_{i, j}$ & $j=1$ & $j=2$ \\
\hline$i=1$ & 1 & 3 \\
\hline$i=2$ & 2 & 4 \\
\hline
\end{tabular}

Neste caso, a única solução ótima é alocar o anunciante 1 ao local 1, com preço 3, e alocar o anunciante 2 ao local 2 com preço 4 . Assim, o anunciante 1 tem utilidade 6 (e não tem incentivo em pagar mais do que 4 pelo local 2). Analogamente, o anunciante 2 tem utilidade 3, e paga 4 pelo local 2 pois este é o preço de reserva. Ademais, seu preço máximo pelo local 1 é 3, e portanto o anunciante 2 não pode pagar mais do que 3 pelo local 1. Após apresentar o algoritmo, vamos mostrar a simulação do algoritmo para esta instância.

\subsection{Grafo do leilão e posição geral}

Aqui iremos analisar algumas propriedades do problema. Primeiramente, note que apesar de ser algo bastante intuitivo, um leilão genérico nem sempre possui uma alocação ótima. Por exemplo, considere um leilão genérico com apenas um local e dois anunciantes tal que $r_{i, 1}<m_{i, 1}<v_{i, 1}$, para $1 \leq i \leq 2$, e $m_{1,1}=m_{2,1}$. Tal leilão não possui alocação ótima. De fato, observe que, nesse exemplo, em uma alocação estável e viável, o preço do local deve ser igual ao preço máximo que os anunciantes oferecem por ele. Considere então as duas possíveis alocações estáveis e viáveis. Ou o local é alocado ao anunciante 1, ou ao anunciante 2. Em ambos os casos, a alocação é estável e viável, porém não é ótima. Nesta seção são apresentadas condições de suficiência para que um leilão genérico possua uma alocação ótima. Seguem algumas definições.

Grafo do leilão: O grafo do leilão de um leilão genérico $(v, m, r, n, k)$ é o multi-grafo bipartido dirigido com pesos e com bipartição $\left(I, J \cup\left\{j_{0}\right\}\right)$, onde $j_{0}$ é um local artificial, $I$ é o conjunto de anunciantes, e $J$ é o conjunto de locais. Existem cinco tipos de arcos nesse grafo. Para cada anunciante $i$ de $I$, e para cada local $j$ de $J$, temos:

- um arco à frente de $i$ para $j$ com peso $-v_{i, j}$

- um arco inverso de $j$ para $i$ com peso $v_{i, j}$,

- um arco de preço mínimo de $i$ para $j$ com peso $r_{i, j}-v_{i, j}$,

- um arco de preço máximo de $i$ para $j$ com peso $m_{i, j}-v_{i, j}$,

- um arco terminal de $i$ para $j_{0}$ com peso 0 .

Passeio alternante: Um passeio alternante no grafo do leilão começa em um vértice $i$, segue alternando arcos à frente e arcos inversos, e termina em um arco de preço mínimo, preço máximo, 
ou arco terminal. Um passeio alternante no grafo do leilão pode revisitar qualquer vértice (diferentemente do passeio alternante no grafo da alocação definido adiante na seção 4.5). Observe que um passeio alternante sempre termina em um local (um elemento do conjunto $J$ ). O peso $w(P)$ de um passeio alternante $P$ é a soma dos pesos de seus arcos.

Posição geral: Um leilão genérico $(v, m, r, n, k)$ está em posição geral se, para todo anunciante $i$, não existem dois passeios alternantes com mesmo peso no grafo do leilão que começam no vértice $i$ e terminam em arcos distintos.

Teorema 4.4.1. Existe uma alocação ótima para o leilão genérico $(v, m, r, n, k)$ se o leilão está em posição geral.

O teorema segue como consequência do algoritmo que iremos apresentar na seção 4.6. Ademais, a posição geral é apenas uma condição de suficiência para que exista uma alocação ótima, mas não é necessária. Por exemplo, consideremos um leilão genérico que não está em posição geral, mas que possui uma alocação ótima: apenas um anunciante e um local, com $r_{1,1}=m_{1,1}<v_{1,1}$. Claramente, a alocação ótima é atribuir o local ao anunciante pelo preço mínimo. Note que esse leilão não está em posição geral. Analisaremos melhor algumas propriedades da posição geral.

Veja que se, para um par $(i, j)$, temos $r_{i, j}=v_{i, j}$, então o passeio alternante $(i, j)$ usando o arco de preço mínimo terá o mesmo peso que o passeio alternante $\left(i, j_{0}\right)$ usando o arco terminal. Portanto, em um leilão em posição geral, não existe um par $(i, j)$ tal que $r_{i, j}=v_{i, j}$. Analogamente, em um leilão em posição geral não existe um par $(i, j)$ tal que $m_{i, j}=v_{i, j}$ ou que $r_{i, j}=m_{i, j}$. Portanto, em um leilão em posição geral temos que $r_{i, j} \neq m_{i, j}, r_{i, j} \neq v_{i, j}$ e $m_{i, j} \neq v_{i, j}$, para todo $i$ e $j$. Em especial, para um anunciante $i$ interessado em um local $j$, vale que $r_{i, j}<m_{i, j}<v_{i, j}$. Também, se $v_{i_{1}, j}=v_{i_{2}, j}$ para dois anunciantes $i_{1}$ e $i_{2}$, então o leilão não está em posição geral pois os passeios alternantes $\left(i_{1}, j, i_{2}, j_{0}\right)$ e $\left(i_{1}, j_{0}\right)$ possuem o mesmo peso. Analogamente, em um leilão em posição geral, para dois anunciantes $i_{1}$ e $i_{2}$, temos que $r_{i_{1}, j} \neq r_{i_{2}, j}$ e $m_{i_{1}, j} \neq m_{i_{2}, j}$, para todo $j$. Em especial, para um local $j \in J$, no máximo um anunciante $i \in I$ tem preço de reserva $r_{i, j}=0$.

\subsection{Grafo de uma alocação}

O chamado grafo de uma alocação $(\mu, p, u)$ é um subgrafo do grafo do leilão com pesos ajustados. Para cada anunciante $i$ de $I$, e para cada local $j$ de $J$, temos

- um arco à frente de $i$ para $j$ com peso $u_{i}+p_{j}-v_{i, j}$, se $r_{i, j} \leq p_{j}<m_{i, j}$,

- um arco inverso de $j$ para $i$ com peso $v_{i, j}-u_{i}-p_{j}$, se $(i, j) \in \mu$,

- um arco de preço mínimo de $i$ para $j$ com peso $u_{i}+r_{i, j}-v_{i, j}$, se $u_{i}+r_{i, j}>v_{i, j}$ e $m_{i, j}>r_{i, j}$,

- um arco de preço máximo de $i$ para $j$ com peso $u_{i}+m_{i, j}-v_{i, j}$, se $u_{i}+m_{i, j}>v_{i, j}$ e $m_{i, j}>r_{i, j}$,

- um arco terminal de $i$ para $j_{0}$ com peso $u_{i}$, se $u_{i}>0$.

Observe que se $(\mu, p, u)$ for estável, então os arcos à frente têm peso não-negativo e se for viável, os arcos inversos têm peso nulo.

Um passeio alternante no grafo da alocação $(\mu, p, u)$ é parecido com um passeio alternante no grafo do leilão. Ele começa em um vértice que representa um anunciante não alocado $i_{0} \operatorname{com} u_{i_{0}}>0$, segue alternando arcos à frente e arcos inversos, e termina com um arco de preço mínimo, preço 
máximo ou arco terminal. Todos os vértices de um passeio alternante devem ser distintos, exceto pelo último vértice, que pode ocorrer duas vezes no passeio.

Seja $P=\left(i_{0}, j_{1}, i_{1}, j_{2}, \ldots, j_{l-1}, i_{l-1}, j_{l}\right)$ um passeio alternante que termina em um arco de preço mínimo no grafo de uma alocação $(\mu, p, u)$. Seu peso, denotado por $w(P)$, é dado por

$\left(u_{0}+p_{1}-v_{0,1}\right)+\left(v_{1,1}-u_{1}-p_{1}\right)+\left(u_{1}+p_{2}-v_{1,2}\right)+\cdots+\left(v_{l-1, l-1}-u_{l-1}-p_{l-1}\right)+\left(u_{l-1}+r_{l-1, l}-v_{l-1, l}\right)$.

Simplificando os termos que ocorrem com sinais negativos e positivos, que são os preços de todos os locais do passeio $P$, com exceção de $j_{l}$, e as utilidades de todos os anunciantes, com exceção de $i_{0}$, obtemos:

$$
\left(u_{0}-v_{0,1}\right)+\left(v_{1,1}\right)+\left(-v_{1,2}\right)+\cdots+\left(v_{l-1, l-1}\right)+\left(r_{l-1, l}-v_{l-1, l}\right) .
$$

Como o grafo de uma alocação é um subgrafo do grafo do leilão, o passeio $P$ também existe no grafo do leilão, e seu peso nesse grafo é

$$
\left(-v_{0,1}\right)+\left(v_{1,1}\right)+\left(-v_{1,2}\right)+\cdots+\left(v_{l-1, l-1}\right)+\left(r_{l-1, l}-v_{l-1, l}\right) .
$$

Obtemos resultados análogos quando $P$ termina em um arco de preço máximo, ou em um arco terminal. Logo, a diferença do peso de um passeio $P$ no grafo de uma alocação e no grafo do leilão é exatamente $u_{0}$. Ou seja, dois caminhos alternantes no grafo do leilão que começam em $i$ e têm pesos iguais implicam em dois potenciais caminhos alternantes no grafo de uma alocação que começam em $i$ e têm pesos iguais.

\subsection{Algoritmo StableMatch}

Apresentaremos um algoritmo que encontra em tempo $O\left(k^{2} n^{2}\right)$ uma alocação que é viável e estável, e que é ótima segundo Aggarwal et al. [AMPP09], para um leilão $(v, m, r, n, k)$ genérico em posição geral. Sugerimos adaptações para a implementação do algoritmo de forma que funcione para um leilão que não esteja em posição geral, conforme descrito na seção 4.12.

O algoritmo é conhecido como StableMatch. O algoritmo começa com uma alocação vazia $\left(\mu^{(0)}, p^{(0)}, u^{(0)}\right)$, onde $\mu^{(0)}=\emptyset$, e, para cada $(i, j) \in I \times J, p_{j}^{(0)}=0$, e $u_{i}^{(0)}=B, \operatorname{com} B=\max \left(v_{i, j}\right)+1$. Na iteração $t$, o algoritmo começa com uma alocação $\left(\mu^{(t)}, p^{(t)}, u^{(t)}\right)$ e tenta construir uma alocação $\left(\mu^{(t+1)}, p^{(t+1)}, u^{(t+1)}\right)$. O algoritmo para quando não consegue atualizar a alocação, e devolve a alocação $\left(\mu^{(T)}, p^{(T)}, u^{(T)}\right)$ da última iteração.

Considere uma alocação $\left(\mu^{(t)}, p^{(t)}, u^{(t)}\right)$ e o grafo dessa alocação $G^{(t)}$. Uma iteração do algoritmo Stable Match consiste dos seguintes passos:

1. Se não houver passeio alternante em $G^{(t)}$, pare e devolva a alocação $\left(\mu^{(t)}, p^{(t)}, u^{(t)}\right)$. Caso contrário, considere um passeio alternante $P$ de peso $w^{(t)}(P)$ mínimo, no grafo $G^{(t)}$. Digamos que $P=\left(i_{0}, j_{1}, i_{1}, j_{2}, i_{2}, \ldots, j_{l}, i_{l}, j_{l+1}\right)$, para algum $l \geq 0$.

2. Seja $d^{(t)}\left(i_{0}, y\right)$ o peso de um caminho de peso mínimo em $G^{(t)}$ de $i_{0}$ a cada vértice $y$, usando apenas arcos à frente e inversos. Se um vértice $y$ não é atingível a partir de $i_{0}$ por um caminho assim, então $d^{(t)}\left(i_{0}, y\right)=\infty$. 
3. Atualize a utilidade de cada anunciante $i$ de $I$, de acordo com o vetor $u^{(t+1)}$, que representa as utilidades ao fim da iteração $t$ :

$$
u_{i}^{(t+1)}=u_{i}^{(t)}-\max \left(w^{(t)}(P)-d^{(t)}\left(i_{0}, i\right), 0\right) .
$$

4. Atualize o preço de cada local $j$ de $J$, de acordo com o vetor $p^{(t+1)}$, definido a partir de

$$
p_{j}^{(t+)}=p_{j}^{(t)}+\max \left(w^{(t)}(P)-d^{(t)}\left(i_{0}, j\right), 0\right) .
$$

Cada preço $p_{j}^{(t+1)}$ vale $p_{j}^{(t+)}$ com uma única exceção. No caso em que o último arco de $P$ é um arco de preço mínimo, o preço do local $j_{l+1}$ é dado por

$$
p_{j_{l+1}}^{(t+1)}=\max \left(p_{j_{l+1}}^{(t+)}, r_{i_{l}, j_{l+1}}\right) .
$$

Deste modo, o preço do local em questão não será menor do que seu preço de reserva.

5. Atualize a alocação $\mu^{(t)}$ ao longo do caminho alternante $P$ para obter a nova alocação $\mu^{(t+1)}$ e depois comece uma nova iteração. A operação de atualização da alocação será explicada detalhadamente a seguir.

Para obtermos a nova alocação $\mu^{(t+1)}$, removemos todos os pares $(i, j)$ de $\mu^{(t)}$ representados pelos arcos inversos do passeio alternante $P$, e inserimos os pares $(i, j)$ que são representados pelos outros arcos de $P$. Esta operação é chamada de diferença simétrica de $\mu(t)$ e $P$, e a denotamos por $\mu^{(t+1)}=\mu^{(t)} \oplus E_{P}=\left(\mu^{(t)} \cup E_{P}\right) \backslash\left(\mu^{(t)} \cap E_{P}\right)$. Além disso, alguns ajustes são necessários. A última aresta de $P$ e o último vértice de $P$ merecem certa atenção durante essa operação. Por isso, vamos considerar três casos:

Caso 1: $P$ termina com um arco terminal. Ou seja, se $j_{l+1}$ é o local artificial, então tome $\mu^{(t+1)}=\mu^{(t)} \oplus\left(E_{P} \backslash\left\{\left(i_{l}, j_{l+1}\right)\right\}\right)$.

Caso 2: $P$ termina com um arco de preço máximo. Consideramos dois subcasos:

Caso 2.1: $l>0$ e $j_{l+1}=j_{l}$. Tome $\mu^{(t+1)}=\mu^{(t)} \oplus\left(E_{P} \backslash\left\{\left(i_{l}, j_{l+1}\right)\right\}\right)$.

Caso 2.2: $l=0$ ou $j_{l+1} \neq j_{l}$. Tome $\mu^{(t+1)}=\mu^{(t)}$.

Caso 3: $P$ termina com um arco de preço mínimo. Consideramos três subcasos:

Caso 3.1: O local $j_{l+1}$ não está alocado em $\mu^{(t)}$. Tome $\mu^{(t+1)}=\mu^{(t)} \oplus E_{P}$.

Caso 3.2: O local $j_{l+1}$ está alocado em $\mu^{(t)}$ e o preço mínimo $r_{i_{l}, j_{l+1}} \leq p_{j_{l+1}}^{(t+)}$. Tome $\mu^{(t+1)}=\mu^{(t)}$.

Caso 3.3: O local $j_{l+1}$ está alocado em $\mu^{(t)}$ a um anunciante $i^{\prime}$, e $r_{i_{l}, j_{l+1}}>p_{j_{l+1}}^{(t+)}$. Se $P$ é um caminho, ou seja, se $P$ visita o vértice $j_{l+1}$ uma única vez, então $\mu^{(t+1)}=\left(\mu^{(t)} \backslash\left\{\left(i^{\prime}, j_{l+1}\right)\right\}\right) \oplus E_{P}$. Caso $P$ visite o vértice $j_{l+1}$ duas vezes, então $j_{l+1}=j_{d}$, para algum $1 \leq d<l$. Vale que $d \neq l$, pois $i_{l}$ está alocado ao local $j_{l}$ mas não pode estar alocado ao local $j_{l+1}$, pois temos que $r_{i_{l}, j_{l+1}}>p_{j_{l+1}}^{(t+)}$. Dessa forma, temos um circuito $C$ no final do passeio $P$ com pelo menos dois anunciantes e dois locais, e temos que $i^{\prime}=i_{d}$. Neste caso, execute $\mu^{(t+1)}=\mu^{(t)} \oplus C$. 


\subsection{Exemplo passo a passo do algoritmo}

Vamos simular a execução do algoritmo para o leilão genérico do exemplo 2 , com $n=2, k=2$ e os valores verdadeiros, preços máximos e mínimos exibidos novamente na tabela 4.3.

Tabela 4.3: Exemplo 2.

\begin{tabular}{|c|c|c|}
\hline$v_{i, j}$ & $j=1$ & $j=2$ \\
\hline$i=1$ & 9 & 6 \\
\hline$i=2$ & 10 & 7 \\
\hline
\end{tabular}

\begin{tabular}{|c|c|c|}
\hline$m_{i, j}$ & $j=1$ & $j=2$ \\
\hline$i=1$ & 4 & 5 \\
\hline$i=2$ & 3 & 6 \\
\hline
\end{tabular}

\begin{tabular}{|c|c|c|}
\hline$r_{i, j}$ & $j=1$ & $j=2$ \\
\hline$i=1$ & 1 & 3 \\
\hline$i=2$ & 2 & 4 \\
\hline
\end{tabular}

- Iteração 0. $p_{1}^{(0)}=0, p_{2}^{(0)}=0, u_{1}^{(0)}=11, u_{2}^{(0)}=11, \mu^{(0)}=\{\} . P^{(0)}=\left(i_{0}=1, j_{1}=1\right)$, passeio com peso 3 que termina em arco de preço mínimo - Caso 3.1.

- Iteração 1. $p_{1}^{(1)}=1, p_{2}^{(1)}=0, u_{1}^{(1)}=8, u_{2}^{(1)}=11, \mu^{(1)}=\{(1,1)\} . P^{(1)}=\left(i_{0}=2, j_{1}=1\right)$, passeio com peso 3 que termina em arco de preço mínimo - Caso 3.3.

- Iteração 2. $p_{1}^{(2)}=2, p_{2}^{(2)}=0, u_{1}^{(2)}=8, u_{2}^{(2)}=8, \mu^{(2)}=\{(2,1)\} \cdot P^{(2)}=\left(i_{0}=1, j_{1}=1, i_{1}=\right.$ $2, j_{2}=1$ ), passeio com peso 5 que termina em arco de preço máximo - Caso 2.1.

- Iteração 3. $p_{1}^{(3)}=3, p_{2}^{(3)}=0, u_{1}^{(3)}=6, u_{2}^{(3)}=7, \mu^{(3)}=\{(1,1)\} \cdot P^{(3)}=\left(i_{0}=2, j_{1}=2\right)$, passeio com peso 4 que termina em arco de preço mínimo - Caso 3.1.

- Iteração 4. $p_{1}^{(4)}=3, p_{2}^{(4)}=4, u_{1}^{(4)}=6, u_{2}^{(4)}=3, \mu^{(4)}=\{(1,1),(2,2)\}$. Não existe passeio alternante, e o algoritmo devolve a solução atual $\left(\mu^{(4)}, p^{(4)}, u^{(4)}\right)$.

\subsection{Consumo de tempo do algoritmo}

Inicialmente, o grafo $G^{(0)}$ da alocação $\left(\mu^{(0)}, p^{(0)}, u^{(0)}\right)$ possui no máximo $n k$ arcos de preço mínimo, $n k$ arcos de preço máximo, e $n$ arcos terminais. Vamos mostrar que, a cada iteração do algoritmo, a soma do número de arcos destes tipos diminui de um. Com isso, conseguiremos concluir que o número de iterações do algoritmo é limitado por $2 n k+n$, ou seja, é $O(n k)$.

Considere uma iteração $t<T$ do algoritmo StableMatch. A última aresta do passeio alternante de peso mínimo $P=\left(i_{0}, j_{1}, i_{1}, \ldots, l_{l}, i_{l}, j_{l+1}\right)$ em $G^{(t)}$ não aparece no grafo $G^{(t+1)}$. Vamos mostrar que a aresta $(i, j)=\left(i_{l}, j_{l+1}\right)$ não aparece em $G^{(t+1)}$, utilizando a regra de atualização das utilidades (4.10).

Caso 1: $(i, j)$ é um arco terminal. Então $w^{(t)}(P)=d^{(t)}\left(i_{0}, i\right)+u_{i}^{(t)}$. Portanto,

$$
u_{i}^{(t+1)}=u_{i}^{(t)}-\left(w^{(t)}(P)-d^{(t)}\left(i_{0}, i\right)\right)=0 .
$$

Caso 2: $(i, j)$ é um arco de preço máximo. Então $w^{(t)}(P)=d^{(t)}\left(i_{0}, i\right)+\left(u_{i}^{(t)}+m_{i, j}-v_{i, j}\right)$. Portanto,

$$
u_{i}^{(t+1)}=u_{i}^{(t)}-\left(w^{(t)}(P)-d^{(t)}\left(i_{0}, i\right)\right)=v_{i, j}-m_{i, j} .
$$

Caso 3: $(i, j)$ é um arco de preço mínimo. Então $w^{(t)}(P)=d^{(t)}\left(i_{0}, i\right)+\left(u_{i}^{(t)}+r_{i, j}-v_{i, j}\right)$. Portanto,

$$
u_{i}^{(t+1)}=u_{i}^{(t)}-\left(w^{(t)}(P)-d^{(t)}\left(i_{0}, i\right)\right)=v_{i, j}-r_{i, j} .
$$


Como a utilidade para os anunciantes nunca aumenta e o preço dos locais nunca diminui ao longo do algoritmo, então o arco $\left(i_{l}, j_{l+1}\right)$ não aparece no grafo da alocação $G^{\left(t^{\prime}\right)}$, para $t^{\prime}>t$.

Basta agora verificarmos qual é o consumo de tempo de uma iteração. Primeiramente, vamos relembrar que o custo dos arcos de $G^{(t)}$ são sempre maiores ou iguais a zero, para toda iteração $t$. Portanto podemos usar o algoritmo de Dijkstra para encontrar o passeio alternante de peso mínimo, o que consome tempo $O(n k)$ para computar os passeios com um único arco, mais $O\left(k^{2}\right)$ para computar os demais passeios, pois existem no máximo $k$ arcos inversos (e portanto, no máximo $k$ anunciantes atingíveis por passeios com mais de um arco). Também utilizamos o algortimo de Dijkstra para atualizar as distâncias $d^{(t)}\left(i_{0}, x\right)$, para $x \in I \cup J$, o que consome tempo $O\left(k^{2}\right)$. Assim, o consumo de tempo de uma iteração do algoritmo é $O\left(n k+k^{2}\right)$.

Como em geral temos $n>k$, concluímos que o consumo de tempo do algoritmo todo é $O(n k) \times$ $O(n k)$, ou seja, $O\left(k^{2} n^{2}\right)$.

\subsection{Correção do algoritmo: viabilidade e estabilidade}

Verificaremos que a alocação obtida ao fim do algoritmo é estável e viável. Para isso, vamos demonstrar alguns invariantes que valem ao início de cada iteração do algoritmo.

- Invariante $(A 1)$ : A alocação $\left(\mu^{(t)}, p^{(t)}, u^{(t)}\right)$ é estável para o leilão genérico $(v, m, r, n, k)$, ou seja, pelo menos uma das seguintes desigualdades é válida:

$$
\begin{array}{r}
u_{i}^{(t)}+p_{j}^{(t)} \geq v_{i, j} \\
p_{j}^{(t)} \geq m_{i, j} \\
u_{i}^{(t)}+r_{i, j} \geq v_{i, j}
\end{array}
$$

para todo $(i, j) \in I \times J$.

- Invariante $(A 2)$ : A alocação $\left(\mu^{(t)}, p^{(t)}, u^{(t)}\right)$ é semi viável, ou seja, para todo par $(i, j) \in \mu^{(t)}$, temos:

$$
\begin{aligned}
& r_{i, j} \leq p_{j}^{(t)} \leq m_{i, j} \\
& u_{i}^{(t)}+p_{j}^{(t)}=v_{i, j} .
\end{aligned}
$$

- Invariante $(A 3)$ : Todo local não alocado em $\mu^{(t)}$ tem preço $p^{(t)}$ zero.

Antes de mostrar que tais invariantes são válidos, vamos verificar que esses invariantes garantem estabilidade e viabilidade ao fim do algoritmo.

Seja $\left(\mu^{(T)}, p^{(T)}, u^{(T)}\right)$ a alocação devolvida pelo algoritmo. Essa alocação é estável, pelo invariante $(A 1)$. Pelo invariante $(A 3)$, os locais não alocados têm preço zero. Ademais, a utilidade para os anunciantes não alocados em $\mu^{(T)}$ é zero, pois se existir um anunciante não alocado em $\mu^{(T)}$ com utilidade positiva, o caminho dele para o local artificial $j_{0}$ com um único arco é um caminho alternante em $G^{(T)}$, e portanto o algoritmo não teria terminado. Isso e o invariante $(A 2)$ garantem que a alocação $\left(\mu^{(T)}, p^{(T)}, u^{(T)}\right)$ é também viável. 
4.9.1 Prova dos invariantes $(A 1),(A 2)$ e $(A 3)$

A prova dos invariantes $(A 1),(A 2)$ e $(A 3)$ depende de dois invariantes extras do algoritmo:

- Invariante (B1): Se um anunciante $i$ está interessado em um local $j$ e $u_{i}^{(t)}+m_{i, j}=v_{i, j}$, então $(i, j) \notin \mu^{(t)}$.

- Invariante (B2): Se um anunciante $i$ está interessado em um local $j$ e $u_{i}^{(t)}+r_{i, j}=v_{i, j}$, então $p_{j}^{(t)} \geq r_{i, j}$.

Para provar $(A 1),(A 2)$ e $(A 3)$, vamos assumir que os invariantes $(B 1)$ e $(B 2)$ valem no ínicio de cada iteração.

Para $t=0$, temos $u_{i}^{(0)}=B, p_{j}^{(0)}=0, r_{i, j} \geq 0$, e $\mu^{(0)}=\emptyset$ para todo anunciante $i$ e local $j$, onde $B=\left(\max v_{i, j}\right)+1$.

Então, para todo par $(i, j)$, vale (4.15), satisfazendo o invariante $(A 1)$. Trivialmente, os invariantes $(A 2)$ e $(A 3)$ também valem ao ínicio da primeira iteração, pois $\mu^{(0)}=\emptyset$, e $p_{j}^{(0)}=0$ para todo $j$ em $J$.

Seja $t \geq 0$ e suponha, por indução, que a alocação $\left(\mu^{(t)}, p^{(t)}, u^{(t)}\right)$ satisfaz os invariantes $(A 1)$, $(A 2)$ e (A3). Suponha que $t$ não é a última iteração do algoritmo, ou seja, $t<T$. Vamos mostrar que a alocação $\left(\mu^{(t+1)}, p^{(t+1)}, u^{(t+1)}\right)$ satisfaz $(A 1),(A 2)$ e $(A 3)$.

\section{Prova do invariante $(A 1)$.}

Consideramos três casos para mostrar que a alocação $\left(\mu^{(t+1)}, p^{(t+1)}, u^{(t+1)}\right)$ satisfaz $(A 1)$, e portanto é estável. Seja $P$ o caminho escolhido no passo 1 do algoritmo. Para cada $i \in I$ e $j \in J$, temos:

Caso 1: $p_{j}^{(t)} \geq m_{i, j}$.

A desigualdade (4.14) é válida, e continua sendo válida para $p_{j}^{(t+1)}$, pois $p_{j}^{(t+1)} \geq p_{j}^{(t)}$.

Caso 2: $r_{i, j} \leq p_{j}^{(t)}<m_{i, j}$.

Como $\left(\mu^{(t)}, p^{(t)}, u^{(t)}\right)$ é estável, sabemos que (4.13) é válida, pois (4.14) não é válida e $p_{j}^{(t)} \geq r_{i, j}$, o que implica que se (4.15) é válida, (4.13) também é. Se $d^{(t)}\left(i_{0}, i\right) \geq w^{(t)}(P)$, então, como $u_{i}^{(t+1)}=u_{i}^{(t)}$ e $p_{j}^{(t+1)} \geq p_{j}^{(t)}$, temos que $u_{i}^{(t+1)}+p_{j}^{(t+1)} \geq u_{i}^{(t)}+p_{j}^{(t)} \geq v_{i, j}$.

Por outro lado, se $d^{(t)}\left(i_{0}, i\right)<w^{(t)}(P)$, então

$$
\begin{array}{r}
u_{i}^{(t+1)}=u_{i}^{(t)}-\left(w^{(t)}(P)-d^{(t)}\left(i_{0}, i\right)\right) \mathrm{e} \\
p_{j}^{(t+1)} \geq p_{j}^{(t+)} \geq p_{j}^{(t)}+\left(w^{(t)}(P)-d^{(t)}\left(i_{0}, j\right)\right) .
\end{array}
$$

Como $r_{i, j} \leq p_{j}^{(t)}<m_{i, j}$, temos um arco à frente de $i$ para $j$ em $G^{(t)}$, e então

$$
d^{(t)}\left(i_{0}, j\right) \leq d^{(t)}\left(i_{0}, i\right)+\left(u_{i}^{(t)}+p_{j}^{(t)}-v_{i, j}\right) .
$$


Juntando (4.18), (4.19) e (4.20), deduzimos que

$$
\begin{aligned}
u_{i}^{(t+1)}+p_{j}^{(t+1)} & \geq\left(u_{i}^{(t)}-w^{(t)}(P)+d^{(t)}\left(i_{0}, i\right)\right)+\left(p_{j}^{(t)}+w^{(t)}(P)-d^{(t)}\left(i_{0}, j\right)\right) \\
& =u_{i}^{(t)}+d^{(t)}\left(i_{0}, i\right)+p_{j}^{(t)}-d^{(t)}\left(i_{0}, j\right) \\
& \geq u_{i}^{(t)}+d^{(t)}\left(i_{0}, i\right)+p_{j}^{(t)}-\left(d^{(t)}\left(i_{0}, i\right)+u_{i}^{(t)}-p_{j}^{(t)}-v_{i, j}\right) \\
& =v_{i, j} .
\end{aligned}
$$

Portanto, $u_{i}^{(t+1)}$ e $p_{j}^{(t+1)}$ satisfazem (4.13).

Caso 3: $p_{j}^{(t)}<r_{i, j}$.

Vamos considerar apenas os casos em que $p^{(t)}<m_{i, j}$, pois caso contrário, o Caso 1 nos garante estabilidade. Ademais, como $0 \leq p^{(t)}<m_{i, j}$, então $i$ está interessado em $j$, e temos que $r_{i, j}<m_{i, j}$. Logo (4.14) não vale.

Como $\left(\mu^{(t)}, p^{(t)}, u^{(t)}\right)$ é estável e não vale (4.14), então com certeza (4.15) é válida, pois (4.13) implica (4.15) neste caso. Se $d^{(t)}\left(i_{0}, i\right) \geq w^{(t)}(P)$, então $u_{i}^{(t+1)}=u_{i}^{(t)}$ e (4.15) continua válida com $u_{i}^{(t+1)}$ no lugar de $u_{i}^{(t)}$.

Por outro lado, se $d^{(t)}\left(i_{0}, i\right)<w^{(t)}(P)$, temos

$$
u_{i}^{(t+1)}=u_{i}^{(t)}-\left(w^{(t)}(P)-d^{(t)}\left(i_{0}, i\right)\right) .
$$

Pelo invariante $(A 2)$, como $p^{(t)}<r_{i, j}$, temos que $(i, j) \notin \mu^{(t)}$. Como $p^{(t)}<r_{i, j}$ e $i$ está interessado em $j$, então, pelo invariante (B2), temos que $u_{i}^{(t)}+r_{i, j} \neq v_{i, j}$. Logo, como vale (4.15), temos que $u_{i}^{(t)}+r_{i, j}>v_{i, j}$. Isso e o fato de $r_{i, j}<m_{i, j}$ implicam que existe arco de preço mínimo de $i$ para $j$ em $G^{(t)}$ e portanto

$$
w^{(t)}(P) \leq d^{(t)}\left(i_{0}, i\right)+\left(u_{i}^{(t)}+r_{i, j}-v_{i, j}\right)
$$

Por (4.21) e (4.22) temos que

$$
\begin{aligned}
u_{i}^{(t+1)} & =u_{i}^{(t)}-w^{(t)}(P)+d^{(t)}\left(i_{0}, i\right) \\
& \geq u_{i}^{(t)}-\left(d^{(t)}\left(i_{0}, i\right)+u_{i}^{(t)}+r_{i, j}-v_{i, j}\right)+d^{(t)}\left(i_{0}, i\right) \\
& =v_{i, j}-r_{i, j} .
\end{aligned}
$$

Concluindo que (4.15) continua válida com $u_{i}^{(t+1)}$ no lugar de $u_{i}^{(t)}$.

Com isso, temos a verificação do invariante $(A 1)$.

\section{Prova do invariante $(A 2)$.}

Vamos primeiro verificar que a alocação $\left(\mu^{(t)}, p^{(t+)}, u^{(t+1)}\right)$ satisfaz $(A 2)$. Para todo par $(i, j) \in \mu^{(t)}$, sabemos que em $G^{(t)}$ existe um arco inverso de $j$ para $i$ de peso 0 , pois $u_{i}^{(t)}+p_{j}^{(t)}=v_{i, j}$, pelo invariante $(A 2)$. Portanto

$$
d^{(t)}\left(i_{0}, i\right)=d^{(t)}\left(i_{0}, j\right)
$$

Assim, pelas atualizações dos passos 3 e 4 do algoritmo, vale que $u_{i}^{(t+1)}+p_{j}^{(t+)}=u_{i}^{(t)}+p_{j}^{(t)}$, mantendo a validade da igualdade (4.17) para $p^{(t+)}$ e $u^{(t+1)}$ no lugar de $p^{(t)}$ e $u^{(t)}$. Para mostrar que (4.16) vale, consideramos dois casos. Se $w^{(t)}(P) \leq d^{(t)}\left(i_{0}, j\right)$, então $p_{j}^{(t+)}=p_{j}^{(t)}$, e (4.16) trivial- 
mente continua válida para $p^{(t+)}$ no lugar de $p^{(t)}$. Caso contrário, $w^{(t)}(P)>d^{(t)}\left(i_{0}, j\right)$, e teremos a atualização de preço

$$
p_{j}^{(t+)}=p_{j}^{(t)}+\left(w^{(t)}(P)-d^{(t)}\left(i_{0}, j\right)\right) .
$$

Se existir o arco de preço máximo de $i$ para $j$, temos que

$$
w^{(t)}(P) \leq d^{(t)}\left(i_{0}, i\right)+\left(u_{i}^{(t)}+m_{i, j}-v_{i, j}\right)
$$

e conseguimos mostrar que (4.16) é válida para $p^{(t+)}$ no lugar de $p^{(t)}$. De fato, ao somar (4.23), (4.24) e (4.25), obtemos que $p^{(t+)} \leq\left(u_{i}^{(t)}+p_{j}^{(t)}-v_{i, j}\right)+m_{i, j}$. Por $(A 2)$, temos que $u_{i}^{(t)}+p_{j}^{(t)}-v_{i, j}=0$, e segue que $p^{(t+)} \leq m_{i, j}$. Por outro lado, $p^{(t+)} \geq p^{(t)} \geq r_{i, j}$, e portanto (4.16) vale com $p^{(t+)}$ no lugar de $p^{(t)}$.

Basta agora mostrar que o arco de preço máximo de $i$ para $j$ existe em $G^{(t)}$, e para isso precisamos verificar que $u_{i}^{(t)}+m_{i, j}>v_{i, j}$. Como $p_{j}^{(t)} \leq m_{i, j}$, temos que $u_{i}^{(t)}+m_{i, j} \geq u_{i}^{(t)}+p_{j}^{(t)}=v_{i, j}$, por $(A 2)$. Além disso, pelo invariante $(B 1)$, temos que $u_{i}^{(t)}+m_{i, j} \neq v_{i, j}$, confirmando a existência do arco de preço máximo.

Agora vamos provar que o invariante $(A 2)$ vale para a alocação $\left(\mu^{(t+1)}, p^{(t+1)}, u^{(t+1)}\right)$. Como o último arco do passeio alternante $P$ não será adicionado à alocação se for um arco de preço máximo ou terminal em $G^{(t)}$, os pares $(i, j) \in \mu^{(t)} \cap \mu^{(t+1)}$ foram tratados no caso acima, pois, para os locais em questão, vale que $p_{j}^{(t+1)}=p_{j}^{(t+)}$. Falta mostrar que os pares $(i, j) \in \mu^{(t+1)} \backslash \mu^{(t)}$ também satisfazem (4.16) e (4.17). Seja $P=\left(i_{0}, j_{1}, i_{1}, \ldots, j_{l}, i_{l}, j_{l+1}\right)$ o caminho alternante escolhido na iteração $t$. Os pares $(i, j) \in \mu^{(t+1)} \backslash \mu^{(t)}$ são arestas de $P$ da forma $(i, j)=\left(i_{x}, j_{x+1}\right)$. Para mostrar que tais pares satisfazem (4.16) e (4.17), vamos considerar dois casos.

Caso 1: $x<l$.

Nesse caso, o par $(i, j)=\left(i_{x}, j_{x+1}\right)$ é um arco à frente no grafo $G^{(t)}$ de peso $u_{i}^{(t)}+p_{j}^{(t)}-v_{i, j}$, e como ele está no passeio alternante $P$ que tem peso mínimo,

$$
d^{(t)}\left(i_{0}, j\right)=d^{(t)}\left(i_{0}, i\right)+\left(u_{i}^{(t)}+p_{j}^{(t)}-v_{i, j}\right) .
$$

Como $w^{(t)}(P) \geq d^{(t)}\left(i_{0}, i\right)$ e $w^{(t)}(P) \geq d^{(t)}\left(i_{0}, j\right)$, foram feitas as seguintes atualizações nos preços e nas utilidades:

$$
\begin{aligned}
& u_{i}^{(t+1)}=u_{i}^{(t)}-\left(w^{(t)}(P)-d^{(t)}\left(i_{0}, i\right)\right), \\
& p_{j}^{(t+1)}=p_{j}^{(t)}+\left(w^{(t)}(P)-d^{(t)}\left(i_{0}, j\right)\right) .
\end{aligned}
$$

Mas então

$$
\begin{aligned}
u_{i}^{(t+1)}+p_{j}^{(t+1)} & =\left(u_{i}^{(t)}-w^{(t)}(P)+d^{(t)}\left(i_{0}, i\right)\right)+\left(p_{j}^{(t)}+w^{(t)}(P)-d^{(t)}\left(i_{0}, j\right)\right) \\
& =u_{i}^{(t)}+d^{(t)}\left(i_{0}, i\right)+p_{j}^{(t)}-d^{(t)}\left(i_{0}, j\right) \\
& =u_{i}^{(t)}+d^{(t)}\left(i_{0}, i\right)+p_{j}^{(t)}-\left(d^{(t)}\left(i_{0}, i\right)+u_{i}^{(t)}+p_{j}^{(t)}-v_{i, j}\right) \\
& =v_{i, j},
\end{aligned}
$$

e (4.17) vale com $u_{i}^{(t+1)}$ e $p_{j}^{(t+1)}$ no lugar de $u_{i}^{(t)}$ e $p_{j}^{(t)}$.

Falta verificar que (4.16) vale com $p_{j}^{(t+1)}$ no lugar de $p_{j}^{(t)}$. Como $(i, j)$ é um arco à frente em 
$G^{(t)}$, vale que $p_{j}^{(t)} \in\left[r_{i, j}, m_{i, j}\right)$. Logo, já que a alocação $\left(\mu^{(t)}, p^{(t)}, u^{(t)}\right)$ é estável, deve valer que $u_{j}^{(t)}+p_{j}^{(t)} \geq v_{i, j}$. Disso e como $p^{(t)}<m_{i, j}$, temos que $u_{i}^{(t)}+m_{i, j}>v_{i, j}$, o que implica que existe um arco de preço máximo de $i$ para $j$ em $G^{(t)}$ com peso $u_{i}^{(t)}+m_{i, j}-v_{i, j}$. Assim,

$$
w^{(t)}(P) \leq d^{(t)}\left(i_{0}, i\right)+\left(u_{i}^{(t)}+m_{i, j}-v_{i, j}\right) .
$$

Para verificar que $p_{j}^{(t+1)}$ satisfaz (4.16), veja que $p_{j}^{(t+1)} \geq p_{j}^{(t)} \geq r_{i, j}$, e que

$$
\begin{aligned}
p_{j}^{(t+1)} & =p_{j}^{(t)}+w^{(t)}(P)-\left(d^{(t)}\left(i_{0}, i\right)+u_{i}^{(t)}+p_{j}^{(t)}-v_{i, j}\right) \\
& =w^{(t)}(P)-d^{(t)}\left(i_{0}, i\right)-u_{i}^{(t)}+v_{i, j} \\
& \leq\left(d^{(t)}\left(i_{0}, i\right)+u_{i}^{(t)}+m_{i, j}-v_{i, j}\right)-d^{(t)}\left(i_{0}, i\right)-u_{i}^{(t)}+v_{i, j} \\
& =m_{i, j} .
\end{aligned}
$$

Caso 2: $x=l$.

Neste caso, temos $(i, j)=\left(i_{l}, j_{l+1}\right) \in \mu^{(t+1)} \backslash \mu^{(t)}$. Assim, o arco $(i, j)$ é um arco de preço mínimo em $G^{(t)}$. Pelo funcionamento do algoritmo, nos únicos casos em que o par $(i, j)=\left(i_{l}, j_{l+1}\right)$ é adicionado à alocação, vale que $r_{i, j} \geq p_{j}^{(t)}$ (casos 3.1 e 3.3 da atualização da alocação), e por ser um arco de preço mínimo, pela regra de atualização de preços (4.12) do algoritmo, vale que $p_{j}^{(t+1)}=r_{i, j}$, concluindo que (4.16) vale com $p_{j}^{(t+1)}$ no lugar de $p_{j}^{(t)}$.

Para mostrar que (4.17) vale com $u_{i}^{(t+1)}$ e $p_{j}^{(t+1)}$ no lugar de $u_{i}^{(t)}$ e $p_{j}^{(t)}$, temos que $p_{j}^{(t+1)}=r_{i, j}$ conforme mostrado acima, e temos que o passeio alternante $P$ terminou com arco $(i, j)$ de preço mínimo de peso $u_{i}^{(t)}+r_{i, j}-v_{i, j}$, e então, por (4.27), temos que:

$$
\begin{aligned}
u_{i}^{(t+1)}+p_{j}^{(t+1)} & =\left(u_{i}^{(t)}-w^{(t)}(P)+d^{(t)}\left(i_{0}, i\right)\right)+r_{i, j} \\
& =u_{i}^{(t)}-\left(d^{(t)}\left(i_{0}, i\right)+u_{i}^{(t)}+r_{i, j}-v_{i, j}\right)+d^{(t)}\left(i_{0}, i\right)+r_{i, j} \\
& =v_{i, j} .
\end{aligned}
$$

Isso conclui a prova de que o invariante $(A 2)$ é válido a cada iteração do algoritmo.

\section{Prova do invariante $(A 3)$.}

Vamos mostrar que a alocação $\left(\mu^{(t+1)}, p^{(t+1)}, u^{(t+1)}\right)$ satisfaz o invariante $(A 3)$.

Como todos os locais não alocados em $\mu^{(t)}$ têm preço $p_{j}^{(t)}=0$, se temos que $r_{i, j}>0$, para todo par $(i, j) \in I \times J^{1}$, então não existe arco à frente $(i, j) \mathrm{em} G^{(t)} \operatorname{com} j \notin \mu^{(t)}$. Assim, a distância $d^{(t)}\left(i_{0}, j\right)$ é infinita, para todo local $j \notin \mu^{(t)}$, fazendo com que seu preço não seja alterado na atualização de preços do passo 4 do algoritmo dado pela atribuição (4.11). Além disso, todos os locais alocados em $\mu^{(t)}$ continuam alocados em $\mu^{(t+1)}$. Portanto, se temos que $r_{i, j}>0$, para todo $\operatorname{par}(i, j) \in I \times J$, o invariante $(A 3)$ vale para a alocação $\left(\mu^{(t+1)}, p^{(t+1)}, u^{(t+1)}\right)$.

Por outro lado, se $r_{i, j}=0$ para um par $(i, j) \in I \times J$ tal que $j \notin \mu^{(t)}$, temos que verificar que o preço do local $j$ não se altera pelo passo 4 do algoritmo dado pela atribuição (4.11) na iteração $t$. Como o arco à frente $(i, j)$ tem o mesmo peso do arco de preço mínimo $(i, j)$ neste caso, então vale

\footnotetext{
${ }^{1}$ Segundo Aggarwal et al. [AMPP09], vale que $r_{i, j}>0$, para todo par $(i, j) \in I \times J$, para um leilão em posição geral. Porém, essa afirmação não é verdadeira conforme apresentado na seção 4.13.
} 
que $w^{(t)}(P) \leq d^{(t)}\left(i_{0}, j\right)$, e o preço não será alterado, ou seja, $p_{j}^{(t+1)}=p_{j}^{(t+)}=p_{j}^{(t)}=0$. Portanto o invariante $(A 3)$ vale para a alocação $\left(\mu^{(t+1)}, p^{(t+1)}, u^{(t+1)}\right)$.

\subsubsection{Invariantes $(B 1)$ e $(B 2)$.}

Aggarwal et al. [AMPP09] não apresentaram uma prova dos invariantes (B1) e (B2). Eles apenas mencionam que esta prova é técnica e que por isso será omitida. Portanto, elaboramos as demonstrações dos invariantes apresentadas a seguir. A prova é por indução em $t$. Observe que (B1) e $(B 2)$ valem para $t=0$. Suponha que $(B 1)$ e $(B 2)$ valem para um $t \geq 0$ e vamos provar que $(B 1)$ e (B2) para $t+1$.

\section{Prova do invariante $(B 1)$.}

Suponha que $m_{i, j}>r_{i, j}$ e $u_{i}^{(t+1)}+m_{i, j}=v_{i, j}$, então vamos provar que vale que $(i, j) \notin \mu^{(t+1)}$. Seja $P=\left(i_{0}, j_{1}, \ldots, i_{\ell}, j_{\ell+1}\right)$ o passeio alternante escolhido pelo algoritmo. Consideramos dois casos.

Caso 1: $u_{i}^{(t+1)}=u_{i}^{(t)}$.

Como $u_{i}^{(t+1)}+m_{i, j}=v_{i, j}$, então $u_{i}^{(t)}+m_{i, j}=v_{i, j}$, como $m_{i, j}>r_{i, j}$, o anunciante $i$ está interessado no local $j$, assim, por $(B 1)$, sabemos que $(i, j) \notin \mu^{(t)}$. Logo, se $(i, j) \notin P$, o par $(i, j)$ não estará alocado em $\mu^{(t+1)}$. Assim, vamos considerar o caso em que $(i, j) \in P$. Existem duas possibilidades para o par $(i, j)=\left(i_{x}, j_{x+1}\right)$ : ou $i$ segue por um arco à frente para $j$ (ou seja, $x<\ell$ ), ou $(i, j$ ) é o último arco do passeio $P$ (ou seja, $x=\ell$ ). Vamos considerar esses dois casos.

Caso 1.1: $x=\ell$. Como $u_{i}^{(t)}+r_{i, j}<u_{i}^{(t)}+m_{i, j}=v_{i, j}$, verificamos que $(i, j)$ não é arco de preço mínimo nem arco de preço máximo. A única possibilidade que resta é $(i, j)$ ser arco terminal, e pelo funcionamento do algoritmo, neste caso, vale que $(i, j) \notin \mu^{(t+1)}$.

Caso 1.2: $x<\ell$. Como $u_{i}^{(t+1)}+r_{i, j}<u_{i}^{(t+1)}+m_{i, j}=v_{i, j}$, temos que (4.13) não vale para $\left(\mu^{(t+1)}, p^{(t+1)}, u^{(t+1)}\right)$. Logo, vale que $p_{j}^{(t+1)} \geq m_{i, j}$, caso contrário nem (4.14) nem (4.15) seriam válidas, contrariando o invariante $(A 1)$. Se $p_{j}^{(t+1)}>m_{i, j}$, então por $(A 2)$ temos que $(i, j) \notin \mu^{(t+1)}$, como queríamos. Resta analisar o caso em $p_{j}^{(t+1)}=m_{i, j}$.

Como $(i, j)$ é um arco à frente vale que $r_{i, j} \leq p_{j}^{(t)}<m_{i, j}$, e $d^{(t)}\left(i_{0}, j\right)=d^{(t)}\left(i_{0}, i\right)+u_{i}^{(t)}+p_{j}^{(t)}-v_{i, j}$. Isso significa que $m_{i, j}=p_{j}^{(t+1)}=p_{j}^{(t)}+w^{(t)}(P)-d^{(t)}\left(i_{0}, j\right)=p_{j}^{(t)}+w^{(t)}(P)-d^{(t)}\left(i_{0}, i\right)-u_{i}^{(t)}-p_{j}^{(t)}+v_{i, j}$. Mas então vale que $d^{(t)}\left(i_{0}, i\right)=w^{(t)}(P)$, e o custo de cada arco de $i$ até $j_{\ell+1}$ deve ser nulo. Em especial, o custo de $(i, j)$ deve ser nulo, ou seja, $u_{i}^{(t)}+p_{j}^{(t)}=v_{i, j}$. Temos que $u_{i}^{(t+1)}+p_{j}^{(t+1)}>$ $u_{i}^{(t)}+p_{j}^{(t)}=v_{i, j}, \operatorname{logo}$ por $(A 2)$ vale que $(i, j) \notin \mu^{(t+1)}$.

Caso 2: $u_{i}^{(t+1)}<u_{i}^{(t)}$.

Neste caso $w^{(t)}(P)>d^{(t)}\left(i_{0}, i\right)$ e $u_{i}^{(t+1)}=u_{i}^{(t)}-w^{(t)}(P)+d^{(t)}\left(i_{0}, i\right)$. Como $u_{i}^{(t+1)}=v_{i, j}-m_{i, j}$, temos que $w^{(t)}(P)=d^{(t)}\left(i_{0}, i\right)+u_{i}^{(t)}+m_{i, j}-v_{i, j}$. Como $u_{i}^{(t)}>u_{i}^{(t+1)}=v_{i, j}-m_{i, j}$, existe arco de preço máximo de $i$ para $j$ em $G^{(t)}$ de peso $u_{i}^{(t)}+m_{i, j}-v_{i, j}$. Então, como o leilão está em posição geral, $P$ termina com o arco $(i, j)$ de preço máximo. Logo, pelo funcionamento da atualização da alocação do algoritmo no caso em que $P$ termina com arco de preço máximo, vale que $(i, j) \notin \mu^{(t+1)}$.

\section{Prova do invariante $(B 2)$.}

Suponha que $m_{i, j}>r_{i, j}, u_{i}^{(t+1)}+r_{i, j}=v_{i, j}$, e vamos provar que vale que $p^{(t+1)} \geq r_{i, j}$. Seja $P=\left(i_{0}, j_{1}, \ldots, i_{\ell}, j_{\ell+1}\right)$ o passeio alternante escolhido pelo algoritmo. Consideramos dois casos. 
Caso 1: $u_{i}^{(t+1)}=u_{i}^{(t)}$.

Neste caso, como $m_{i, j}>r_{i, j}$ e $u_{i}^{(t)}+r_{i, j}=v_{i, j}$, por $(B 2)$ temos que $p_{j}^{(t+1)} \geq p_{j}^{(t)} \geq r_{i, j}$, e portanto o invariante continua valendo no início da iteração $t+1$.

Caso 2: $u_{i}^{(t+1)}<u_{i}^{(t)}$.

Neste caso $w^{(t)}(P)>d^{(t)}\left(i_{0}, i\right)$ e $u_{i}^{(t+1)}=u_{i}^{(t)}-w^{(t)}(P)+d^{(t)}\left(i_{0}, i\right)$. Como $u_{i}^{(t+1)}=v_{i, j}-r_{i, j}$, temos que $w^{(t)}(P)=d^{(t)}\left(i_{0}, i\right)+u_{i}^{(t)}+r_{i, j}-v_{i, j}$. Como $u_{i}^{(t)}>u_{i}^{(t+1)}=v_{i, j}-r_{i, j}$, existe arco de preço mínimo de $i$ para $j$ em $G^{(t)}$ de peso $u_{i}^{(t)}+r_{i, j}-v_{i, j}$. Então, como o leilão está em posição geral, $P$ termina com o arco $(i, j)$ de preço mínimo. Logo, pelo funcionamento da atualização de preços do algoritmo no caso em que $P$ termina com arco de preço mínimo, vale que $p^{(t+1)} \geq r_{i, j}$.

\subsection{Propriedades de alocações viáveis e estáveis}

As seguintes propriedades são essenciais para a demonstração da otimalidade da alocação produzida pelo algoritmo. Aggarwal et al. [AMPP09] consideram tais propriedades sem apresentar provas para elas, assim elaboramos as demonstrações aqui apresentadas.

Seja $(v, m, r, n, k)$ um leilão em posição geral e $(\mu, p, u)$ uma alocação estável e viável para esse leilão. Como sempre, denotamos por $I$ o conjunto de anunciantes e por $J$ o conjunto de locais.

Dizemos que um par $(i, j)$ em $I \times J$ é $m$-justo se $(i, j) \in \mu$ e $p_{j}=m_{i, j}$, e um $\operatorname{par}(i, j) \notin \mu$ é $p$-justo se $u_{i}+p_{j}=v_{i, j}$. Um caminho no grafo da alocação $(\mu, p, u)$ é $j$-alternante se começa num arco $(i, j)$ m-justo e alterna arcos p-justos e pares de $\mu$.

Fato 1. Não existe caminho j-alternante que termine em um anunciante desalocado.

Demonstração. Seja $H=\left(i_{1}, j_{1}, \ldots, i_{\ell}\right)$ um passeio j-alternante que termine em um $i_{\ell}$ desalocado. Assim, no grafo do leilão, o passeio alternante $P_{1}=\left(i_{\ell}, j_{0}\right)$ usando arco terminal tem peso 0 , e o passeio alternante $P_{2}=\left(i_{\ell}, j_{\ell-1}, i_{\ell-1}, j_{\ell-2}, \ldots, i_{2}, j_{1}, i_{1}, j_{1}\right)$ terminando em arco de preço máximo tem mesmo peso 0 também, contrariando a posição geral do leilão. De fato, vale que

$$
\begin{aligned}
w\left(P_{2}\right) & =-v_{i_{\ell}, j_{\ell-1}}+v_{i_{\ell-1}, j_{\ell-1}}-\cdots-v_{i_{2}, j_{1}}+v_{i_{1}, j_{1}}+\left(m_{i_{1}, j_{1}}-v_{i_{1}, j_{1}}\right) \\
& =-\left(u_{i_{\ell}}+p_{j_{\ell-1}}\right)+\left(u_{i_{\ell-1}}+p_{j_{\ell-1}}\right)-\cdots-\left(u_{i_{2}}+p_{j_{1}}\right)+\left(u_{i_{1}}+p_{j_{1}}\right)+\left(m_{i_{1}, j_{1}}-v_{i_{1}, j_{1}}\right) \\
& =u_{i_{\ell}}+u_{i_{1}}+m_{i_{1}, j_{1}}-v_{i_{1}, j_{1}} \\
& =u_{i_{\ell}}-p_{j_{1}}+m_{i_{1}, j_{1}}=-u_{i_{\ell}}=0,
\end{aligned}
$$

pois $p_{j_{1}}=m_{i_{1}, j_{1}}$.

Fato 2. Nâo existe caminho $j$-alternante que termine em um arco $(i, j) \in \mu$ com $p_{j}=r_{i, j}$.

Demonstração. Seja $H=\left(i_{1}, j_{1}, \ldots, i_{\ell}, j_{\ell}\right)$ um passeio j-alternante que termine em par $\left(i_{\ell}, j_{\ell}\right)$ com $p_{j_{\ell}}=r_{i_{\ell}, j_{\ell}}$. Assim, no grafo do leilão, o passeio alternante $P_{1}=\left(i_{\ell}, j_{\ell}\right)$ usando arco de preço mínimo tem peso $r_{i_{\ell}, j_{\ell}}-v_{i_{\ell}, j_{\ell}}=-u_{i_{\ell}}$, e o passeio alternante $P_{2}=\left(i_{\ell}, j_{\ell-1}, i_{\ell-1}, j_{\ell-2}, \ldots, i_{2}, j_{1}, i_{1}, j_{1}\right)$ terminando em arco de preço máximo tem mesmo peso $-u_{i_{\ell}}$ também, contrariando a posição geral 
do leilão. De fato, vale que

$$
\begin{aligned}
w\left(P_{2}\right) & =-v_{i_{\ell}, j_{\ell-1}}+v_{i_{\ell-1}, j_{\ell-1}}-\cdots-v_{i_{2}, j_{1}}+v_{i_{1}, j_{1}}+\left(m_{i_{1}, j_{1}}-v_{i_{1}, j_{1}}\right) \\
& =-\left(u_{i_{\ell}}+p_{j_{\ell-1}}\right)+\left(u_{i_{\ell-1}}+p_{j_{\ell-1}}\right)-\cdots-\left(u_{i_{2}}+p_{j_{1}}\right)+\left(u_{i_{1}}+p_{j_{1}}\right)+\left(m_{i_{1}, j_{1}}-v_{i_{1}, j_{1}}\right) \\
& =u_{i_{\ell}}+u_{i_{1}}+m_{i_{1}, j_{1}}-v_{i_{1}, j_{1}} \\
& =u_{i_{\ell}}-p_{j_{1}}+m_{i_{1}, j_{1}}=-u_{i_{\ell}},
\end{aligned}
$$

pois $p_{j_{1}}=m_{i_{1}, j_{1}}$.

Lema 4.10.1. Se $(\mu, p, u)$ é uma alocação viável e estável em $(v, m, r, n, k)$ então existe uma alocação $\left(\mu^{\prime}, p^{\prime}, u^{\prime}\right)$ viável e estável sem pares m-justos tal que $u_{i}^{\prime} \geq u_{i}$ para todo $i \in I$ e $p_{j}^{\prime} \leq p_{j}$ para todo $j \in J$.

Demonstração. A prova é por indução no número de pares m-justos de $(\mu, p, u)$. Se não há tais pares, não há nada a provar. Seja então $\left(i_{1}, j_{1}\right)$ um par m-justo. Seja $\hat{I}$ o conjunto de todos os anunciantes em $I$ tais que existe um passeio j-alternante de $i_{1}$ até cada anunciante de $\hat{I}$. Faça $\hat{I}:=\hat{I} \cup\left\{i_{1}\right\}$. Seja $\hat{J}$ o conjunto de todos os locais em $J$ tais que existe um passeio j-alternante de $i_{1}$ até cada local em $\hat{J}$.

Fato 3. Não existe $(i, j) \notin \mu$ tal que $j \in \hat{J}, p_{j}=m_{i, j}, u_{i}+p_{j}<v_{i, j}$ e $u_{i}+r_{i, j}<v_{i, j}$.

Demonstração. Seja $H=\left(i_{1}, j_{1}, \ldots, j_{\ell-1}\right)$ um passeio j-alternante para o qual existe um anunciante $i_{\ell} \operatorname{com} p_{j_{\ell-1}}=m_{i_{\ell}, j_{\ell-1}}, u_{i_{\ell}}+p_{j_{\ell-1}}<v_{i_{\ell}, j_{\ell-1}}$ e $u_{i_{\ell}}+r_{i_{\ell}, j_{\ell-1}}<v_{i_{\ell}, j_{\ell-1}}$. Assim, no grafo do leilão, o passeio alternante $P_{1}=\left(i_{\ell}, j_{\ell-1}\right)$ usando arco de preço máximo tem peso $m_{i_{\ell}, j_{\ell-1}}-v_{i_{\ell}, j_{\ell-1}}$, e o passeio alternante $P_{2}=\left(i_{\ell}, j_{\ell-1}, i_{\ell-1}, j_{\ell-2}, \ldots, i_{2}, j_{1}, i_{1}, j_{1}\right)$ terminando em arco de preço máximo tem mesmo peso $-v_{i_{\ell}, j_{\ell-1}}+m_{i_{\ell}, j_{\ell-1}}$, contrariando a posição geral do leilão. De fato, vale que

$$
\begin{aligned}
w\left(P_{2}\right) & =-v_{i_{\ell}, j_{\ell-1}}+v_{i_{\ell-1}, j_{\ell-1}}-\cdots-v_{i_{2}, j_{1}}+v_{i_{1}, j_{1}}+\left(m_{i_{1}, j_{1}}-v_{i_{1}, j_{1}}\right) \\
& =-v_{i_{\ell}, j_{\ell-1}}+\left(u_{i_{\ell-1}}+p_{j_{\ell-1}}\right)-\cdots-\left(u_{i_{2}}+p_{j_{1}}\right)+\left(u_{i_{1}}+p_{j_{1}}\right)+\left(m_{i_{1}, j_{1}}-v_{i_{1}, j_{1}}\right) \\
& =-v_{i_{\ell}, j_{\ell-1}}+p_{j_{\ell-1}}+u_{i_{1}}+m_{i_{1}, j_{1}}-v_{i_{1}, j_{1}} \\
& =-v_{i_{\ell}, j_{\ell-1}}+p_{j_{\ell-1}}=-v_{i_{\ell}, j_{\ell-1}}+m_{i_{\ell}, j_{\ell-1}},
\end{aligned}
$$

pois $p_{j_{\ell-1}}=m_{i_{\ell}, j_{\ell-1}}$.

Para $\epsilon>0$, seja $\left(\mu^{\prime}, p^{\prime}, u^{\prime}\right)$ definida por $\mu^{\prime}=\mu, p_{j}^{\prime}=p_{j}-\epsilon$ para $j \in \hat{J}$ e $p_{j}^{\prime}=p_{j}$ para $j \notin \hat{J}$, $u_{i}^{\prime}=u_{i}+\epsilon$ para $i \in \hat{I}$ e $u_{i}^{\prime}=u_{i}$ para $i \notin \hat{I}$. Pelos fatos 1,2 e 3 , existe $\epsilon>0$ tal que $\left(\mu^{\prime}, p^{\prime}, u^{\prime}\right)$ é estável e viável. Ademais, o par $\left(i_{1}, j_{1}\right)$ não é m-justo em $\left(\mu^{\prime}, p^{\prime}, u^{\prime}\right)$, e nenhum novo par m-justo foi produzido.

Para argumentar que $\left(\mu^{\prime}, p^{\prime}, u^{\prime}\right)$ é estável e viável, note que as condições de estabilidade e viabilidade para cada par $(i, j) \operatorname{com} i \notin \hat{I}$ e $j \notin \hat{J}$ ou $(i, j) \in \mu$ não são afetadas pela alteração feita, e o fato 1 nos permite escolher $\epsilon>0$ que garanta viabilidade. Para um par $(i, j)$ com $i \in \hat{I}$ e $j \notin \hat{J}$, as condições de estabilidade também continuam valendo, pois aumentamos as utilidades e diminuímos os preços. Para um $\operatorname{par}(i, j) \notin \mu \operatorname{com} j \notin \hat{J}$, se $(i, j)$ é p-justo, a soma e subtração de $\epsilon$ se compensam e o fato 0 garante viabilidade, e se $(i, j)$ não é p-justo, então o fato 2 nos permite escolher $\epsilon>0$ que garanta estabilidade, pois teremos folga em alguma desigualdade das condições de estabilidade. 
Analogamente, dizemos que um par $(i, j)$ em $I \times J$ é $r$-justo se $(i, j) \notin \mu$ e $u_{i}+r_{i, j}=v_{i, j}$.

Lema 4.10.2. Se $(\mu, p, u)$ é uma alocação viável e estável em $(v, m, r, n, k)$ sem pares $m$-justos, então existe uma alocação $\left(\mu^{\prime}, p^{\prime}, u^{\prime}\right)$ viável e estável sem pares $m$-justos nem $r$-justos tal que $u_{i}^{\prime} \geq u_{i}$ para todo $i \in I$ e $p_{j}^{\prime} \leq p_{j}$ para todo $j \in J$.

A demonstração do lema 4.10.2 é semelhante à demonstração do lema 4.10.1, e por isso será omitida. Mas note que, se $\left(i_{1}, j_{1}\right)$ é um par r-justo, ao ajustar os preços e utilidades, o par $\left(i_{1}, j_{1}\right)$ deixa de ser r-justo podendo até gerar novos pares r-justos, mas o par $\left(i_{1}, j_{1}\right)$ nunca mais será justo ao realizar esse ajuste novamente, e portanto podemos construir iterativamente uma nova alocação sem pares r-justos. Ademais, note que, neste caso é necessário adaptar os fatos 1, 2 e 3 para, em vez do último arco m-justo, usar o arco r-justo no passeio. Concretamente, podemos utilizar o passeio j-alternante $P_{2}=\left(i_{\ell}, j_{\ell-1}, i_{\ell-1}, j_{\ell-2}, \ldots, i_{2}, j^{*}, i_{1}, j_{1}\right)$ terminando em arco de preço mínimo, tal que $\left(i_{1}, j^{*}\right) \in \mu$.

\subsection{Correção do algoritmo: otimalidade da alocação produzida}

Mostraremos que a alocação $\left(\mu^{(T)}, p^{(T)}, u^{(T)}\right)$ devolvida pelo algoritmo é ótima para um leilão genérico $(v, m, r, n, k)$ em posição geral. Para verificar que a alocação devolvida pelo algoritmo é ótima, vamos mostrar o seguinte lema.

Lema 4.11.1. Para toda alocação $\left(\mu^{\prime}, p^{\prime}, u^{\prime}\right)$ viável e estável, vale que $u_{i}^{(t)} \geq u_{i}^{\prime}$ para todo anunciante i em $I$, e $p_{j}^{(t)} \leq p_{j}^{\prime}$ para todo local $j$ em $J$, ao ínicio de cada iteração $t$ do algoritmo.

Veja que isso é suficiente para que a alocação devolvida pelo algoritmo seja ótima, pois já sabemos que ela é estável e viável. Vamos mostrar o lema por indução em $t$. Para $t=0$, temos que $p_{j}^{\prime} \geq 0=p_{j}^{(t)}$, para todo $j$ de $J$, e $u_{i}^{\prime} \leq B=u_{i}^{(t)}$, para todo $i$ de $I$. Para $t \geq 0$, suponha que $u_{i}^{(t)} \geq u_{i}^{\prime}$ para todo $i$ de $I$ e $p_{j}^{(t)} \leq p_{j}^{\prime}$ para todo $j$ de $J$. A prova do lema 4.11.1 é composta pelas proposições 1 e 2 enunciadas a seguir e demonstradas mais adiante.

Proposição 1: $u_{i}^{(t+1)} \geq u_{i}^{\prime}$ e $p_{j}^{(t+)} \leq p_{j}^{\prime}$ para todo $(i, j)$ em $I \times J$.

Proposição 2: $p_{j}^{(t+1)} \leq p_{j}^{\prime}$ para todo $(i, j)$ em $I \times J$.

Considere as atualizações de preços e utilidades feitas nos passos 3 e 4 do algoritmo como funções contínuas numa variável $x$. Denotamos, para todo $i \in I$, por $u_{i}(x)$ a função contínua não-crescente

$$
u_{i}(x)=u_{i}^{(t)}-\max \left(x-d^{(t)}\left(i_{0}, i\right), 0\right)
$$

e para todo $j \in J$ por $p_{j}(x)$ a função contínua não-descrescente

$$
p_{j}(x)=p_{j}^{(t)}+\max \left(x-d^{(t)}\left(i_{0}, j\right), 0\right) .
$$

Vamos provar que não existe uma alocação $\left(u^{\prime}, p^{\prime}, \mu^{\prime}\right)$ estável e viável, tal que para algum $y^{\prime} \in$ $\left[0, w^{(t)}(P)\right]$ vale que $u_{i}\left(y^{\prime}\right)<u_{i}^{\prime}$ para algum $i \in I$, ou $p_{j}\left(y^{\prime}\right)>p_{j}^{\prime}$ para algum $j \in J$. Isso implicará que $u_{i}^{(t+1)} \geq u_{i}^{\prime}$, para todo $i \in I$, e $p_{j}^{(t+)} \leq p_{j}^{\prime}$, para todo $j \in J$, para toda alocação $\left(u^{\prime}, p^{\prime}, \mu^{\prime}\right)$ estável e viável. Vamos provar esse fato por contradição. 
Suponha que exista uma alocação $\left(u^{\prime}, p^{\prime}, \mu^{\prime}\right)$ estável e viável, tal que para algum $y^{\prime} \in\left[0, w^{(t)}(P)\right]$ vale que $u_{i}\left(y^{\prime}\right)<u_{i}^{\prime}$ para algum $i \in I$, ou $p_{j}\left(y^{\prime}\right)>p_{j}^{\prime}$ para algum $j \in J$. Pelos lemas $4.10 .1 \mathrm{e}$ lema 4.10.2, podemos assumir que não há pares m-justos nem pares r-justos em $\left(\mu^{\prime}, p^{\prime}, u^{\prime}\right)$. Seja $y \in\left[0, w^{(t)}(P)\right]$ o maior valor possível tal que $u_{i}(y) \geq u_{i}^{\prime}$ para todo $i \in I$ e $p_{j}(y) \leq p_{j}^{\prime}$ para todo $j \in J$, e definimos os conjuntos $I^{\prime}$ e $J^{\prime}$ por

$$
\begin{gathered}
I^{\prime}=\left\{i \in I \mid u_{i}(y)=u_{i}^{\prime} \text { e } d^{(t)}\left(i_{0}, i\right) \leq y\right\}, \\
J^{\prime}=\left\{j \in J \mid p_{j}(y)=p_{j}^{\prime} \text { e } d^{(t)}\left(i_{0}, j\right) \leq y\right\} .
\end{gathered}
$$

Note que $y<y^{\prime} \leq w^{(t)}(P)$ por causa da monotonicidade das funções $u_{i}(x)$ e $p_{j}(x)$.

Antes de demonstrar as proposições, vamos mostrar as seguintes afirmações para concluir que todo $i \in I^{\prime}$ está alocado em $\mu^{(t)}$ a um local $j \in J^{\prime}$ : todo local $j \in J^{\prime}$ está alocado em $\mu^{(t)}$ a um anunciante $i \in I^{\prime}$; e todo anunciante $i \in I^{\prime}$ está alocado em $\mu^{\prime}$ a um local $j \in J^{\prime}$.

Fato 4. Todo local $j \in J^{\prime}$ está alocado em $\mu^{(t)}$ a um anunciante $i \in I^{\prime}$.

Demonstração. Como $j \in J^{\prime}$, tem-se que $d^{(t)}\left(i_{0}, j\right) \leq y<w^{(t)}(P)$. Se $j$ estivesse desalocado em $\mu^{(t)}$, pelo invariante $(A 3), p_{j}^{(t)}=0$ e todos os arcos a frente incidentes em $j$ teriam o mesmo peso que os arcos de preço mínimo correspondentes, pois só existiria arco à frente caso $r_{i, j}=0$. Assim valeria que $d^{(t)}\left(i_{0}, j\right)=\infty$, ou $d^{(t)}\left(i_{0}, j\right) \geq w^{(t)}(P)$, uma contradição. Portanto, o local $j$ está alocado em $\mu^{(t)}$ a algum anunciante $i \in I$.

Queremos mostrar que $i \in I^{\prime}$, ou seja, que $d^{(t)}\left(i_{0}, i\right) \leq y$ e $u_{i}(y)=u_{i}^{\prime}$. Como $j$ está alocado a $i$ em $\mu^{(t)}$, há arco inverso de $j$ para $i$ em $G^{(t)}$ e seu peso é 0 pelo invariante (A2). Assim, $d^{(t)}\left(i_{0}, i\right)=d^{(t)}\left(i_{0}, j\right) \leq y$, pois $j \in J^{\prime}$. Resta mostrar que $u_{i}(y)=u_{i}^{\prime}$. Pela escolha de $y$, temos que $u_{i}(y) \geq u_{i}^{\prime}$. Como $d^{(t)}\left(i_{0}, i\right)=d^{(t)}\left(i_{0}, j\right)$, temos também que $u_{i}(y)+p_{j}(y)=u_{i}^{(t)}+p_{j}^{(t)}=v_{i, j}$ pela definição de $u_{i}(x)$ e $p_{j}(x)$ e pelo invariante $(A 2)$. Ou seja, $u_{i}(y)=v_{i, j}-p_{j}(y)=v_{i, j}-p_{j}^{\prime}$ pois $j \in J^{\prime}$.

Se mostrarmos que $u_{i}^{\prime}+p_{j}^{\prime} \geq v_{i, j}$, a prova termina, pois, pela equação acima, teremos $u_{i}(y) \leq u_{i}^{\prime}$, implicando que $u_{i}(y)=u_{i}^{\prime}$. Para isso, basta mostrar que $p_{j}^{\prime} \in\left[r_{i, j}, m_{i, j}\right)$, pois isso implica que $u_{i}^{\prime}+p_{j}^{\prime} \geq v_{i, j}$ já que $\left(\mu^{\prime}, p^{\prime}, u^{\prime}\right)$ é estável. Veja que $p_{j}^{\prime} \in\left[r_{i, j}, m_{i, j}\right]$ pois $\left(\mu^{\prime}, p^{\prime}, u^{\prime}\right)$ é viável. Então, temos que mostrar apenas que $p_{j}^{\prime}<m_{i, j}$.

Pela posição geral, $r_{i, j}<m_{i, j}$. Os invariantes $(A 2)$ e $(B 1)$ então implicam que $p_{j}^{(t)} \in\left[r_{i, j}, m_{i, j}\right)$. Consequentemente, existe um arco de preço máximo de $i$ para $j$ em $G^{(t)}$ já que $r_{i, j}<m_{i, j}$ e $u_{i}^{(t)}+m_{i, j}>u_{i}^{(t)}+p_{j}^{(t)}=v_{i, j}$. Logo $w^{(t)}(P) \leq d^{(t)}\left(i_{0}, i\right)+u_{i}^{(t)}+m_{i, j}-v_{i, j}$. Mas então

$$
\begin{aligned}
p_{j}^{\prime}=p_{j}(y) & =p_{j}^{(t)}+y-d^{(t)}\left(i_{0}, j\right) \\
& =p_{j}^{(t)}+y-d^{(t)}\left(i_{0}, i\right) \\
& <p_{j}^{(t)}+w^{(t)}(P)-d^{(t)}\left(i_{0}, i\right) \\
& \leq p_{j}^{(t)}+u_{i}^{(t)}+m_{i, j}-v_{i, j} \\
& =m_{i, j} .
\end{aligned}
$$

Assim, terminamos a verificação de que todo local $j \in J^{\prime}$ está alocado em $\mu^{(t)}$ a um anunciante $i \in I^{\prime}$. 
Fato 5. Todo anunciante $i \in I^{\prime}$ está alocado em $\mu^{\prime}$ a um local $j \in J^{\prime}$.

Demonstração. Observe que $u_{i}^{\prime}>0$ já que

$$
u_{i}^{\prime}=u_{i}(y)=u_{i}^{(t)}-\left(y-d^{(t)}\left(i_{0}, i\right)\right)>u_{i}^{(t)}-\left(w^{(t)}(P)-d^{(t)}\left(i_{0}, i\right)\right)=u_{i}^{(t+1)} \geq 0 .
$$

Assim o anunciante $i$ está alocado em $\mu^{\prime}$ a algum local $j \in J$.

Queremos mostrar que $j \in J^{\prime}$, ou seja, que $p_{j}(y)=p_{j}^{\prime}$ e $d^{(t)}\left(i_{0}, j\right) \leq y$. Pela escolha de $y$, temos que $p_{j}(y) \leq p_{j}^{\prime}$. Se provarmos que $p_{j}(y) \geq v_{i, j}-u_{i}(y)$ então, como $u_{i}(y)=u_{i}^{\prime}$ já que $i \in I^{\prime}$ e $u_{i}^{\prime}+p_{j}^{\prime}=v_{i, j}$ pois $\left(\mu^{\prime}, p^{\prime}, u^{\prime}\right)$ é viável, temos que

$$
p_{j}(y) \geq v_{i, j}-u_{i}(y)=v_{i, j}-u_{i}^{\prime}=p_{j}^{\prime} .
$$

Ou seja, para mostrar que $p_{j}(y)=p_{j}^{\prime}$, é suficiente mostrarmos que $p_{j}(y) \geq v_{i, j}-u_{i}(y)$.

Para isso, primeiramente iremos mostrar que existe em $G^{(t)}$ arco à frente de $i$ para $j$, ou seja, que $r_{i, j} \leq p_{j}^{(t)}<m_{i, j}$. Como $\left(\mu^{\prime}, p^{\prime}, u^{\prime}\right)$ é viável e $(i, j) \in \mu^{\prime}$, temos que $p_{j}^{\prime} \in\left[r_{i, j}, m_{i, j}\right]$. Por indução, temos $p_{j}^{(t)} \leq p_{j}^{\prime}$. Logo, $p_{j}^{(t)} \leq m_{i, j}$. Como não há par $(i, j) \in \mu^{\prime}$ m-justo, se $(i, j) \in \mu^{\prime}$ então $p_{j}^{\prime} \neq m_{i, j}$, e portanto temos que $p^{(t)}<m_{i, j}$.

Se existir arco de preço mínimo de $i$ para $j$ em $G^{(t)}$, então $w^{(t)}(P) \leq d^{(t)}\left(i_{0}, i\right)+u^{(t)}+r_{i, j}-v_{i, j}$, e assim teríamos $u_{i}\left(w^{(t)}(P)\right) \geq v_{i, j}-r_{i, j}$. Mas, como $i$ está alocado a $j$ em $\mu^{\prime}$, temos que $u_{i}^{\prime} \leq v_{i, j}-r_{i, j}$, e como $u_{i}(y)=u_{i}^{\prime}$ e $u_{i}\left(w^{(t)}(P)\right)<u_{i}^{\prime}$ pela escolha de $y$, então temos $u_{i}\left(w^{(t)}(P)\right)<u_{i}^{\prime} \leq v_{i, j}-r_{i, j}$, o que implica que não existe arco de preço mínimo de $i$ para $j \mathrm{em} G^{(t)}$, uma contradição. Portanto vale que $u_{i}^{(t)}+r_{i, j} \leq v_{i, j}$. A alocação $\left(\mu^{(t)}, p^{(t)}, u^{(t)}\right)$ é estável. Como $p_{j}^{(t)}<m_{i, j}$, então ou $u_{i}^{(t)}+r_{i, j}=v_{i, j}$, ou $u_{i}^{(t)}+p_{j}^{(t)} \geq v_{i, j}$. Se vale a primeira condição, então, pelos invariantes $(A 2)$ e $(B 2)$, temos que $p_{j}^{(t)} \geq r_{i, j}$; se vale a segunda condição, também temos que $p_{j}^{(t)} \geq r_{i, j}$. Portanto, temos que $r_{i, j} \leq p_{j}^{(t)}<m_{i, j}$, e existe arco à frente de $i$ para $j$ em $G^{(t)}$. Assim, temos que

$$
d^{(t)}\left(i_{0}, j\right) \leq d^{(t)}\left(i_{0}, i\right)+\left(u_{i}^{(t)}+p_{j}^{(t)}-v_{i, j}\right) .
$$

Da definição de $p_{j}(y)$, vale que $p_{j}(y) \geq p_{j}^{(t)}+y-d^{(t)}\left(i_{0}, j\right)$. Portanto,

$$
\begin{aligned}
p_{j}(y) & \geq p_{j}^{(t)}+y-\left(d^{(t)}\left(i_{0}, i\right)+u_{i}^{(t)}+p_{j}^{(t)}-v_{i, j}\right) \\
& =v_{i, j}-\left(u_{i}^{(t)}-\left(y-d^{(t)}\left(i_{0}, i\right)\right)\right) \\
& =v_{i, j}-u_{i}(y),
\end{aligned}
$$

o que conclui a prova de que $p_{j}(y)=p_{j}^{\prime}$.

Resta mostrar que $d^{(t)}\left(i_{0}, j\right) \leq y$. Como $u_{i}(y)=u_{i}^{(t)}-y+d^{(t)}\left(i_{0}, i\right)$, de (4.30) deduzimos que

$$
\begin{aligned}
d^{(t)}\left(i_{0}, j\right) & \leq u_{i}(y)+y+p_{j}^{(t)}-v_{i, j} \\
& =u_{i}^{\prime}+y+p_{j}^{(t)}-v_{i, j} \\
& \leq y+u_{i}^{\prime}+p_{j}(y)-v_{i, j} \\
& =y+p_{j}(y)-p_{j}^{\prime} \\
& =y
\end{aligned}
$$

pois $i \in I^{\prime}$ pela hipótese de indução pela viabilidade de $\left(\mu^{\prime}, p^{\prime}, u^{\prime}\right)$ pelo que provamos anteriormente. 
Das duas afirmações acima, podemos deduzir que $\left|I^{\prime}\right|=\left|J^{\prime}\right|$. Portanto, vale também o reverso destas afirmações. Ou seja, todo local $j \in J^{\prime}$ está alocado em $\mu^{\prime}$ a um anunciante $i \in I^{\prime}$, e todo anunciante $i \in I^{\prime}$ está alocado em $\mu^{(t)}$ a um local $j \in J^{\prime}$.

\subsubsection{Prova da proposição 1}

Considere $j \in J^{\prime}$ com o menor valor $d^{(t)}\left(i_{0}, j\right)$. Considere um caminho de peso mínimo em $G^{(t)}$ de $i_{0}$ para $j$ que usa apenas arcos à frente e arcos inversos. O vértice anterior a $j$ nesse caminho é um anunciante $i$ que não está em $I^{\prime}$, pois ele não está alocado em $\mu^{(t)}$ a um local em $J^{\prime}$, pela escolha de $j$ e pelos fatos 4 e 5 .

Vamos mostrar que $u_{i}^{\prime}$ e $p_{j}^{\prime}$ não satisfazem as condições de estabilidade. Para que a alocação $\left(\mu^{\prime}, p^{\prime}, u^{\prime}\right)$ seja estável, pelo menos uma das seguintes equações deve ser válida:

$$
\begin{aligned}
u_{i}^{\prime}+p_{j}^{\prime} & \geq v_{i, j}, \\
u_{i}^{\prime}+r_{i, j} & \geq v_{i, j}, \\
p_{j}^{\prime} & \geq m_{i, j} .
\end{aligned}
$$

Como $j \in J^{\prime}$, vale que $p_{j}(y)=p_{j}^{\prime}$ e $d^{(t)}\left(i_{0}, j\right) \leq y$. Logo $d^{(t)}\left(i_{0}, i\right) \leq d^{(t)}\left(i_{0}, j\right)$, e temos que $d^{(t)}\left(i_{0}, i\right) \leq y$. Assim sendo, $u_{i}(y)>u_{i}^{\prime}$, já que $i \notin I^{\prime}$.

Como há um arco à frente de $i$ para $j$ em $G^{(t)}$, temos $p_{j}^{(t)} \in\left[r_{i, j}, m_{i, j}\right)$. Como $u_{i}(y)=u_{i}^{(t)}-$ $y+d^{(t)}\left(i_{0}, i\right)$ e $p_{j}(y)=p_{j}^{(t)}+y-d^{(t)}\left(i_{0}, j\right)$ e também há um arco à frente de $i$ para $j$ de custo $u_{i}^{(t)}+p_{j}^{(t)}-v_{i, j}$, temos que

$$
u_{i}(y)+p_{j}(y)=u_{i}^{(t)}+p_{j}^{(t)}-\left(u_{i}^{(t)}+p_{j}^{(t)}-v_{i, j}\right)=v_{i, j} .
$$

Logo $u_{i}^{\prime}+p_{j}^{\prime}<u_{i}(y)+p_{j}(y)=v_{i, j}$ e portanto (4.31) não vale. Por hipótese de indução, temos que $p_{j}^{\prime} \geq p_{j}^{(t)} \geq r_{i, j}$, e portanto (4.32) também não vale.

Como $p_{j}^{(t)}<m_{i, j}$ e $u_{i}^{(t)}+p_{j}^{(t)} \geq v_{i, j}$, vale que $u_{i}^{(t)}+m_{i, j}>v_{i, j}$, e portanto existe arco de preço máximo de $i$ para $j$. Observe então que

$$
w^{(t)}(P) \leq d^{(t)}\left(i_{0}, i\right)+\left(u_{i}^{(t)}+m_{i, j}-v_{i, j}\right)
$$

pois $w^{(t)}(P)$ está limitado pelo peso do caminho de $i_{0}$ até $i$ usando apenas arcos à frente e arcos inversos, mais o custo de um arco de preço máximo de $i$ para $j$. Como $y<w^{(t)}(P)$, pela escolha de $y$, então:

$$
\begin{aligned}
y-d^{(t)}\left(i_{0}, j\right) & \leq w^{(t)}(P)-d^{(t)}\left(i_{0}, j\right) \\
& \leq\left(d^{(t)}\left(i_{0}, i\right)+\left(u_{i}^{(t)}+m_{i, j}-v_{i, j}\right)\right)-\left(d^{(t)}\left(i_{0}, i\right)+\left(u_{i}^{(t)}+p_{j}^{(t)}-v_{i, j}\right)\right) \\
& \leq m_{i, j}-p_{j}^{(t)} .
\end{aligned}
$$


Disso e da definição de $p_{j}(y)$, concluímos que $p_{j}(y)<m_{i, j}$. De fato, vale que:

$$
\begin{aligned}
p_{j}(y) & =p_{j}^{(t)}+\left(y-d^{(t)}\left(i_{0}, j\right)\right) \\
& <p_{j}^{(t)}+\left(w^{(t)}(P)-d^{(t)}\left(i_{0}, j\right)\right) \\
& \leq p_{j}^{(t)}+\left(m_{i, j}-p_{j}^{(t)}\right) \\
& =m_{i, j} .
\end{aligned}
$$

pois $j \in J^{\prime}$ pois $y \in w^{(t)}(P)$

Além disso, como $j \in J^{\prime}$, vale que $p_{j}^{\prime}=p(y)$, concluindo que $p_{j}^{\prime}<m_{i, j}$, e que (4.33) também não vale.

Com isso concluímos que a alocação $\left(\mu^{\prime}, p^{\prime}, u^{\prime}\right)$ não é estável e viável. Isso prova que $u_{i}^{(t+1)} \geq u_{i}^{\prime}$ e $p_{j}^{(t+)} \leq p_{j}^{\prime}$, completando a prova da proposição 1 .

\subsubsection{Prova da proposição 2}

Da proposição 1 , temos que $p_{j}^{(t+)} \leq p_{j}^{\prime}$ para todo $(i, j)$ em $I \times J$. Ademais, sabemos que $p_{j}^{(t+1)}$ difere de $p_{j}^{(t+)}$ apenas quando o passeio alternante $P$ termina em um arco de preço mínimo $(i, j)=\left(i_{l}, j_{l+1}\right)$ tal que $p_{j}^{(t+)}<r_{i, j}$. Nesse caso, o algoritmo toma $p_{j}^{(t+1)}=r_{i, j}$. Logo, precisamos verificar que $r_{i, j} \leq p_{j}^{\prime}$.

Como a alocação $\left(\mu^{\prime}, p^{\prime}, u^{\prime}\right)$ é estável, vale pelo menos uma entre (4.31), (4.32) e (4.33). Vamos considerar esses três casos.

Se (4.31) vale, como o passeio alternante $P$ termina em um arco de preço mínimo $(i, j)$ e $p_{j}^{(t+)}<r_{i, j}$, vale que $u_{i}^{(t+1)}=v_{i, j}-r_{i, j}$, e vale também que $u_{i}^{(t+1)} \geq u_{i}^{\prime}$, pela proposição 1 . Então, se vale (4.31), substituindo $u_{i}^{\prime}$ por $u_{i}^{(t+1)}$ em (4.31), temos que $\left(v_{i, j}-r_{i, j}\right)+p_{j}^{\prime} \geq v_{i, j}$. Portanto, neste caso, vale que $r_{i, j} \leq p_{j}^{\prime}$.

Se (4.33) vale, como existe arco de preço mínimo de $i$ para $j$ em $G^{(t)}$, temos que $r_{i, j} \leq m_{i, j}$. Se vale (4.33), ou seja, se $m_{i, j} \leq p_{j}^{\prime}$, então também vale que $r_{i, j} \leq p_{j}^{\prime}$.

Por outro lado, suponha que não valem (4.31) nem (4.33), então (4.32) deve valer, pois $\left(\mu^{\prime}, p^{\prime}, u^{\prime}\right)$ é estável. Como o passeio alternante de peso mínimo terminou em um arco de preço mínimo e $p_{j}^{(t+)}<r_{i, j}$, temos que $p_{j}^{(t+1)}=r_{i, j}$, e também $u_{i}^{(t+1)}+p_{j}^{(t+1)}=v_{i, j}$. Como já foi provado, pela proposição 1 , vale que $u_{i}^{(t+1)} \geq u_{i}^{\prime}$. Assim, vale que $u_{i}^{\prime}+r_{i, j} \leq v_{i, j}$. Como vale (4.32), temos que $u_{i}^{\prime}+r_{i, j}=v_{i, j}$. Logo, como (4.31) não vale, teríamos que $p_{j}^{\prime}<r_{i, j}$, o que implica que $(i, j) \notin \mu^{\prime}$. Como não há $\operatorname{par}(i, j) \notin \mu^{\prime}$ r-justo, então $u_{i}^{\prime}+r_{i, j} \neq v_{i, j}$, e portanto este caso não ocorre, concluindo a prova.

Portanto, vale que $u_{i}^{(t+1)} \geq u_{i}^{\prime}$, e que $p_{j}^{(t+1)} \leq p_{j}^{\prime}$, para toda alocação $\left(\mu^{\prime}, p^{\prime}, u^{\prime}\right)$ estável e viável, o que conclui a prova por indução e portanto o fim da prova do lema 4.11.1.

\subsection{Detalhes de implementação sobre a posição geral}

Nesta seção, sugerimos ajustes no algoritmo para que funcione para instâncias que não estão em posição geral.

Note que, exceto pelos invariantes $(B 1)$ e $(B 2)$, a posição geral não é necessária ao longo de 
nenhuma parte das demonstrações de correção do algoritmo. Ademais, o invariante ( $B 1)$ é utilizado para garantir a existência de um arco de preço máximo entre o par $(i, j)$ em questão, e o invariante (B2) é sempre utilizado para garantir existência de um arco de preço mínimo entre o par $(i, j)$ em questão.

Assim, para que o algoritmo funcione para um leilão que não está em posição geral, alteramos as condições de desigualdades estritas para existência dos arcos de preço mínimo e máximo, de modo que para cada anunciante $i$ de $I$, e para cada local $j$ de $J$, temos:

- um arco à frente de $i$ para $j$ com peso $u_{i}+p_{j}-v_{i, j}$, se $r_{i, j} \leq p_{j}<m_{i, j}$,

- um arco inverso de $j$ para $i$ com peso $v_{i, j}-u_{i}-p_{j}$, se $(i, j) \in \mu$,

- um arco de preço mínimo de $i$ para $j$ com peso $u_{i}+r_{i, j}-v_{i, j}$, se $u_{i}+r_{i, j} \geq v_{i, j}$ e $m_{i, j} \geq r_{i, j}$,

- um arco de preço máximo de $i$ para $j$ com peso $u_{i}+m_{i, j}-v_{i, j}$, se $u_{i}+m_{i, j} \geq v_{i, j}$ e $m_{i, j} \geq r_{i, j}$,

- um arco terminal de $i$ para $j_{0}$ com peso $u_{i}$, se $u_{i}>0$.

A desigualdade estrita é realmente necessária para garantir que o último arco do passeio alternante de peso mínimo não existirá nas futuras iterações do algoritmo, para que o algoritmo termine. Ao realizarmos esse ajuste nas condições de existência dos arcos de preço mínimo e máximo, precisamos também nos certificar de que o último arco do passeio alternante de peso mínimo irá sempre deixar de existir. Para isso, na implementação do algoritmo, adicionamos essa condição extra para a existência do arco, ou seja, que ele não tenha ocorrido como último arco de nenhum passeio alternante de peso mínimo de uma iteração precedente. Aparentemente, todas as demonstrações continuariam valendo ao trocar as desigualdades estritas da definição de existência dos arcos de preço máximo e mínimo, com pequenas alterações. Mas essa última condição extra de remoção do último arco do passeio alternante é uma condição mais forte, que dificultaria as demonstrações, caso apresentássemos esta versão adaptada do algoritmo em vez da versão original.

Foram construídas instâncias para o leilão genérico de forma que, sem as alterações sugeridas, o algoritmo devolve uma solução não estável ou não viável. Porém, ao realizar esses ajustes, a solução encontrada (para todos os casos testados) é sempre viável e estável, mas não foi possível verificar se a solução é ótima. Aparentemente, os ajustes sugeridos são suficientes para que o algoritmo resolva instâncias arbitrárias do problema do leilão genérico. Veja mais detalhes sobre esses ajustes no algoritmo nos exemplos da seção 4.13 .

\subsection{Exemplos especiais}

Veja um exemplo na tabela 4.4, com $n=2$ e $k=2$, em que o leilão está em posição geral, e tem um dos preços de reserva igual a 0 .

Tabela 4.4: Exemplo com preço de reserva igual a 0.

\begin{tabular}{|c|c|c|}
\hline$v_{i, j}$ & $j=1$ & $j=2$ \\
\hline$i=1$ & 45 & 61 \\
\hline$i=2$ & 57 & 73 \\
\hline
\end{tabular}

\begin{tabular}{|c|c|c|}
\hline$m_{i, j}$ & $j=1$ & $j=2$ \\
\hline$i=1$ & 31 & 27 \\
\hline$i=2$ & 23 & 43 \\
\hline
\end{tabular}

\begin{tabular}{|c|c|c|}
\hline$r_{i, j}$ & $j=1$ & $j=2$ \\
\hline$i=1$ & 0 & 13 \\
\hline$i=2$ & 17 & 19 \\
\hline
\end{tabular}

De fato, vamos enumerar todos os passeios alternantes no grafo do leilão para o exemplo acima para verificar que ele está em posição geral. Primeiramente, note que um passeio alternante no 
grafo do leilão pode passar mais de uma vez por um mesmo vértice, mas neste exemplo todos os circuitos alternando arcos à frente e inversos têm custo zero (e podem portanto ser ignorados). Por exemplo, para a instância acima temos $P^{\prime}=\left(i_{0}^{\prime}=1, j_{1}^{\prime}=1, i_{1}^{\prime}=2, j_{2}^{\prime}=2, i_{2}^{\prime}=1\right)$ de peso $-v_{1,1}+v_{2,1}-v_{2,2}+v_{1,2}=-45+57-73+61=0$. Portanto, basta verificarmos os passeios que não repetem vértices, a menos do último vértice.

Lista dos passeios que começam no anunciante $i_{0}=1$.

- Passeios alternantes que terminam no arco mínimo $(i=1, j=1)$ : $P=\left(i_{0}=1, j_{1}=1\right), w(P)=-45$.

- Passeios alternantes que terminam no arco máximo $(i=1, j=1)$ : $P=\left(i_{0}=1, j_{1}=1\right), w(P)=-14$.

- Passeios alternantes que terminam no arco mínimo $(i=1, j=2)$ : $P=\left(i_{0}=1, j_{1}=2\right), w(P)=-48$.

- Passeios alternantes que terminam no arco máximo $(i=1, j=2)$ : $P=\left(i_{0}=1, j_{1}=2\right), w(P)=-34$.

- Passeios alternantes que terminam no arco terminal $(i=1, j=0)$ : $P=\left(i_{0}=1, j_{1}=0\right), w(P)=0$.

- Passeios alternantes que terminam no arco mínimo $(i=2, j=1)$ :

$P_{1}=\left(i_{0}=1, j_{1}=2, i_{1}=2, j_{2}=1\right), w\left(P_{1}\right)=-28 ;$ $P_{2}=\left(i_{0}=1, j_{1}=1, i_{1}=2, j_{2}=1\right), w\left(P_{2}\right)=-28$.

- Passeios alternantes que terminam no arco máximo $(i=2, j=1)$ : $P_{1}=\left(i_{0}=1, j_{1}=2, i_{1}=2, j_{2}=1\right), w\left(P_{1}\right)=-22 ;$ $P_{2}=\left(i_{0}=1, j_{1}=1, i_{1}=2, j_{2}=1\right), w\left(P_{2}\right)=-22$.

- Passeios alternantes que terminam no arco mínimo $(i=2, j=2)$ : $P_{1}=\left(i_{0}=1, j_{1}=2, i_{1}=2, j_{2}=2\right), w\left(P_{1}\right)=-42$; $P_{2}=\left(i_{0}=1, j_{1}=1, i_{1}=2, j_{2}=2\right), w\left(P_{2}\right)=-42$.

- Passeios alternantes que terminam no arco máximo $(i=2, j=2)$ :

$P_{1}=\left(i_{0}=1, j_{1}=2, i_{1}=2, j_{2}=2\right), w\left(P_{1}\right)=-18 ;$ $P_{2}=\left(i_{0}=1, j_{1}=1, i_{1}=2, j_{2}=2\right), w\left(P_{2}\right)=-18$.

- Passeios alternantes que terminam no arco terminal $(i=2, j=0)$ : $P_{1}=\left(i_{0}=1, j_{1}=2, i_{1}=2, j_{2}=0\right), w\left(P_{1}\right)=12 ;$ $P_{2}=\left(i_{0}=1, j_{1}=1, i_{1}=2, j_{2}=0\right), w\left(P_{2}\right)=12$.

Lista dos passeios que começam no anunciante $i_{0}=2$.

- Passeios alternantes que terminam no arco mínimo $(i=1, j=1)$ : $P_{1}=\left(i_{0}=2, j_{1}=2, i_{1}=1, j_{2}=1\right), w\left(P_{1}\right)=-57$; $P_{2}=\left(i_{0}=2, j_{1}=1, i_{1}=1, j_{2}=1\right), w\left(P_{2}\right)=-57$.

- Passeios alternantes que terminam no arco máximo $(i=1, j=1)$ :

$P_{1}=\left(i_{0}=2, j_{1}=2, i_{1}=1, j_{2}=1\right), w\left(P_{1}\right)=-26$; $P_{2}=\left(i_{0}=2, j_{1}=1, i_{1}=1, j_{2}=1\right), w\left(P_{2}\right)=-26$. 
- Passeios alternantes que terminam no arco mínimo $(i=1, j=2)$ :

$P_{1}=\left(i_{0}=2, j_{1}=2, i_{1}=1, j_{2}=2\right), w\left(P_{1}\right)=-60 ;$

$P_{2}=\left(i_{0}=2, j_{1}=1, i_{1}=1, j_{2}=2\right), w\left(P_{2}\right)=-60$.

- Passeios alternantes que terminam no arco máximo $(i=1, j=2)$ :

$P_{1}=\left(i_{0}=2, j_{1}=2, i_{1}=1, j_{2}=2\right), w\left(P_{1}\right)=-46$;

$P_{2}=\left(i_{0}=2, j_{1}=1, i_{1}=1, j_{2}=2\right), w\left(P_{2}\right)=-46$.

- Passeios alternantes que terminam no arco terminal $(i=1, j=0)$ :

$P_{1}=\left(i_{0}=2, j_{1}=2, i_{1}=1, j_{2}=0\right), w\left(P_{1}\right)=-12 ;$

$P_{2}=\left(i_{0}=2, j_{1}=1, i_{1}=1, j_{2}=0\right), w\left(P_{2}\right)=-12$.

- Passeios alternantes que terminam no arco mínimo $(i=2, j=1)$ :

$P=\left(i_{0}=2, j_{1}=1\right), w(P)=-40$

- Passeios alternantes que terminam no arco máximo $(i=2, j=1)$ :

$P=\left(i_{0}=2, j_{1}=1\right), w(P)=-34$

- Passeios alternantes que terminam no arco mínimo $(i=2, j=2)$ :

$P=\left(i_{0}=2, j_{1}=2\right), w(P)=-54$

- Passeios alternantes que terminam no arco máximo $(i=2, j=2)$ :

$P=\left(i_{0}=2, j_{1}=2\right), w(P)=-30$

- Passeios alternantes que terminam no arco terminal $(i=2, j=0)$ :

$P=\left(i_{0}=2, j_{1}=0\right), w(P)=0$.

Vejamos um segundo exemplo, para argumentar que uma simples afirmação feita pelos autores é uma afirmação muito vaga. Os autores afirmam que, para que o algoritmo funcione para instâncias que não estão em posição geral, basta utilizar um critério de desempate baseado no último arco do passeio alternante. Note, porém, que para o exemplo apresentado na tabela 4.5, não existem passeios alternantes a menos do passeio com arco terminal. Portanto, o algoritmo (sem os ajustes sugeridos) devolve uma alocação vazia, sendo que existe uma alocação ótima tal que o anunciante 1 paga 5 pelo local 1, encontrada quando realizamos os ajustes no algoritmo.

Tabela 4.5: Regra de desempate não funciona

\begin{tabular}{|c|c|}
\hline$v_{i, j}$ & $j=1$ \\
\hline$i=1$ & 10 \\
\hline
\end{tabular}

\begin{tabular}{|c|c|}
\hline$m_{i, j}$ & $j=1$ \\
\hline$i=1$ & 5 \\
\hline
\end{tabular}

\begin{tabular}{|c|c|}
\hline$r_{i, j}$ & $j=1$ \\
\hline$i=1$ & 5 \\
\hline
\end{tabular}

Vamos apresentar um outro exemplo, para mostrar outras dificuldades que existem para uma instância que não está em posição geral, e argumentar que as modificações sugeridas na seção 4.12 sobre detalhes da implementação podem ser suficientes para que o algoritmo funcione para instâncias arbitrárias. Considere a instância apresentada na tabela 4.6.

Tabela 4.6: Exemplo que não está em posição geral.

\begin{tabular}{|c|c|c|}
\hline$v_{i, j}$ & $j=1$ & $j=2$ \\
\hline$i=1$ & 10 & 10 \\
\hline$i=2$ & 10 & 10 \\
\hline
\end{tabular}

\begin{tabular}{|c|c|c|}
\hline$m_{i, j}$ & $j=1$ & $j=2$ \\
\hline$i=1$ & 10 & 10 \\
\hline$i=2$ & 10 & 10 \\
\hline
\end{tabular}

\begin{tabular}{|c|c|c|}
\hline$r_{i, j}$ & $j=1$ & $j=2$ \\
\hline$i=1$ & 0 & 0 \\
\hline$i=2$ & 0 & 0 \\
\hline
\end{tabular}


Simulando o algorimo de uma maneira intuitiva para este exemplo, primeiramente obteremos o passeio alternante mínimo que utiliza apenas o arco mínimo do anunciante 1 para o local 1 . Na segunda iteração, temos dois passeios alternantes com o mesmo peso, que é o mínimo, que são os passeios com um único arco mínimo do anunciante $i=2$ para o local $j=\{1,2\}$. Porém, note que pelas regras do algoritmo, se utilizarmos o passeio alternante $P=\left(i_{0}=2, j_{1}=1\right)$, que termina com arco de peso mínimo, o anunciante 2 irá continuar desalocado, mas agora com utilidade igual a 10, e assim não existem mais arcos mínimos saindo do vértice do anunciante 2. Utilizando o arco de preço máximo $(i=2, j=1)$ na terceira iteração, o algoritmo termina com o anunciante 1 alocado ao item 1 , com preço 0 , e o anunciante 2 desalocado.

Porém, ao realizarmos os ajustes sugeridos no algoritmo, na terceira iteração ainda existirá um arco de preço mínimo do anunciante 2 para o local 2, e assim o algoritmo devolve uma alocação ótima. 


\section{Capítulo 5}

\section{Conclusões e trabalhos futuros}

Neste projeto apresentamos inicialmente o modelo que chamamos de leilões simplificados. Para este modelo, apresentamos o mecanismo próximo preço, que ordena os anunciantes por suas ofertas (eventualmente multiplicadas por um fator, que representa a chamada qualidade do anúncio), e utiliza o segundo preço para determinar o pagamento dos anunciantes. Esse modelo e esse mecanismo são a base para o que é atualmente utilizado por empresas como Google, Yahoo e Microsoft. Mostramos que o mecanismo próximo preço garante boas propriedades. De fato, o mecanismo possui um equilíbrio com lucro tão bom quanto o lucro que seria obtido por um equilíbrio para o (único) mecanismo à prova de estratégia para este modelo. Isso serve de motivação para que este mecanismo continue em prática, e não seja substituído pelo mecanismo à prova de estratégia.

O modelo dos leilões simplificados depende de estimativas para o cálculo das taxas de cliques e dos pesos associados aos anunciantes, que são características que poderiam vir a ser estudadas mais detalhadamente, mas não foi o foco deste trabalho. Ademais, o modelo pode ser estendido de diversas formas. Por exemplo, inserindo preços mínimos de venda para os locais da página [EDFMM08], ou permitindo que os anunciantes ofertem por apenas um subconjunto dos locais da página [AFM06]. Ambas as características estão presentes no modelo que chamamos de leilões genéricos, apresentado neste projeto.

Os leilões genéricos permitem uma grande flexibilidade ao leiloeiro, que determina o preço mínimo de venda de cada local da página para cada anunciante, e permitem uma grande flexibilidade aos anunciantes, que podem determinar o preço máximo que estão dispostos a pagar por cada local da página, além de considerar o valor verdadeiro por cada local. Os autores Aggarwal, Muthukrishnan, Pál e Pál [AMPP09] apresentam um algoritmo eficiente para produzir uma alocação ótima de anunciantes e locais. Ou seja, o algoritmo produz uma alocação estável e viável que, dentre todas as alocações estáveis e viáveis, maximiza a utilidade de cada anunciante. Esse algoritmo foi estudado neste projeto, e também foi implementado. Apesar deste modelo ser bastante robusto, ele pode não ser interessante na prática, pois demanda que os anunciantes informem muitos valores ao leilão.

Com a motivação de que, considerando a competição entre anúncios que são exibidos na mesma página, a taxa de cliques pode não ser uma boa estimativa para medir o retorno obtido pelos anunciantes, os autores Arpita Ghosh e Amin Sayedi [GS10] propuseram uma variação dos leilões simplificados. Este modelo, que chamamos de leilões com exclusividade, permite a exibição exclusiva de um anunciante, introduzindo um valor a mais às ofertas dos anunciantes. Para este modelo, os autores propõem dois mecanismos, o $\mathrm{GSP}_{2 D}$ e o $\mathrm{NP}_{2 D}$, e analisam o bem estar social dos anunciantes e o lucro do leiloeiro quando comparados ao mecanismo $\mathrm{VCG}_{2 D}$, que é à prova de estratégia. Dessa 
análise, para equilíbrios bons e livres de inveja, obtemos que o bem estar social do $\mathrm{GSP}_{2 D}$ é pelo menos um terço do bem estar social do $\mathrm{VCG}_{2 D}$, e o lucro do $\mathrm{GSP}_{2 D}$ é pelo menos metade do lucro do $\mathrm{VCG}_{2 D}$. Mostramos que os fatores são justos, construindo exemplos de pior caso. Para o $\mathrm{NP}_{2 D}$, os resultados não são tão diretos, e dependem de outros fatores.

Muitas outras particularidades fazem parte deste problema, como o fato de anunciantes poderem ofertar por palavras chaves dos seus concorrentes [SJS11]; ou o fato de que cada anunciante está interessado em abranger um grande número de palavras chaves similares (broad match), sendo incapaz de ofertar um valor particular para cada busca realizada por usuários [Dha11]. Esses e outros fatores influenciam o cenário de leilões para publicidade na Internet.

\subsection{Considerações Finais}

Encontramos algumas dificuldades durante o estudo dos artigos que apresentamos neste projeto, o que nos levou a adaptar alguns modelos, mecanismos, e demonstrações.

No trabalho de Ghosh e Sayedi [GS10], os autores não definem o comportamento do mecanismo $\mathrm{GSP}_{2 D}$ no caso de igualdade entre a maior oferta e o lucro esperado na saída múltipla. Eles definem que a saída é exclusiva se a maior oferta for maior ou igual ao lucro esperado na saída múltipla (i.e. $m_{\text {eomax }} \geq \sum_{i=1}^{k} \theta_{i} m_{i+1}^{\prime}$ ), porém, definem também que a saída é múltipla se a maior oferta for menor ou igual ao lucro esperado na saída múltipla (i.e. $m_{\text {eomax }} \leq \sum_{i=1}^{k} \theta_{i} m_{i+1}^{\prime}$ ). Optamos por alterar essa definição, deixando a desigualdade estrita para o caso da saída exclusiva, o que teve certas implicações em alguns exemplos, demonstrações e equilíbrios. Ademais, os autores citam o trabalho de Varian [Var07] para as demonstrações nos casos em que utilizam a hipótese de equilíbrios livres de inveja. Porém, há uma inconsistência, pois Varian assume taxas de cliques estritamente decrescentes em seu trabalho (i.e. $\theta_{1}>\cdots>\theta_{k}$ ), enquanto Ghosh e Sayedi assumem taxas de cliques não crescentes (i.e. $\theta_{1} \geq \cdots \geq \theta_{k}$ ), o que nos levou a adaptar algumas demonstrações. Ademais, alteramos a demonstração do caso 3 da eficiência do $\mathrm{GSP}_{2 D}$, apresentada na seção 3.6.1, pois achamos que há uma falha na demonstração apresentada no artigo.

No trabalho de Aggarwal, Muthukrishnan, Pál e Pál [AMPP09], a primeira dificuldade é o fato de o artigo não estar completo, pois os invariantes $(B 1)$ e $(B 2)$ não foram demonstrados. Além disso, algumas afirmações e passagens matemáticas são apresentadas sem muitos detalhes. Em especial, estava errada uma afirmação que dizia que preços de reserva são estritamente positivos para instâncias em posição geral. Foi possível contornar essa hipótese para demonstrar o que queríamos. Conseguimos também completar a demonstração de otimalidade do algoritmo, que está incompleta no artigo original. Ademais, conseguimos elaborar demonstrações para os invariantes (B1) e (B2). Além disso, os autores não explicam os ajustes que devem ser feitos para que o algoritmo funcione em instâncias que não estão em posição geral, o que não parece ser uma tarefa tão simples. 


\section{Referências Bibliográficas}

[AFM06] G. Aggarwal, J. Feldman, e S. Muthukrishnan. Bidding to the top: VCG and equilibria of position-based auctions. Em Proceedings of the 4th international conference on Approximation and Online Algorithms, WAOA'06, páginas 15-28, Berlin, Heidelberg, 2006. Springer-Verlag. Disponível também em http://arxiv.org/abs/cs/0607117. 73

[Agg05] G. Aggarwal. Privacy Protection and Advertising in a Networked World. Tese de Doutorado, Stanford University, Setembro 2005. 12

[AGM06] G. Aggarwal, A. Goel, e R. Motwani. Truthful auctions for pricing search keywords. Em Proceedings of the 7th ACM conference on Electronic commerce, EC '06, páginas 1-7, New York, NY, USA, 2006. ACM. 1, 11, 12

[AMPP09] G. Aggarwal, S. Muthukrishnan, D. Pál, e M. Pál. General auction mechanism for search advertising. Em Proceedings of the 18th international conference on World wide web, WWW '09, páginas 241-250, New York, NY, USA, 2009. ACM. Disponível também em http://arxiv.org/abs/0807.1297. 1, 47, 52, 59, 60, 61, 73, 74

[Dha11] P. Dhangwatnotai. Multi-keyword sponsored search. Em Proceedings of the 12th ACM conference on Electronic commerce, páginas 91-100. ACM, 2011. 74

[EDFMM08] E. Even-Dar, J. Feldman, Y. Mansour, e S. Muthukrishnan. Position auctions with bidder-specific minimum prices. Em Proceedings of the 4th International Workshop on Internet and Network Economics, WINE '08, páginas 577-584, Berlin, Heidelberg, 2008. Springer-Verlag. 73

[EOS05] B. Edelman, M. Ostrovsky, e M. Schwarz. Internet advertising and the generalized second price auction: Selling billions of dollars worth of keywords. Working Paper 11765, National Bureau of Economic Research, November 2005. 2

[GS10] A. Ghosh e A. Sayedi. Expressive auctions for externalities in online advertising. Em Proceedings of the 19th international conference on World wide web, WWW '10, páginas 371-380, New York, NY, USA, 2010. ACM. 25, 43, 73, 74

[IJMT05] N. Immorlica, K. Jain, M. Mahdian, e K. Talwar. Click fraud resistant methods for learning clickthrough rates. Em In Proceedings of the 1st Workshop on Internet and Network Economics 3828. Springer LNCS (2005) 34-45; www.ece.northwestern. edu/nickle/pubs/clickfraud.pdf, 2005. 4

[JS11] K. Jerath e A. Sayedi. Exclusive Display in Sponsored Search Advertising. SSRN eLibrary, 2011. 25

[Mil08] P. Milgrom. Simplified mechanisms with an application to sponsored-search auctions, 2008.

[MMN $\left.{ }^{+} 10\right]$ P. Maillé, E. Markakis, M. Naldi, G.D. Stamoulis, e B. Tuffin. Sponsored search auctions: An overview of research with emphasis on game theoretic aspects. 2010. 23 
[Mut09] S. Muthukrishnan. Bidding on configurations in internet ad auctions. Em Hung Ngo, editor, Computing and Combinatorics, volume 5609 of Lecture Notes in Computer Science, páginas 1-6. Springer Berlin / Heidelberg, 2009. 10.1007/978-3-642-02882-31. 45

[NRTV07] N. Nisan, T. Roughgarden, E. Tardos, e V. Vazirani, editors. Algorithmic Game Theory. Cambridge University Press, 2007. 1

[Ric07] M. Richardson. Predicting clicks: Estimating the click-through rate for new ads. Em In Proceedings of the 16th International World Wide Web Conference (WWW-07), páginas 521-530. ACM Press, 2007. 4

[SJS11] A. Sayedi, K. Jerath, e K. Srinivasan. Competitive poaching in sponsored search advertising and strategic impact on traditional advertising. 2011. 74

[Var07] H.R. Varian. Position auctions. International Journal of Industrial Organization, 25(6):1163-1178, 2007. 74

[Yua09] J. Yuan. Essays on Sponsored Search Auctions. Tese de Doutorado, UNIVERSITY OF MINNESOTA, 2009. 23

[Yua12] J. Yuan. Examining the yahoo! sponsored search auctions: A regression discontinuity design approach. International Journal of Economics and Finance, 4(3):p139, 2012. 2 